The copyright of this thesis vests in the author. No quotation from it or information derived from it is to be published without full acknowledgement of the source. The thesis is to be used for private study or noncommercial research purposes only.

Published by the University of Cape Town (UCT) in terms of the non-exclusive license granted to UCT by the author. 


\title{
IELHAAM ISAACS
}

\section{WITTGENSTEIN'S PHILOSOPHY OF LANGUAGE}

\author{
DOCTORAL DISSERTATION
}

UNIVERSITY OF CAPE TOWN

2005 


\section{Contents}

Acknowledgements

Abbreviations

Abstract

III

Introduction

IV

1 Tractatus Theory of Language

1

2 Account of Philosophy in the Tractatus

3 Linguistic Regularity

4 The Private Language Argument

5 Necessity in the Later Work

6 Philosophical Method in the PI 106

References 


\section{Acknowledgements}

I am indebted to my supervisor Professor David Pears, for his guidance, patience, encouragement and sense of humour.

I also wish to thank my sponsors, the A.W. Mellon Foundation for their generous support of my doctoral dissertation.

Last but not least. I am grateful to Antonio Donato for his moral support, especially during the last frantic days before my submission. 


\section{Abbreviations}

TLP

PI

Tractatus Logico-Philosophicus

\section{Philosophical Investigations}




\section{Abstract}

This thesis traces the development of Wittgenstein's philosophy of language from the TLP to his later writings. The question that looms in the background of my discussions is whether language owes allegiance to extra-linguistic features or whether we can explain language solely in terms of conventional linguistic practices. The dilemma seems to offer two equally untenable options. I explore how the realist explanation makes an empty offer and how the conventionalist alternative seems to undermine the objectivity of language which realism seems to preserve. I conclude that $\mathrm{W}$ offers an account that satisfies the requirement for objectivity in language without committing the fatal error of realism. In chapter one I examine his account of language in the TLP, an account that I claim has strong realist overtones. In chapter two I explore the implications of this account for the status of philosophical propositions and philosophical method. Chapter three is the first of three chapters that examine his later view of meaning. I explore his account of language in the PI by examining his discussions of following a rule, the cluster of arguments that make up his celebrated Private Language Argument and his new account of necessity and show how his TLP account of language is gradually dismantled and replaced with a very different outlook on language. In the last chapter I explore the new philosophical method that he advocates, and link this new method to his later view of language. 


\section{Introduction}

The TLP saw language as a sophisticated calculus that pays homage to the atemporal logical form of the world. The form of the world has at its nodal points simple objects; once we attach names to objects the calculus takes over, as it were, and governs how the names can be used. The first obvious problem with such an account is that it puts language on a static basis and so does not accommodate the plasticity of language. Often times the way we use words change gradually over time - new rules evolve, concepts expand. Any account which makes language owe allegiance to a static atemporal independent reality - whether the TLP's logical form, platonic universals or the Russellian-type most-general features of the world - will not be able to explain this dynamism of language. The most crippling problem with this account, however, is that it appeals to items that are not independently identifiable. We cannot identify Wittgenstein's 'logical form' or the platonist's universals independently of our existing vocabulary. Such realist theories are bogus; they take the form of an explanation in that they posit one phenomenon to explain another, but it turns out that we have no independent access to the explanans. All realism offers is an empty shell of an explanation - the requisite ingredients are absent. It is attractive because it seems to promise an explanation that preserves the objectivity of the rules of language, but it fails not because the explanation is wrong, but because the explanation is empty. But even if we could have access to such language-independent realities, how would they guide us? We have to grasp them in some Way. In the PI Wittgenstein considers various candidates as the mental counter-part of the languageindependent reality - a mental image, a formula, a definition. He concludes that any mental counterpart cannot take us from language to the world. Any image or formula can always be applied in more than one way and so meaning will be indeterminate. The moral of the story is that a realist theory of language cannot explain the interface between language and the world. The breakthrough in Wittgenstein's later work is that he realises he is looking for answers in the wrong direction. Rather than looking outwards towards something recondite, he discovered that the answers lie closer to home. Given the failure of realism the only other place to look for answers is our actual linguistic practices. When the focus was changed, the nature of the explanation changed explaining language in terms of how language is actually applied does not yield a metaphysical cxplanation but a scientific one. Linguistic practices are explained in terms of facts that gave rise to them - our human natures. our environment, the need for communication, and so on. We gain such explanatory information by observing the way our practices have developed, hence Wittgenstein's concern with observation and description in the PI. 'Application' or 'use' are the new watchwords 
in the later work. By examining language in terms of the application of words the problem of the proliferation of meaning is eliminated. Application takes us across the bridge from language to the world where an inage or formula left us with a vista of empty pathways. The characteristic feature of the later conventionalism is that its appeal to actual application still preserves the objectivity of language. If an activity is to count as speaking a language there has to be criteria in virtue of which our application of words can be said to be correct. These criteria must be independent of what we would do and should tell us what we should do. The appeal of realism is thus not hard to appreciate: realism offers us criteria that are allegedly independent of what we would do and so offers an objective explanation of language. A conventionalist account of language seems to undermine the recuirement of objectivity: on the conventionalist account what we happen to do (our conventional practices) determine what we should do. Wittgenstein articulates his linguistic conventionalism by means of the notion of an incompletely specifiable technique that develops in the context of various natural and environmental factors and so does not develop capriciously. Speaking a language involves mastery of this technique and we judge whether someone has used a word correctly by judging whether he has applied the technique in the way we do.

Wittgenstein's explanation of logic in the TLP is minimally realist. While full-blown realism requires further truths - that there are universals, for example - the minimalist realism in the TLP only requires that names have objects as their meaning and propositions have sense. This relationship between language and the world is not one of correspondence, but one where logic shows the logical scaffolding of the world. When the doctrine of showing in the particular form it took in the TLP was abandoned, the residual strings that bound logic to the world were cut loose completely and logic emerged entirely autonomous. Here again, as in his later account of meaning, logic does not lose its objectivity. Its objectivity is secured by an explanation of a very different kind to the traditional metaphysical fare of his predecessors (including the author of the TLP). Here too he offers an empirical account to explain the existence of logical (analytic) propositions and logical inferences (proof in logic and proof using logic).

Wittgenstein believed that all philosophical probiems are the result of misunderstanding the logic of our language. His task therefore is not to take these problems on face-value and attempt to answer them, but to show that they constitute misuses of language and in this way dissolve them. He thus needed an account of language that draws the line between propositions that are genuine uses of language and those that are not. In his earlier account of language Wittgenstein had attempted to 
provide us with a theory of meaning. The theory yielded the 'general form of a proposition' - a form that all diverse propositions must, on analysis, bear. He had always maintained that philosophy should not attempt a theory of meaning, but had presented a theory anyway in the TLP. Later he declared that all we can do is describe the actual uses of language. These descriptions make a contribution to philosophy in that (i) they reveal all the interconnections between different uses of language that are not immediately discernable from everyday use and so can help us see what is a legitimate use of language and what is not, and (ii) they are developed against the background, and for the purpose of, dissolving philosophical problems. Whereas in the TLP the boundary of sense was drawn by means of a theory of language; in the PI the boundary is not drawn, but discovered Wittgenstein indicates that there is value in attempting to cross the limit, so as to feel where the limit is. This way we discover the limit for the different uses of language. The TLP's theory of meaning went against the de jure practice of philosophy advocated in that book. In the PI however, the abundant dialectical discussions on actual uses of language, misuses of language, and the consequences of such misuses exemplifies his later prescription of philosophical method. The new account of philosophy does not replace the earlier mistaken theories, and sees no need for any replacement. It knocks down 'houses of cards', as Wittgenstein's puts it, so as to clear the ground for a new kind of account which describes what human beings actually do. 


\section{Chapter 1: Wittgenstein's Picture Theory of Language}

\section{Background}

In Russell's Principia Mathematica' he fails to satisfactorily explain the nature of logical necessity and in his 1913 Theory of Knowledge ${ }^{2}$ he provides what Wittgenstein believed was a mistaken account of sense. Wittgenstein's theory of factual propositions is intended to address both these concerns. It answers the questions: (a) in virtue of what does a proposition have sense? and (b) what explains the 'necessary' character of logical propositions? The short answer to the first question is: Russell maintained that a proposition has sense if (i) it can be analysed into simple parts which contain names that designate objects that we are acquainted with and (ii) someone $S$ is acquainted both with the objects in the world for which the words in the proposition stand as well as the 'form' of a proposition. The form of a proposition is thus something depicted by the proposition and something that $S$ is accuainted with in much the same way as $S$ is acquainted with the objects for which the words in the proposition stand. Wittgenstein maintained that a proposition has sense if (i) it can be analysed into simple constituents that contain indefinable names that designate internally simple objects, and (ii) it has a certain logical form that cannot be depicted by the proposition but is shown by the proposition. Forms are thus not logical objects. The short answer to the second question is: whereas Russell maintained that logical propositions describe the world at the utmost general level and that logical relations and logical connectives stand for logical objects, Wittgenstein believed that logical propositions do not describe anything at all and that there are no logical objects. Logical propositions express connections between different forms of sentences. These forms are not objects in the world, nor do they exist in another world: rather, logical forms are internal or intrinsic to factual discourse.

These points need amplification. I deal with (b) first. The question here is: what explains the necessary character of logical propositions? When we make factual claims about the world, our sentences are combinations of constituent factual sentences that are combined truth-functionally i.e. the constituent factual sentences are combined in such a way that the truth or falsehood of the combinations will depend on the truth or falsehood of what went into them. We can test whether the resultant proposition i.e. the one that is a combination of the two factual sentence components, is factual, by running through all their combinations of truth and falsity. There are three possible outcomes to this test. The compound proposition may turn out true for some combinations of the truth-values of its components, but false for 
others. However, it may come out true for all combinations, or false for all combinations. In such cases i.e. Where the constituent propositions are combined in such a way that they come out either all true or all false for all possible true-false combinations of their constituent parts, the combination makes no factual claim about the world. Wittgenstein calls these kinds of sentences 'tautologies' (all true-false combinations are true) and 'contradictions' (all true-false combinations are false). Tautologies and contradictions are limiting cases: they represent the boundary of factual discourse and are not part of it. They reveal the connections between the forms of factual sentences. If two sentences of given forms are combined by a logical connective and they produce a tautology, then this shows that tautologies are the result of certain combinations of language. They are not, as Russell thought, descriptions of logical realities that lie outside language. Logical propositions for Wittgenstein are thus a by-product of the ordinary use of propositions to state facts and are not descriptions of anything.

I now tum to (a). The question here is: in virtue of what does a proposition have sense? Wittgenstein's answer comes via what can be described as the two linchpins of the TLP: his version of logical atomism and his Picture Theory. From his atomism we get: a proposition has sense if it can be ultimately analysed into expressions containing simple, indefinable names that designate internally simple objects; his Picture Theory maintains that the names in a proposition must be concatenated in a way that mirrors the logical arrangement of the objects in the state of affairs which it depicts. Furthermore, the way the names are concatenated (its logical form) is something internal to the proposition - it is not an extra item in the proposition and it does not depict any sort of item (logical object) in the world. This account of the possibility of language is clearly a realist one - it posits an extra-linguistic reality that is supposed to explain and justify the logical form language takes. Language enjoys certain options on the surface, but deeper down it is based on the intrinsic nature of objects. which is not something we create but is set independently over and against us. In Notebooks \&. July 1916 Wittgenstein says: The world is given to me, i.e. My will enters into the world completely from outside it as into something that is already there... There are two godheads: the world and my independent I.

The atomistic understanding of the structure of language is something that Wittgenstein inherited from Russell. For both. the sense of a proposition must be understood in terms of its constituent parts - the whole is the sum of its parts. However, they differed in two fundamental ways: (a) they approached analysis in completely different ways, and (b) they had different criteria as to what is to count as the 
simplest units of analysis. Russell approached the analysis of a complex proposition by asking what it would be in virtue of that we understand or learn a proposition. His solution is that we understand a proposition if we are acquainted with what its constituent parts designates. On the face of it, this seems a reasonable criterion - how else would we then learn the meaning of a word unless we are acquainted with the object it designates? So analysis must end with simple constituents, but these constituents must pick out familiar objects in the world that we could not come to know unless we were acquainted with them. Wittgenstein approached the matter quite differently. His thesis is a logical one, driven by a logical requirement. This is how he saw the matter: if the sense of a proposition depends on the sense of its constituent parts, then the analysis can only be complete when we have reached a point when we can analyse no further. If our analysis stops at a level where the analysed propositions contain terms that are not simple i.e. which can be further analysed, then the job is not done. We have to reach the point where we can analyse no further if we are to be true to the theory that the sense of a proposition is a function of the sense of its constituent parts. In TLP 2.0211 he offers a regress argument. one that is supposed to explain why analysis must end with expressions containing completely simple terms that designate objects that are internally simple. Given his criterion of simplicity, these end products of analyses must be such that they are logically independent from any other proposition on the same level. If they were not, they would not be completely simple, since they would either imply or exclude some other proposition. This is how he argues:

If the world had no substance, then whether a proposition had sense would depend on whether another proposition was true. (TLP 2.0211)

And then he says:

In that case we could not sketch any picture of the world (true or false). (TLP 2.0212)

His point is that if we stop the analysis at a level where the analysed propositions contain terms that can still be further analysed i.e. they are complex, then the sense of the original propositions would depend on it being true that the complex is constituted by such-and-such simpler items (it would depend on whether another proposition was true). But this would drive the analyses further down, since now the sense of the original proposition contains this further proposition, which must also be analysed ad 
infinitum. The point is that either you drive the analyses to the point of completely simple items or you face an infinite regress in which case "we could not sketch any picture of the world (true or false)." So the sense of a proposition must ultimately be a function of indefinable simple names designating internally simple objects - otherwise the whole business of a proposition's meaning something would never get off the ground. The buck has to stop somewhere, and it only stops when it can go no further. Although Wittgenstein could give no examples of these completely simple objects he believed he had had offered an a priori argument for their existence (TLP 3.23).

However. both Wittgenstein and Russell believed that the mere attachment of names to objects is not enough to explain why a particular arrangement of names constitutes a sentence with sense. Russell's original explanation had been that when a subject $S$ judges that $a R b$ (that $a$ stands in some relation ' $R$ ' to h). $S$ must be acquainted with three elements $a, R$ and $b$. The trouble with this of course is that $S$ 's acquaintance with $a, R$ and $b$ is not enough to explain how he succeeds in grasping $a R b$ rather than $b R a$ or for that matter why $a R b$ makes sense and RRb does not. Russell's 1913 Theory of Knowledge manuscript suggests that the extra thing that is needed by $S$ in order to understand a proposition is acquaintance with the 'pure form' of the proposition. This 'pure form' is a 'logical object'; it is not however a constituent of a proposition since, he argued, if the form of the proposition was a constituent of the proposition there would have to be a new way in which it and the two other constituents are put together, and if we take this way as again a constituent, we find ourselves embarked on an endless regress." Russell claims that our knowledge of forms is a special kind of acquaintance, a 'logical experience. If his notion of a 'logical experience' is going to do any work at all, it has to be kept separate from his idea of 'judgment'. For in 'judgment' we 'judge' whether a proposition is true or not; and whatever logical experience is, it has to be the kind of thing that is prior to and separate from judgment. As Wittgenstein says in TLP 5.552 :

The 'experience' that we need in order to understand logic is not that something or other is the state of things, but that something is: that, however, is not an experience.

Logic is prior to every experience - that something is so.

It is prior to the question 'How?' not prior to the question 'What?' 
However. Russell equated the pure form of a proposition with what is designated by "something standing in a dual relationship to something else." It appears that in order to understand the pure form of a proposition and hence in order to understand a proposition, we then have to be acquainted with the complex of "something standing in a relationship to something else." The trouble with this is that it makes the sense of a proposition depend on the truth of another proposition. ${ }^{4}$ It does not separate judgment' (determining whether a proposition is true or not) from 'logical experience' (determining whether it makes sense).

In May 1913 Wittgenstein read Russell's manuscript which contained the idea that we do not only need acquaintance with the objects for which the names in a proposition stand, but also acquaintance with logical objects. With great vehemence Wittgenstein had said that Russell's theory was all wrong - that he had tried Russell's view and knew it could not work. ${ }^{5}$ A letter which Wittgenstein had written to Russell in June 1913 throws light on Wittgenstein's reference that he had tried Russell's position before:

.... I can now express my objection to your theory of judgment exactly: I believe it is obvious that, from the proposition 'A judges that (say) $a$ is in relation $R$ to $b$ ', if correctly analysed, the propositions ' $a R b . v .-a R b$ must follow directly without the use of any other premiss. This condition is not fulfilled by your theory. ${ }^{6}$

Here Wittgenstein gives the impression that he has expressed this objection before, but not precisely cnough. Pears suggests that the June 1913 entry in Notebooks refers to the main fault in Russell's 1910) Theory of Judgment which remained uncorrected in his 1913 theory, viz. that Russell requires our understanding of a proposition to involve our being acquainted with the abstract form $\mathrm{x} \xi \mathrm{y}$. This does not solve. but postpones the problem: we would now need to be acquainted with another proposition of that form ad infinitum. Wittgenstein's more precise criticism of Russell's position was obviously a better version of a criticism he had made earlier, not just to Russell's earlier work, but to his own: In Votchooks entry 21 October 1914 he says:

I thought that the possibility of the truth of the proposition øa was tied up with the fact $(\exists x, \varnothing) \cdot \varnothing x$. But it is impossible to see why $\varnothing$ a should only be possible if there is another proposition of the same form. $\varnothing$ a surely does not need any precedent. (For 
Wittgenstein's criticism of Russell had struck a devastating blow and Russell immediately suspended further work on his project. The vehemence with which Wittgenstein treated Russell's 1913 Theory of Judgment can be understood given that his fundamental conviction, more fully expressed in his later Picture Theory, was that the sense of a proposition could never depend on the truth of another proposition. The key feature of his Picture Theory is that it introduces a distinction between what a proposition says and what cannot be said by it, but only shown. For a proposition to say something true (to picture or depict the world truly) it has to already have a sense. That a proposition has sense is logically prior to whether it is true. Hence what a proposition says must be distinguished from what makes it possible for it to say what it does. And what makes it possible to say what it does (to say anything at all) is that it must already posses a certain (logical) form. Whether a proposition makes sense is a prior and independent matter to whether it is true. The logical form of a proposition is shown in its structure and this must be distinguished from what it says. Wittgenstein thus draws a distinction between 'truth-conditions' and 'sense-conditions' by this saying/showing distinction - a distinction that Russell's account failed to secure. For in Russell's case, the sense of a sentence depends on whether some other sentence is true - clearly putting the cart before the horse and staring straight into the face of an infinite regress: if whether $F a$ has sense is dependent on whether $(\exists \mathrm{x})(\exists \xi) \xi \mathrm{x}$ is true, then $(\exists \mathrm{x})$ $(\exists \equiv)$ X $\mathrm{x}$ must have a sense, and so its sense would depend on the truth of another singular proposition of the same form - for example $F b$ - and that starts an infinite regress. ${ }^{8}$ The saying/showing distinction makes the distinction between sense and truth: the sense of a proposition cannot be said (pictured) but only shown by a proposition, the truth of a proposition depends on whether it pictures the world truly. A proposition cannot say what is part of the preconditions for its saying anything at all. Hence 'logical form cannot be apprehended by a 'logical experience'.

Rusiell's account fails to explain how we distinguish between $a R b$ and $b R a$ or why $a R b$ makes sense and why $R R b$ does not. Wittgenstein's account explains this without positing or requiring extra items: the logical form of a proposition is something internal to the proposition in the same way as the shape of a piece in a puzzle is internal to that piece. What holds the proposition together, the glue, so to speak is not an additional element, as the cement between tiles would be an additional element to the tiles. 
Rather, the proposition hangs together in the way the pieces of a puzzle fit together - the shape of the individual pieces determine which other pieces can fit into them.

In a state-of-affairs objects fit into one another link the links of a chain. (TLP 2.03)

So

\section{The logical form of the proposition must already be given by the form of the} component parts. (Notebooks, 1914-16, p. 23)

The theory Wittgenstein offered looked like this: a proposition pictures a possible situation in the world because the elements in the proposition map onto elements in the world, and the logical arrangement of the elements in the proposition mirrors the logical arrangement of the elements in the world. The elements in the world (objects) have an intrinsic logical form (its 'shape') that determines which other objects it can combine with, and the way in which the elements in a proposition can combine depends on the form of the objects that they represent. This is the bare bones of Wittgenstein's picture theory - a theory that essentially seems to be Russell's 1913 theory without the requirement of logical forms as objects of acquaintance." This difference between the two philosophers is deep. Wittgenstein is not just denying that the form of a proposition is a specific kind of item; he is saying that it is nothing of the sort - not this or that kind of constituent item. Form is the possibility of structure. (TLP2.033). A parallel difference runs between their related conception of logical connectives: whereas for Russell logical connectives, like logical forms, stand for a special kind of object. for Wittgenstein they do not stand for anything at all; they indicate the different ways of producing truth-functional combinations of the sentences that they connect. If Russell's view is a kind of platonic realism - positing the existence of special kinds of logical items such as connectives that exist in some Platonic hinterland, Wittgenstein's position could be described as closer to the Aristotelian notion of 'forms" - where forms are immanent and not transcendent, as in Plato.

Wittgenstein's views on logic stand in sharp distinction to those of Russell in that they are entirely antiplatonic. For Wittgenstein logical propositions do not describe anything, they represent internal comnections between sentences and are really only by-products of our use of factual language to make 
claims about the world. However, although Wittgenstein does not adopt a full-blooded realist stance in his account of logic, there are realist undertones - undertones which suggest not the conventional realist package, but which can best be described as a kind of 'minimalist' or "vestigial"10 realism. Whereas full-blown realism requires the existence of universals or general all-pervasive features of the world. Wittgenstein's realism only requires that names have meaning and elementary propositions have sense.

The propositions of logic describe the scaffolding of the world, or rather they represent it. They have no 'subject-matter'. They presuppose that names have meaning and elementary propositions sense; and that is there connexion with the world. It is clear that something about the world must be indicated by the fact that certain combinations of symbols - whose essence involves the possession of a determinate character - are tautologies. This contains the decisive point. We have said that some things are arbitrary in the symbols that we use and that some things are not. In logic it is only the latter that express: but that means that logic is not a field in which we express what we wish with the help of signs, but rather one in which the nature of the absolutely necessary signs speaks for itself. If we know the logical syntax of any sign-language, then we have already been given all the propositions of logic. (TLP 6.124)

\section{Tractatus Theory of Language}

The characteristic feature about the methodology of the TLP is that it does not ask whether language is possible but starts off by acknowledging that language is possible and then asks what conditions must obtain given this possibility. This is much like the way in which Kant proceeded: Kant started off by acknowledging that we have knowledge rather than skeptically questioning whether we can claim to have any knowledge: what he wanted to know was what made this possible. In asking what makes factual language possible Wittgenstein was looking for the a priori conditions for language to work given that language is possible, what features of language, the world and the relation between them, are necessary. These features, he believed, were not the result of an investigation; rather they were something that can be worked out independently of any investigation. The inquiry is a strictly logical 
one. In TLP 6.124 he is convinced that the world must have the features that make language possible. And in PI 107 where he comments on his views held in the TLP he remarks:

....the crystalline purity of logic was, of course, not a result of investigation: it was a requirement.

And again in PI 92:

We ask "What is language?" "What is a proposition?" And the answer to these questions is to be given once and for all; and independently of any future experience.

It is here that the method of inquiry of the TLP on the one hand, and the $P I$, on the other, into the nature of a proposition are in sharp contrast for, as we will come to see, the PI advocates an empirical method. Whereas in the TLP the question is: how must things be given that language is possible, the question in the $P I$ is: how are things in fact. given that language is possible. The emphasis is on describing how things in fact are, rather than attempting to deduce a priori the necessary conditions for the possibility of language. But more of this later.

In the TLP the theory of propositional meaning takes the form of first presenting the necessary features of the world, and then presenting the structure and function of language. Although Wittgenstein believed that the structure of language reveals the structure of the world, he presents an account of the world first. Some commentators" have objected to this presentation: if language reveals the logical characteristics of the world, then the story should be told in that order - the exposition of language first and then the exposition of the world. Consequently, in their exegesis of the TLP, these commentators start off by first examining those statements in the TLP which deal with language and then follow with an exegesis of the account of the world. Other commentators have thought it important to stick to the order in the TLP. Fogelin ${ }^{12}$, for instance, sees the method in the TLP as natural. It begins with the claim that the world is all that there is (the totality of facts) and then goes on to examine an important subset of this totality i.e. those facts (the propositions of language) that are used to represent other facts (the world). Thus, maintains Fogelin, irrespective of how the argument may proceed, the account of language presupposes the account of the world. According to Fann ${ }^{3}$, although Wittgenstein's statements about the world are conclusions from his exposition of language, the latter is preceded by 
the former because the former (his account of the world) anticipates and is required by the theory of language that follows it. Although it is language that reveals the structure of the world, the latter idea (that the world has a fixed logical structure) is one that Wittgenstein already contemplated, in rudimentary form, before working out his account of language. Thus we find him saying, in Notebooks $p 53^{i+}$ :

The great problem round which everything that I write turns is: Is there an order in the world a priori, and if so what does it consist in?

Xorman Malcolm ${ }^{15}$ claims that Wittgenstein's view of the logical structure of the world is one of the ideas that inspired his writings in the TLP: both his entry on page 53 of Notebooks, as well as a later entry on page 62 ('The world has a fixed structure.') seems to confirm this view. It seems then that although language reveals the structure of the world, the idea of the world having a fixed structure may have preceded his claims about language.

I look at his account of the world first. The world, according to the TLP, is the totality of facts in logical space. A fact is the existence of a state of affairs. A state of affairs is a configuration of objects. An object is a simple substance. Every object, to be an object, must be able to enter into combinations with other objects. The possibility that each object has of combining with other objects is called its 'space'. The totality of such space is called 'logical space.' Since objects always occur in combination with other objects, the basic constituents of the factual world are elementary facts. The world then consists ultimately of the totality of elementary facts. The totality of logical space is also referred to as the 'form of the world'. ('The fixed form of the world consists of objects.' (TLP 2.023)) Although the actual combinations may change, the possible combinations never do. The form of the world is the form of any possible or conceivable world.

It is obvious that a conceivable world, however different it may be from the real one, must have something - a form - in common with it. (TLP 2.022)

Objects form the substratum of both the actual and the possible world. The form of the world is $a$ miriri. It is logically prior to all experience and all change. 
Wittgenstein's account of language took the form of examining the structure of language and the fiunction of language. The story goes that if we can use language to talk about the world, then some propositions must be directly connected to the world, in the sense that their truth-values are not determined by other propositions but by the way the world is. This led to the bifurcation of propositions into complex (non-elementary) propositions and elementary (basic) propositions. Complex propositions are related to elementary propositions in that they are truth-functions of elementary propositions - the truth-value of complex propositions depends on the truth-value of elementary propositions and the truth-value of elementary propositions depends on the world. (An elementary proposition is true if it is a description of the way the world is - if some feature of the world makes it true.) Elementary propositions admit of no further analyses. They consist ultimately of concatenated simple names and clementary facts consist ultimately of concatenated simple objects.

Objects make up the substance of the world. That is why they cannot be composite. (TLP 2.021)

The argument for logical atomism follows:

If the world had no substance, then whether a proposition had sense would depend on whether another proposition was true.

In that case we could not sketch any picture of the world (true or false). (TLP 2.0211-

Although Wittgenstein was sure a priori that there must be elementary propositions, he was unable to give examples of them since he was unable to perform, in practice, a complete analysis of complex propositions.

The application of logic decides what elementary propositions there are. What belongs to its application, logic cannot anticipate. (TLP 5.557)

Here he indicates that analysis of propositions belongs to the application of logic. His investigation, by contrast. is a purely logical one. so the question of what elementary propositions there are has no bearing on his investigation. Elementary propositions consist of primitive signs called 'names' - a 
proposition is 'a nexus, a concatenation of names.' (TLP 3.26) The contact point between language and the world is at the level of names. Names refer to objects. Because a name is a primitive or simple sign (it is not a product of parts) it refers to simple objects (which are not products of parts). Simple objects are a logical necessity. This, Wittgenstein believed, can be known a priori. Why? The meaning of a name is the object it denotes. If there were no objects names would not denote anything. Elementary propositions that are constituted by names would thus not be about the world. But elementary propositions are about the world (fact-stating discourse is possible). Therefore there must be objects. Although the contact point between language and the world is at the level of names and objects, when we make statements about the world however, we use propositions. To understand how meaningful discourse is possible we thus need to understand the relation between language and the world at the kevel of propositions. In TLP 3.3 Wittgenstein says:

\section{Only propositions have sense; only in the nexus of a proposition does a name have} meaning.

However. he also says that the meaning of a name is the object it denotes. In the context of TLP 3.3 the picture seems to be that the meaning of a name is the object it denotes, but it only so denotes if. when it occurs in a proposition. it is combined with other names in a way that reflects "the possibilities of combinations of their objects'. This correlates with how objects occur i.e. objects only occur in some or other combination with other objects. So for a sign to be a name it must occur in the nexus of a proposition: for something to be an object it must occur in the nexus of a state of affairs.

The account of the function of language is supplied by his Picture Theory. He introduces his comparison between a proposition and a picture in $T L P 2.1$.

\subsection{We picture facts to ourselves.}

2.11 A picture represents a situation in logical space, the existence and non-existence of a state-of-affairs.

$2.12 \mathrm{~A}$ picture is a model of reality.

2.13 In a picture objects have the elements of the picture corresponding to them.

2.131 In a picture the elements of the picture are the representatives of objects. 
2.14 What constitutes a picture is that its elements are related to one another in a determinate way.

$2.141 \mathrm{~A}$ picture is a fact.

2.15 The fact that the elements of a picture are related to one another in a determinate way represents that things are related to one another in the same way.

Line 2.12 tells us in a very general sense what Wittgenstein means by a picture: it is a model of reality. Lines $2.13-2.14$ tell us more specifically what being a picture or a model consists in:

(i) The elements of a picture must correspond to objects (in the world).

(ii) Elements and objects must correspond in the sense that elements represent or stand for objects.

(iii) The elements must be related to one another in a determinate way.

(iv) The way the elements are arranged in a picture must mirror a possible arrangement of things in the world.

So something counts as a picture because its elements are arranged in a determinate way and this arrangement depicts the arrangement of objects in a state of affairs. In the case of ordinary pictures this account seems clear enough. The representation works because the spatial arrangement of the elements in the picture mirrors the spatial arrangement of the objects in a state of affairs. A proposition clearly cilnnot model reality in the same way. A picture depicts spatial arrangement; a proposition does not. As IIittgenstein continues to explicate the picture theory it turns out that (i) spatial arrangement is incssential in the relation between pictures and the world and (ii) what a picture essentially depicts is something logical - the logical as opposed to the spatial arrangement of objects.

2.182 Every picture is at the same time a logical one. (On the other hand, not every picture is, for example, a spatial one.)

2.151 Pictorial form is the possibility that things are related to one another in the same way as the elements of a picture. 
We have come across the notion of logical form in the earlier discussion of objects. There we saw that if an object can occur in a state of affairs, the possibility of that combination must be written into the thing itself. These possibilities (its combinatorial potential) constitute its logical form. When a name is correlated with an object it 'picks up' its logical form. Hence the way the name can occur in a sentence is governed by the way an object combines with other objects.

Der Name vertritt im Satz den gegenstand. (TLP 3.22)

The verb of vertritt, 'vertreten'. is translated as: '..... name is the representative of an object.' in the Pears and McGuiness translation ${ }^{16}$, as 'to deputize for' by Malcolm ${ }^{17}$ and in Anscombe's ${ }^{18}$ translation "go proxy for". So, if someone deputizes, acts as a representative of, or goes proxy for, someone else. then the deputy takes on the powers of whoever he is standing in for. In an elementary proposition a name takes the place of an object. As deputy, the combinatorial powers of the object are taken on by the name. Thus the logical relations between objects and between names are isomorphic. For example, a book can enter into a number of different relations with other objects - it can be 'on top of', between'. 'heavier than' and so on. However, it cannot be the colour of something, nor can we say that it is between its own pages'. These combinations are not included within the logical space of the object. The word 'book' admits of the same combinatorial possibilities that the object does, so 'book' cannot be used as a colour predicate, nor can you say something like the book is in between its own pages. It is important to note that for $\mathrm{W}$, the logical form of a proposition is oftentimes not discernable from the written or spoken sentence. The written or spoken sentence displays its 'grammatical form'. and as Wittgenstein emphasizes, grammatical form is often misleading as to logical form. Consider the wo expressions 'the rose is red' and the morning star is the evening star'. Both have the same grammatical form. They are both of the form ' $\mathrm{x}$ is $\mathrm{y}$ '. However, they do not share the same logical form. In the first expression 'is' is used to predicate something of a rose, in the second it is used as a sign of identity. Thus the homonymy is deceptive. Logical structure, according to the TLP, lies beneath thic surface structure and can only be excavated by logical analysis.

The central problem with this theory is that it is attractive but empty. It is attractive because it seems to offer an almost intuitive familiar kind of explanation, one modeled on the kind of causal explanation in science. In a scientific explanation one phenomenon is explained in terms of another phenomenon that can be identified independently of the phenomenon being explained. In the case of the realist 
explanation of the structure of language, the explanans (in this case the world) cannot be identified independently of the explanadum (language). The trouble with saying that a name can behave in a particular way only because the object which it designates behaves in that particular way is that the behaviour of the object cannot be described independently of our existing vocabulary. Another way of appreciating the flaw in realism is to consider the realist's solution to the problem of the application of general words to things. Wittgenstein concentrated on singular terms in the TLP because he regarded all words as names. As a result he neglected the highly problematic area of how we determine the cxicnsion of a general word. In the $P I$ however, the application of general words to things take centerstage. In the case of the application of general words to things the realist posits an independently existing universal to explain what it is in virtue of that a general word has the particular extension it does. For example, the realist will say that we ought to call some object blue because it is in fact bluc. The trouble with this explanation is that we cannot identify the colour of the flower independently of our colour-vocabulary. or our practice of calling certain objects blue. Compare this with a genuine scientific explanation. For example, in the explanation of high tide in terms of the gravitational force of the moon. the gravitational force of the moon can be identified independently of the tide. The realist's explanation mimics a scientific one, but it is nothing more than the empty shell of an explanation.

It might be objected that the requirement that the meaning of an expression be something that is independently identifiable is unreasonable, since, if we were to take it seriously, dictionaries would be of no help. Typically, dictionaries provide us with expressions which explain the meanings of words such that we are able to. to put it in lay terms, understand what phenomenon or situation in the world the expression being explained picks out or represents. However, dictionaries only leave us with more words: the words used in a definition are themselves open to various ways of understanding, and so must also be explained. Notice how dictionaries, in an effort to overcome the ambiguities or misunderstandings in language sometimes supplement a definition with a picture or a drawing. Notice also that sometimes when we are asked to explain the meaning of a word and we find that whatever explanation we give, there are misunderstandings in what 'we mean', or more and more clarification is called for. we have a tendency to give up explaining and in exasperation point at, or demonstrate (act out) what we mean.

In the history of philosophy realism has enjoyed a persistent presence and it makes one wonder why its impotency, a flaw though not immediately discernable because of its initial charm, but nevertheless 
pretty obvious once pointed out. has not ruined its appeal. One way of attempting to answer this is to see what is lost once realism is called into question. In the case of a theory of language realism explains what gives our sentences their senses by positing what appears to be another (extra-linguistic) reality. This seems satisfying because it seems to provide foundations or justification for the structure of language - foundations in the absence of which our language would appear arbitrary. Something must govern what counts as sense - it can't simply be a matter of caprice. When the putative support structure that realism provides is removed, we feel vertiginous, and this seems to explain why people have returned to realism over and over again in different ways. It gives us the support we need and we think we are getting.

Given that once pointed out, the central flaw in realism is so obvious, one wonders whether Wiltgenstein was not aware of it at all? We could perhaps answer by looking at the role his notorious notion of "showing" plays in the TLP. According to this doctrine, the relationship between a name and the object which is its referent, and the relationship between a proposition and the state-of-affairs it depicts. is one that cannot be stated or captured by a proposition, but is shown. Although you cannot state that an object is the meaning of a name, that the meaning of a name is the object it picks out is shown by its attachment to that object, and:

A proposition shows its sense.

A proposition shows how things stand if it is true.

And it sals that they do so stand.'

It is unclear whether Wittgenstein realised that the realist answer to the relation between words and the world is inadequate and offered his Doctrine of Showing instead. There is at any rate no textual evidence to suggest this. What is clear though is that the Doctrine of Showing masked the real problem in the realist account of the interface between language and the world. With the question of the relationship between language and the world neatly tucked into the 'cannot-be-said-but-only-shown' drawer. the problem was out of the way, so to speak, and did not rear its head for further grappling With. It is interesting to note that Anscombe saw this Doctrine as an embarrassing feature of the TLP. ${ }^{19}$ It was a kind of waste-paper basket, she thought, where all intractable problems were discarded. It was only when Wittgenstein returned to philosophy in 1929 that he first expressed explicit awareness of the 
inadequacy of the realist's account of the relationship between language and the world. In Cambridge Lectures 1 he says:

In all language there is a bridge between a sign and its application. No one can make this for us; we have to bridge the gap ourselves. No explanation ever saves the jump, because any further explanation will itself need a jump. ${ }^{20}$

In the later work Wittgenstein develops the idea that we come to understand the meaning of a word by understanding how it is applied, and that understanding how it is applied is a matter of learning the technique for the application of that word. Although the Doctrine of Showing employs the idea of application (a name shows its meaning by its application to the object named) it failed to do good work in the TLP because it was intimately bound up with logical atomism which explained the relation between language and the world at the level of indefinable names and simple objects. In the later work, when logical atomism was abandoned, the idea of showing, when applied to the application of general words to things. bore fruit.

Rusiell. B.. Principia Mathematica. 1927.

Runsell. B.. Theory of Knowledge, 1913.

ihid.

IIItgenstein of course objected to this. In TLP 2.0211 he says: "If the world had no substance, then whether a proposition had sense would depend on whether another proposition was true.'

"See Monk. Ray, Ludwig Wittgenstein: The Duty of Genius, 1990, p. 81.

"Vothooks. p 121.

Pears. D. F.. The False Prison, Vol, 1, 1987.

Cimbooks. 1914-1916. G.H. von Wright and G.E.M. Anscombe (eds). G.E.M. Anscombe (trans.) 1961, 21 October 1914.

'Athough Russell maintains that logical forms are not extra items, his talk of apprehending logical form by means of

logical experience treats logical form as if it were an extra item in the proposition.

Pars. D.F. Paradox and Platinde in Wittgenstein is Philosophy (unpublished).

(it. Kenny, A. Hittgenstein. 1973.

logelin. R. Hittgenstein. 1976

Fann, K.T., Hittgenstein's Conception of Philosophy, 1969

is Vobooks, 1914-1916.

Malcolm. … Vothing is Hidden: Hittgenstein's Criticism of his Earl. Thought 1986.

"Witgenstein. L. Tractatus Logico-Philosophicus (1922), trans. by D.F. Pears and B.F. McGuiness, 1974.

Vialcolm. ․ 1986, p3.

Inscombe. G.E.M. An Introduction to Witgenstein is Tiactatus, 1959.

inscombe. G. E.M.. An Introduction to Withenstein's Tractatus, 1959.

" cambridge lectures 1.1930-32. p. 67. 


\section{Chapter 2: Account of Philosophy in the Tractatus}

In the TLP Wittgenstein addresses both the status of philosophical propositions and the nature of philosophical method. He prescribes what he believes to be the only correct method of philosophizing. However. there is a discrepancy between what he preaches and what he actually practices in the TLP. As far as the practice goes, it conforms to the method of doing philosophy that he advocated in the 'Preliminary' of Notes on Logic of 1913. There he prescribed that the way to do philosophy is to investigate the logical form of propositions. By the time he wrote the $T L P$ he had come to believe that logical form cannot be described and hence cannot be the subject of investigation. The picture of philosophy in Notes on Logic is that: (i) philosophy is wholly descriptive; it does not consist of a priori deductions. (ii) philosophy is above or below, but not besides the natural sciences. Unlike the sciences, philosophy does not give us descriptions of reality and for this reason can neither confirm nor confute scientific propositions. (iii) the subject matter of philosophy is the logical form of empirical propositions. In this respect Wittgenstein and Russell was in agreement since Russell also maintained that philosophy is the study of logical forms; Wittgenstein however differed from Russell in that he did not believe that logical forms could be named. Russell believed that our knowledge of forms is a special kind of 'logical experience', and that a proposition can therefore depict logical form. He thus treats logical form as if it is another kind of object in the world, which can be spoken about by propositions. Wittgenstein disagrees sharply with this. In TLP 4.121 he says:

Propositions cannot represent logical form: it is mirrored in them.

What finds its reflection in language, language cannot represent.

What expresses itself in language, we cannot express by means of language.

Propositions show the logical form of reality.

They display it. (see also 4.124-4.1241)

And:

The 'experience' that we need in order to understand logic is not that something or other is the state of things, but that something is: that, however, is not an experience.

Logic is prior to every experience - that something is so. 
It is prior to the question 'How?', not prior to the question 'What?' (TLP 5.552)

Furthermore, Russell believed that the correct philosophical method was one that took the sciences as their example in producing knowledge that approximates to the truth. For Wittgenstein however, since philosophy is a description of logical form, and since logical form is part of the pre-conditions of sense, any knowledge about logical form cannot constitute an approximate truth. Philosophy is thus categorically different to the sciences. It is sui generis. By the time Wittgenstein wrote the TLP he rejected the de jure practice of philosophy that he formerly shared with Russell. He now no longer believed that philosophy should be the description of logical form since he now believed that logical form is indescribable. Since the task of philosophy cannot be to describe logical form, philosophy cannot yield any theses or doctrines - not of logical form nor of anything else. Wittgenstein came to believe that the singularity of philosophy did not have to do with having a unique subject matter; rather. its uniqueness had to do with its methodology or the practice of philosophy.

Philosophy does not give us any truths, rather:

Philosophy aims at the logical clarification of thoughts.

Philosophy is not a body of doctrine but an activity.

A philosophical work consists primarily of elucidations.

Philosophy does not result in 'philosophical propositions', but rather in the clarification of propositions.

Without philosophy thoughts are, as it were, cloudy and indistinct: its task is to make them clear and to give them sharp boundaries.

Philosophy settles controversies about the limits of natural science.

It must set limits to what can be thought; and, in doing so, to what cannot be thought.

It must set limits to what can be thought by working outwards through what can be thought.

It will signify what cannot be said, by presenting clearly what can be said. (TLP 4.112 $-4.115)$

Wittgenstein's new conception of what can legitimately be achieved by philosophy is embedded in a particular metaphysical preconception about language viz. that there is a gulf between the surface structure of language and its real logical structure. The surface structure belies its real logical form, and 
one cannot read off the logical form from the surface structure - logical form can only be accessed by logical excavation. Philosophical questions and conundrums are casualties of this feature of language. They are questions that are really the product and manifestation of linguistic confusion. They are thus psculo-questions. As such we should not take them at face value and attempt to answer them but rather attempt to expose them for what they are. The way to do this, Wittgenstein proposed, was to unearth their real logical structure by logical analysis. He believed that language has a common logical structure. All legitimate sentences bear the form: 'this is how things stand.' (TLP 4.5) They all say that things stand thus and so. All propositions are thus descriptive. (See TLP 2.0201, 2.225) When philosophical propositions are subjected to logical analysis, the end product does not bear this form. The correct philosophical task then is to establish or lay bare the real logical structure of language and, armed with this criterion of legitimate propositional structure, expose philosophical problems as misuses of language. In the preface to the TLP Wittgenstein says that 'the subject-matter of the book is the problems of philosophy' and that the aim of the book is to show that the reason why these problems arc posed is that the logic of our language is misunderstood. The corollary of this is that once the logic of our language is understood we will cease to pose such questions since they are not genuine questions but the products of illusion. In order to understand the real logical form of language and prevent ourselves from making such linguistic errors we need, according to $\mathrm{W}$, an adequate sign language or conceptual notation that conforms perspicuously to the logical syntax. Wittgenstein was of course not advocating. as Russell mistakenly believed, the conditions for a logically perfect language. Ordinary language, according to $\mathrm{W}$, is in perfect logical order: the purpose of an adequate sign language is simply to make perspicuous the real logical structure of our language. His intention was to present the logico-metaphysical conditions for any possible language.

In order to understand the sense in which philosophical propositions are manifestations of grammatical mistakes we need to look at his distinction between 'senseless' and 'nonsensical'. According to the TLP logical propositions are 'senseless'. They are senseless because they 'say' nothing. The notion of 'saying' is bound up with the notion of 'sense'. A proposition with sense picks out a logical possibility or picks out an area in logical space. What the proposition says, its sense, is the particular division it makes in logical space. Tautologies and contradictions make no such division. 'A tautology leaves open to reality the whole of logical space: a contradiction fills the whole... of logical space leaving no point of it for reality. Thus neither of them can determine reality in any way' (TLP 4.463) Tautologies and contradictions thus lack sense because they fail to fix a logical situation. However, although they 
lack sense, they are not to be regarded as nonsensical since their signs are combined legitimately. We can set up truth tables for them. They are well-formed. Philosophical propositions on the other hand also lack sense and are therefore non-representational, but they fail to represent for a different reason their sign-combinations are illicit. They fail to fix an area in logical space because no objectcombination maps onto their particular sign- combination. In short, their sign-combination contravenes logical syntax.

Though the point is a more general one, the idea that philosophical propositions transgress the limits of language (contravene the rules of logical syntax) is best explained in connection with the discussion in the $4.12^{\circ} \mathrm{s}$ in the TLP on formal concepts. According to Wittgenstein, formal concepts such as object'. 'number', 'fact' (ontological categories), and 'name', 'proposition' (logico-linguistic categories) in their ordinary language use, function as variables. For example, we say: 'There are two objects which....' which, in logical notation is expressed as ' $\exists$ x $\exists$ y ....'. Such words function as variables over which properties can be predicated. However, in philosophical propositions we attempt to use such words as predicates. Typically, they get used as 'proper-concept words'. For example, we say: ' $\mathrm{x}$ is an object' or 'seven is a number'. Here 'object' and 'number' are used as predicates. And whenever such words are used as proper-concept words (and thus as predicates) '... nonsensical pseudo-propositions are the result.' (TLP 4.1272). So, although one can say 'there are books', one cannot say 'there are objects".

The same applies to the words 'complex', 'fact', 'function', 'number', etc.

They all signify formal concepts, and are represented in conceptual notation by variables, not by functions or classes (as Frege and Russell believed).

' 1 is a number', 'There is only one zero', and all similar expressions are nonsensical.

(It is just as nonsensical to say, ' $2+2$ at 30 ' clock equals 4 '.) (TLP 4.1272)

According to Wittgenstein. when words such as 'object' and 'number' are used as predicates, they can be given neither sense. nor Bedeutung (reference). ${ }^{\prime}$ A word or name only has a meaning (referent) in the context of a proposition (TLP 3.3), so, if an expression does not qualify as a genuine proposition its words lack referents. 
Th.P 3.31 claims that a symbol (a sign together with its sense) contributes toward the sense of a proposition (makes a semantic contribution). Thus, if an expression is used as a symbol - that is, if it is used to make a contribution towards sense but fails to, it is not a genuine symbol and hence any sentence that contains it is not a genuine proposition. Take the expression 'seven is a number'. Anyone capable of understanding this expression must already know the various uses (combinatory possibilities) of the word 'seven'. They must already understand that seven is a number word (and not a colour word. say). Thus to say of seven that it is a number is to make no semantic contribution to the sentence which has not already been made by the word 'seven' alone. 'Seven is a number' does not say anything. Rather. it stipulates a rule for the use of the word 'seven'. or rather, it gives the rule for the combinatory possibilities of 'seven' (that it is to be combined as a number-word and not, say, as a colour-word). In the dictum of Wittgenstein's later work, 'seven is a number' is an act of naming, and since '[n]aming is so far not a move in the language game.' ( $\underline{P I} 49)$, one is thus not saying or communicating anything. 'Seven is a number' is more like stage-setting: it provides one with names so that communication can take place by using them. It's like setting up the chessboard and indicating what is what on the board - that this piece is to act as king and another as queen, etc. Setting up the board like this is not yet playing the game - setting up the board like this does not yet count as a move in the game. Likewise. naming is only setting up the stage in order for a game to be played, hence naming is not yet a move in the language game. Now, failure to make a semantic contribution to the semantic content of a sentence renders such a term, as well as the proposition in which it occurs. meaningless. All philosophical propositions which employ such formal concepts - propositions such as 'seven is a number'. 'John is an object', 'being red is a concept' - suffer the same defect. The point here is that an expression such as 'seven is a number' is not a representational proposition, because 'is a number' is already, in a sense, contained in 'seven'. (If you understand 'seven', you already understand that it is a number.) No semantic contribution has been made in the sense that nothing more is added by 'is a number'.

This defect. however. is a consequence of a more general objection: in 'seven is a number', 'is a number' has no meaning because we have failed to give a meaning to 'is a number'. To understand this point we need to refer to TLP 5.4733. Wittgenstein uses the example 'Socrates is identical' and says that this sentence says nothing because we have failed to give 'identical' any adjectival meaning. If a proposition has no sense, that can only be because we have failed to give a meaning to some of the constituents. (TLP 5.4733) This general objection derives from Wittgenstein's compositionalism - the 
idea that the sense of a proposition is a function of the meanings of its constituent expressions. ("Like Frege and Russell, I construe a proposition as a function of the expressions contained in it.' $\underline{T L P}$. 3.318). The 'compositionalism' argument goes like this: the meaning of a name is determined by the object it stands for. Objects possess logical form. The logical form of objects is their possibility of entering into certain combinations with other objects. Objects, and accordingly, their names, fall into different logical categories: 'seven' can only be combined as in, for example 'give me more than seven apples'. but not as in 'seven is too bright'. The combinatory possibilities of 'seven' exclude the latter combination. When names are combined according to the combinatory possibilities of the objects for which they stand, such a combination depicts a possible state-of-affairs. If they are not, the expression fails to depict a possible state-of-affairs. The reason it fails is that the constituent names have incompatible meanings (the objects for which they stand do not combine in that way). We have, in this case. mixed up categories and committed what in Rylean terms would be called a 'category mistake' 2 . In 'Socrates is identical', 'identical' functions as an adjective - but the combinatory possibilities of 'identical' preclude such a function. The same point was made earlier (' $\mathrm{x}$ is an object', 'seven is a number'). and it was emphasized that such a 'category mistake' amounts to transgressing the limits of sense - to talk unintelligibly.

To sum up. the problem with philosophical propositions is that their sign-combinations are illicit. They are instances of a 'category mistake'. More specifically, these propositions say nothing because we have failed to give a meaning to some of the expressions in them. The particular sense in which we have failed to give a meaning to some of the expressions is by employing formal concepts as genuine concepts. The result of this is that such expressions (formal concepts) fail to make a semantic contribution to the sentence, and thus the sentence as a whole lacks sense. However, that seven is a number or that $\mathrm{x}$ is an object is shown in our use of propositions containing these words, for example 'there are seven more children or 'this object is heavier than that object'. So the trouble with philosophical propositions is that they attempt to say (express as factual) what can only be shown in the actual use of language.

$\therefore t$ the end of the TLP Wittgenstein says:

My propositions serve as elucidations in the following way: anyone who understands me eventually recognises them as nonsensical, when he has used them - as steps - 
to climb up beyond them. (He must, so to speak, throw away the ladder after he has climbed up it.) (TLP 6.54)

Here he is declaring that the theory of propositional meaning articulated in the TLP is self-destructive: given his account of meaning the essential character of (the relationship between) language and the world is impossible to express. These essential features can only show themselves or make themselves manifest. So the propositions of the TLP articulate a theory of meaning that has as its consequence the thesis that the nature of propositional representation cannot be factually discussed. The result of this project is that the very propositions used in the project are nonsensical. However, if these propositions are nonsensical because they are failed attempts at saying something, they are, as the TLP indicates, not factual. What kind of discourse are they then? TLP 6.54 says that they are elucidations. We know so far that. according to the theses of the TLP, what can be shown cannot be said. The main occupants of this ciltegory are the essential features of (the relationship between) language and the world, and what the $T L P$ refers to as the mystical - religion, aesthetic appreciation, and morality. The 'elucidatory' propositions of the TLP seem to be another kind of showing. They are not like the propositions of logic which show the formal features of language, they are not like ordinary factual propositions that show the structure and limits of language, they are not like music or poetry that show the 'mystical'. Perhaps they show in the sense that they commit a wrong (cross the limits of language), to get you to a point where you can look back and see that what you have done was wrong.

More recently a novel approach to the interpretation of the TLP has been developed, one that maintains that just as in the case of the $P I$, the $T L P$ does not subscribe to or advance any metaphysical theses or doctrines. This approach, now commonly referred to as the 'New Wittgenstein' approach, is spearheaded by Cora Diamond ${ }^{3}$, and strongly supported by, amongst others, James Conant ${ }^{4}$ and Warren Goldfarb ${ }^{5}$. They maintain that apart from the preface and the closing remarks of the $T L P$, the rest of the text is to be regarded as plain nonsense. Furthermore, when Wittgenstein says these nonsensical propositions must, in the end be discarded, we must, they advocate, discard them lock, stock and barrel. To maintain that the propositions of the TLP show something that cannot be expressed in words is to take on board a thesis that should have been discarded when the propositions of the TLP were discarded. The value of the TLP. they maintain, does not lie in what Wittgenstein is saying, but in what he is doing by having written the TLP. Wittgenstein's writing of the TLP, Diamond maintains, was tongue-in-cheek - a kind of satire. He played out exactly what he thought cannot and must not be done. 
It was a demonstration of sorts. The only way to understand the $T L P$, she claims, is to read it in the light of the preface and the closing passages, viz. in the preface Wittgenstein maintains that most of the propositions of philosophy are nonsensical and that the book intends to draw the limits of language from the inside, as it were. In the closing passages he maintains that the propositions of the TLP perform a function - they get you to a point where you can see that certain kinds of discourse are illegitimate including the very propositions making the point, but then they must be thrown away simply because they are illegitimate. And when we throw them away, we must not still hold on to something maintained by them. One cannot both throw them away, and at the same time salvage some remarks that one uses as commentary on the TLP. According to Conant the Preface and the concluding sections of the Tractatus form the frame of the text. It is there that Wittgenstein provides us with instructions for how to read what we find in the body of the text. ${ }^{6}$. They (Diamond and Conant) claim that the passages of the TLP must be wrestled with or 'worked through' - one has to struggle to make sense of them - but the final value of these passages is not that they impart some understanding, direct or indirect. but that the reader (should) experience them as 'crumbling in upon themselves. ${ }^{7}$ This is all we are supposed to take away from the reading of the TLP. We wrestle with the passages because - as Proops succinctly puts it - they possess enough 'psychological suggestiveness of sense ${ }^{8}$, however, because we experience them as 'crumbling in upon themselves', their exclusive value lies in their ability to relieve philosophical perplexity and to help us arrive at a kind of self-understanding. In the words of Conant: "The only insight that Tractarian elucidation imparts, in the end, is one about the reader himself: that he is prone to [certain particular] illusions of thought."

The implication of this view is that both the TLP and the PI are continuous in both task and method: in the case of both books the task is to draw the limits of language and the method involves an absence of theses or doctrines. Because this view maintains that the TLP contains no substantive philosophical theses and doctrines, they claim that there is nothing for Wittgenstein to have repudiated in his later work. They are thus skeptical of the 'standard' view that the later Wittgenstein came to regard a number of the central positions he held earlier as seriously mistaken. It is important to see that they are skeptical of the standard view not because they have argued or shown that his later views are not related (by way of continuity or criticism) to his earlier views, but because it is a necessary implication of their reading of the TLP. The framing remarks of the TLP (the Preface and the closing passages). according to this riew, contains 'instructions' for reading the body of the book. The scope of the frame however. has been shifted by some exponents of this view. Diamond remains consistent in her view of 
the frame (the Preface and the closing passages); Conant, however, has shifted from initially holding that all of the TLP should be discarded as nonsense (Conant, 1989), to a view that he shared with Diamond. and then in rather ad hoc fashion, widens the scope of the frame to include TLP 4.112."1 More recently, Conant has remarked that many of the sections to which he had earlier on devoted a lot of attention (Conant 2000), for example, the Preface, sections 3.32-3.326, 4-4.003, 4.111-4.12, 6.536.54 . belong to the frame of the work and are only able to impart their instructions concerning the aim and method of the work if they are recognized as sinnvoll. Furthermore, 'The Tractatus teaches that [whether or not a string of signs is Unsinn] depends on us: on our managing or failing to perceive [rikcnnen] a symbol in the sign. There can be no fixed answer to the question what kind of work a given remark within the text accomplishes. It will depend on the kind of sense a reader of the text will be (tempted to) make of it." "Thus he sees the distinction between what is part of the frame and what is part of the body of the work as not simply a function of where in the text the remark is situated (in fact. one wonders if he now maintains this at all), but as a function of how it occurs to us, the readers (i.e. it will depend on the kind of sense a reader of the text will be tempted to make of it). It appears then that there is no fact of the matter about whether a particular proposition is part of the frame. It all depends on a particular reader`s psychology. It has been well-argued that something is amiss with this line of thought - Proops presents one of the most convincing arguments against the 'New Wittgensteinians'. Looking at the matter the way Diamond and Conant do (that the body of the text is discardable nonsense) leaves unexplained Wittgenstein's wrestling with issues in the Notebooks, the end product of which culminated in the remarks in the TLP. For example, it does not explain Wittgenstein's letter to Russell on August $19^{\text {th }} 1919$ where Wittgenstein is adamant that the main point of the TLP is the Doctrine of Showing (Letters to Russell, Keynes and Moore, p.71, August 19, 1919) - a position corroborated in 'Notes Dictated to Moore' (See Notebooks, pp. 107-9). If the body of the TLP were discardable nonsense. why would Wittgenstein emphasize the centrality of the Doctrine of Showing in his work? It also does not explain his later works, a lot of which are active engagements with views and attitudes he held in the TLP. Furthermore, there seems to be, as Proops argues, no substantive reason for taking the Preface and the closing remarks as framework instructions as to how to read the $T L P$ - as is evident from Conant's ad hoc widening of the scope of the frame. I will not go into any further detail about the defects of the Diamond-Conant view. That could be a thesis on its own. All I wish to do here is to indicate that it would be difficult, on that view, to thread together a consistent picture of what Wittgenstein was up to in the course of his writings - if the TLP was just a satirical 
demonstration of what cannot be done philosophically, what are we to make of his philosophical struggles before and after the TLP?

My discussion below continues in the spirit of what can be called the 'traditional' or 'standard' view, the view against which the New Wittgensteinians are reacting. The standard view maintains that Wittgenstein"s concern to articulate the nature (and hence limits) of representational discourse is an implication of a more central and dominant concern. The real driving force behind his work, he says, is to express the distinction between 'showing' and 'saying'. His reply to Russell's preliminary questions about the TLP goes some way to confirm this:

- Now I'm afraid you haven't really got hold of my main contention, to which the whole business of logical propositions is only a corollary. The main point is the theory of what can be said by propositions - i.e. by language - (and, which comes to the same thing, what can be thought) and what cannot be said by propositions, but only shown; which I believe, is the cardinal problem of philosophy. ${ }^{13}$

In lact. the distinction between what can be said and what can be only be shown pervades the TLP from its preface to its closing admonition:

What we cannot speak about we must pass over in silence. (TLP 7)

And in a letter to von Ficker we read that the TLP

consists of two parts: the one presented here plus all that I have not written. And it is precisely this second part that is the important one. My book draws limits to the sphere of the ethical from the inside as it were, and I am convinced that this is the ONLY rigorous way of drawing these limits... ${ }^{1+}$

Thus Wittgenstein's intention is to draw a distinction between what can be said and what cannot be said - from within the limits of factual discourse - by saying only that which can be said. Only factual discourse constitutes sense. What lies on the 'other side of the limit' is, as Wittgenstein says in the preface to the $T L P$. simply nonsense. But the $T L P$, in attempting to achieve its objective, ends up, by its 
own admission. crossing the limits. The situation is as follows: Wittgenstein's intention is to draw the limit by saying only 'what can be said' - and in so doing indicate what cannot be said precisely by not saying it. Now such an objective could perhaps be achieved by literally saying only what can be said (saying only that which conforms to the rules of syntax). What one would end up with by doing so is an inventory of all sayable expressions. For example: 'the cat is on the mat', 'the cat is not on the mat'. the dog is on the roof. 'the dog is not....' and so on. The entire inventory of sayable expressions would thus constitute 'what can be said' - and the limit would hereby have been drawn from within. (An objection could be raised to the idea of an inventory: an inventory comes to an end. Only "so many things' constitute an inventory - whereas the list of what can be said is, by contrast, endless. In response, perhaps one could say that such a very long(!) inventory would constitute better obedience to Wittgenstein's admonitions: rather say less than what can be said than attempt to say what cannot be said! However, providing an inventory would not make the point that Wittgenstein wants to make that language has limits and that certain things cannot be expressed in language but is shown by language. Rather than giving an inventory, Wittgenstein gave the 'general form of a proposition' - a formula, or trademark, as it were, characteristic of all genuine propositions. Rather than having a list of all genuine propositions. we would instead be equipped with a formula that would enable us to recognize those propositions that 'can be said'. He set about presenting us with this formula by examining the structure and function of language. And this was where the trouble began. Saying what a proposition (essentially) is, involves, as we shall see, understanding (saying or thinking) what it is not. In short, saying what a proposition is involves attempting to take an 'outside' perspective - a perspective where you can 'see' (and hence say) what counts as a proposition. But this then amounts to crossing the limits - it is no longer a view 'from within'. And, since 'what lies on the other side is simply nonsense'. such an outside perspective, which is required in giving a general 'formula' of the proposition, constitutes nonsensical discourse. Hence Wittgenstein's description of the propositions of the TLP as nonsensical. They are attempts to talk about the structure of language and the relationship between language and the world - but it is precisely this, according to the TLP, which is ineffable. However, although the propositions of the TLP cannot be said, what they attempt to talk about - the relationship between language and the world - can be shown by the propositions of logic (tautologies and contradictions) and by ordinary bona fide representational discourse.

What is inexpressible includes: 
a) the logical form shared by propositions and what they depict. (The harmony between thought and reality is inexpressible.)

b) the meaning (bedeutung) of signs and the sense ( $\operatorname{sinn}$ ) of propositions. (Semantics is inexpressible.)

c) logical relations between propositions. (Rules of logical inference are inexpressible.)

d) the logico-syntactic category of signs. (Formal concepts are pseudo-concepts.)

c) the logical structure of thought and the world. (The limits of thought are inexpressible - can only be set from within.)

The Picture Theory of language outlined in Chapter 1 explained that factual meaning is made possible becaluse propositions depict possible situations in the world. Factual propositions are thus bipolar. But why must a proposition satisfy this requirement - why must it depict a possible situation? To say that a proposition is bipolar is to say that it is capable of being true and capable of being false. This contrasts with the notion of bivalence, which states that a proposition is either true or false. For example, the proposition 'the cat is on the mat' is bipolar, since it is possible for it to be both true and false (true when the cat is on the mat, false when the cat is not on the mat). The expression 'the world has logical form is bivalent. since it can only be true (is necessarily true). There are no circumstances under which it could be false. Wittgenstein's conviction is that propositions that admit of bivalence and not bipolarity are not genuine propositions. Why? Some historical details are pertinent here. The view originated with Frege, who claimed that names and propositions have both a sense and a meaning (referent). where the meaning of a proposition is one of the two 'logical objects', namely, the TRUE and the FALSE. Wittgenstein initially followed Frege in claiming that a proposition has a meaning, that is. that a proposition stands for (some or other) object, just as names do. However, Wittgenstein maintained that the meaning of a proposition is not a logical object (its truth-value), but the fact (a state of affairs) that corresponds to the proposition. On the bases of this - that is, that the meaning of a proposition is the state of affairs which corresponds to it - it turns out that the meaning of ' $p$ ' and '-p' are identical: the fact that ' $p$ ' picks out is the very same fact that '-p' picks out. How is this? The proposition 'p' asserts that something is the case, namely, $p$. The proposition '-p' asserts that something is not the case. namely, $\mathrm{p}$. Thus a proposition and its negation pick out the same state of affairs, since the fact that makes it true it the very same fact that makes it false. What 'p' depicts is the self-same thing that ' $-p$ ' depicts. only 'p' asserts that this is not how things are. Thus to understand a proposition 
is to understand what it depicts in its positive and negative sense. A proposition is thus internally related to its negation in much the same way as

is related to

To understand ' $p$ ' is to understand how things would be if '- $p$ '. (T3.144, 3.221)

It can now be seen why, on this account, essential features cannot be represented. Consider the expression 'the world has logical form'. If this is a genuine proposition, then it must pick out a state of affairs which, although it does in fact obtain, need not obtain (that is, it must pick out a situation the negation of which is possible). But this is not so in the case of the sentence in question. One cannot (sensibly) negate 'the world has logical form', since the negation does not present a conceivable or genuine possibility. That is, a world that lacks logical form is not a world (in the Tractarian sense) at all. Logical form is a precondition of sense: to talk of a world that lacks logical form is to talk incoherently. A world that lacks logical form is not a recognizable (describable) world at all. Since the structure of the world is a necessary feature of the world, its denial does not pick out a genuine possibility. The denial would depict a putative situation where the necessary features (the preconditions) are absent - which is an unintelligible situation. Since a proposition picks out a situation that need not obtain, propositions that allegedly talk about essential features cannot be genuine propositions.

Another way of understanding why propositions must be bipolar is to consider Wittgenstein's discussion on the futility of trying to justify a rule. Now, any explanation of the possibility of language is an attempt to explain the possibility of a rule-governed or normative discourse. Wittgenstein argues that the propositions used in such an attempt would have to be meaningless - bipolar propositions cannot justify rules. The rules of a language are such that, given that language, they cannot be otherwise: propositions can thus not justify rules since they would then be (attempting to) pick out a situation which could not be otherwise - they would not be picking out a possible situation. Language cannot express what cannot be otherwise. If a bipolar proposition 'justifies' a rule, then its assertion must rule out a situation that is conceivable. But given the function of the rules, it turns out that the 
rules will rule out as conceivable precisely what the justification implies is conceivable. The rules thus lose their prohibitory function. For example, with regard to colour propositions he says:

If I could describe the point of grammatical conventions by saying that they are made necessary by certain properties of the colours (say), then that would make the conventions superfluous, since in that case I would be able to say precisely that which the conventions exclude my saying. ${ }^{15}$

Colour conventions permit 'reddish-blue', but not 'reddish-green'. According to Wittgenstein any attempt to justify this would render the conventions superfluous, since any justification would have to appeal to the properties of colours. However, since it is conceivable that the colours lack these properties (colours having certain properties are contingent states-of-affairs), precisely that which the conventions prohibit would then be conceivable. The conventions would not act as grammatical rules. The general point is that because language can only state contingencies, any attempt to justify what is taken to be a necessity would itself be a contingent statement. The rules of language, because they are necessary, therefore cannot be accounted for. Furthermore, any attempt to account for the rules must be expressed in a contingent proposition, the denial of which constitutes a genuine possibility. But this possibility is what the rule is supposed to rule out. Rules can therefore not be accounted for. In Wittgenstein's Lectures itwe read:

Language can express one method of projection as opposed to another. It cannot express what cannot be otherwise ... what is essential to the world cannot be said about the world for then it could be otherwise, as any proposition can be negated.

However, although such necessity cannot be stated, that the rules are necessary expresses itself in the (linguistic) rules that certain expressions are permissible and others not. The immediate consequence of the claim that linguistic rules cannot be accounted for - that we cannot say what linguistic rules are $i n$ virtuc of - is that any attempt at a theory of meaning is impossible - in principle. That which makes meaning possible cannot be the subject of investigation, since such an investigation would constitute, on Wittgenstein's grounds, meaningless discourse - an attempt to transcend the bounds of sense. 
In his introduction to the TLP Russell ${ }^{17}$ suggests a way out of this impasse. He maintains that the kind of problem Wittgenstein discusses would only arise for someone who attempts to account for the logic of his language in that very language. The way out of this, Russell suggests, is to construct a metalanguage - a language which admits of a different logic to that of the object-language, and which is to be used to talk about the object-language. The propositions of the meta-language, because they conform to different rules, would admit of sense. So whatever one said in this language about the object-language would qualify as meaningful. But Wittgenstein would never accept this. Talk of a meta-language, according to Wittgenstein, fails to appreciate the heart of the issue. To wit: any language one could construct must conform to certain rules - the same rules. (The world has a fixed logical form and hence language has a fixed logical form.) Wittgenstein's use of rules was not language-specific, differing from language to language. It refers to the very mode of representation amy representation. It is the very possibility of representation. Any language that one could construct must conform to these logical rules. It is the Kantian point - these rules are the preconditions of thought. Any expression that fails to conform to these rules does not count as part of language. Thus these rules are the rules for any meaningful language. So a 'meta-language', if it qualifies as a language at all. will not differ in logic from the object language - in which case it isn't a 'meta-language' such as Russell had in mind. Russell's solution thus does not work. Syntax cannot be stated in any language. Wittgenstein`s denial that a meta-logic is possible does not (merely) rest dogmatically on the claim that there is just one logic that counts as the pre-condition of intelligibility. In Philosophical Grammar ${ }^{18}$ we find him saying that logic determines what is necessary - there is no meta-logic that makes logic necessary. He supports this claim with a regress argument: If it were possible to account for the necessity of logic in some meta-logic then that only postpones the problem; for we would have the selfsame problem with such a meta-language: what grounds this logic? The situation would thus lead to an infinite regress. We would end up with an 'infinite hierarchy' of meta-languages. ${ }^{19}$ Furthermore, any artificial language draws on ordinary language to clarify (at least some of) its expressions. If a language were not translatable in this way - that is, if all its concepts or expressions were such that they were not (or couldn't be) cashed out in ordinary language - a multitude of problems would arise. For one. if ordinary language is, as it surely is, the only language we 'find ourselves with', how do we gain access to such a wholly untranslatable language? Secondly, and importantly, such an idea inherits all the objections Wittgenstein levels against the idea of a 'private language' in the $P I$ - a private language being a radically untranslatable language. Glock ${ }^{20}$ puts the matter succinctly: ordinary language is the 
semantic bedrock. and there is no semantic exit from this language - not upward via a hierarchy of meta-languages, nor downward to reality.

When I talk about language ... I must speak the language of everyday. Is this language somehow too coarse and material for what we want to say? Then how is another one to be constructed? - And how strange that we should be able to do anything at all with the one we have! In giving explanations I already have to use language full-blown (not some sort of preparatory provisional one) .....

The point is thus clear: ordinary language is all we've got. Any move that we make is via this language. There can be nothing more basic nor more sophisticated than this. Wittgenstein levels the same criticism against any attempt to do meta-mathematics (that is, any attempt to provide foundations for mathematics. as Frege and Russell attempted). In Remarks on the Foundations of Mathematics ${ }^{21}$ for instance, we find him commenting on any attempt to ground mathematics in a more basic calculus. He says that

they are no more the foundation of mathematics for us than the painted rock is the support of a painted tower.

It appears that what Wittgenstein means here is that a painted rock appears to support a painted tower, but because it is merely part of a painting, there is no real support going on. In the same way, a more basic calculus may appear to do the job of grounding or supporting mathematics, but there is no real support going on. I suppose one could also say that, just as in the case of the painting, where a painted tower, because it is part of a painting - does not stand in need of the support it appears to be getting (from the painted rock). so it is with mathematics too. It does not stand in need of the support that one thinks one is giving it by means of a more basic calculus.

The closing passage of the TLP proclaims that 'Whereof one cannot speak, thereof one must be silent'. Of course the proper appreciation of Wittgenstein's remarks rests on recalling that 'saying', proposition" and other terms have a very specific meaning in the TLP. So Wittgenstein's conclusion should not be surprising to anyone who has understood him up to that point. What 'can be said' constitutes factual discourse. What cannot be said - the pre-conditions of sense, the propositions of 
logic and the mystical - can only be shown. To try to say what cannot be said but only shown results in nonsense. We must thus be silent. This seems to be the import of the closing passage of the TLP. Silence in the context of this passage docs of course not mean complete silence, it simply means 'do not (try) to say', in the special sense of 'say' in the TLP. 'What can be shown, cannot be said.' (TLP 4.1212) Thus Ramsey's remark: 'But what we can't say we can't say, and we can't whistle either ${ }^{, 22}$ misses Wittgenstein's point completely. Wittgenstein's point is that the inexpressible cannot be said (in factual discourse), but only shown (by music, art, literature, religion and so on). For example, logic can show the limit of the world by arranging symbols in a particular way. ${ }^{23}$ Music and art can show something important about the meaning of life that cannot be captured in factual language. And so too with whistling. So the mystical can be shown. There is not, however, much mention in the TLP of how the mystical can be shown, since Wittgenstein's central concern in the TLP is merely to show that it cannot be said.

As concluding remarks to this section, I want to stress a point that has been made before. Wittgenstein's concern to articulate a distinction between what can and what cannot be said is not fueled with Positivist interests. It was not his goal, as in the case of the Logical Positivists, to banish metaphysics from the realm of meaningful propositions, and in so doing discredit their status. Rather, his intention was to ascribe to metaphysics its 'proper place'. Metaphysics does not belong to the realm of descriptive discourse: however, just because this is so, contra the Positivists, metaphysics has a higher status than that of representational discourse. This 'insignificance of the sayable' is an underlying contention in Wittgenstein's work. Earlier on I quoted Wittgenstein in a letter to von Ficker:

My work consists of two parts: the one presented here plus all that I have not written. And it is precisely this second part that is the important one. ${ }^{2+}$

And again in $\underline{T L P} 6.52$ :

We find that even when all possible scientific questions have been answered, the problems of life remain completely untouched. Of course there are then no questions left, and this itself is the answer. 
I take Wittgenstein to mean that if there are no (scientific or empirical) questions left, but the problems of life remain untouched, then these 'problems' and perhaps their 'solutions' are not a factual business. The 'understanding' or grasping of them is not like grasping contingent states of affairs. They are grasped in some other way. They are inexpressible.

There is indeed the inexpressible. This shows itself; it is what is mystical. (T6.522)

So it seems clear. then. that Wittgenstein's intention, far from being to discredit metaphysics. was to save it from the banal status of representational discourse. The following remarks on the propositions of ethics and religion confirm this sentiment:

My whole tendency and I believe the tendency of all men who ever tried to write or talk Ethics or Religion was to run up against the boundaries of language. This running against the walls of our cage is perfectly, absolutely hopeless. Ethics, so far as it springs from the desire to say something about the ultimate meaning of life, the absolute good, the absolute valuable, can be no science. What it says does not add to our knowledge in any sense. But it is a document of the tendency in the human mind which I personally cannot help respecting deeply and I would not for my life ridicule it. ${ }^{25}$

It seems that just as the attempt to talk about Ethics is a tendency worth respecting, so too with metaphysical propositions. Why? Ethical (and religious) propositions are, according to Wittgenstein, attempts to talk about 'the Absolute' in the domain of Ethics. This amounts pretty much to what goes on in an attempt to talk about the limits of thought. To wit: when we attempt to talk about the limits of thought (which we take to be the essential features of reality) we are in effect assuming an outside position which is, as we've seen, an incoherent project. It is 'absolutely hopeless'. In the same way, an attempt to talk about, say, the 'Absolute Good', is an attempt to make sense of the 'ethical' walls of our cage. However, just because we're in the grip of these ethical grids we can't make sense of them. Attempting to make sense of them is an attempt to get outside our ethical limits, which is, as Wittgenstein says, an utterly hopeless one. But, says Wittgenstein, this attempt is something he would nevel ridicule. The following paragraph again reflects this sentiment: 
Man has the urge to thrust against the limits of language. Think for instance about one's astonishment that anything exists. This astonishment cannot be expressed in the form of a question and there is no answer to it. Anything we can say must, a priori, be only nonsense. Nevertheless, we thrust against the limits of language. But the tendency, the thrust, points to something... I can only say: I don't belittle this human tendency; I take my hat off to it... For me the facts are unimportant. But what men mean when they say that "The world exists" lies close to my heart. ${ }^{26}$

Holiday $^{27}$ suggests that philosophical propositions, as attenpts to cross the bounds of intelligibility, are significant precisely because they tell us something about ourselves, namely, that human beings have an utterly hopeless tendency to want to see from 'outside' - in effect, to see or describe everything. The effect of such a realization ought to be a humbling one. It lets us see ourselves for who we are. By running up against the limits and transgressing the bounds of sense we gain a kind of self-knowledge that reminds us of our imperfections. The point is like the one that can be made about Socrates' dialectics. The Socratic questions have, or are intended to have, the effect of reducing our intelligence to aporia. This way we can get a sense of what we properly are. This Socratic indulgence in dialectics is meant to teach us something about ourselves, and what we learn ought to have a reducing or slurinking effect. Just as the remark of Jesus to those who wanted to stone the adulteress, 'He who hath committed no sin, let him cast the first stone,' had a humbling effect (because now, by putting the matter this way, they could all see that they were not faultless), so too here: seeing that we have a tendency to transgress the bounds of sense ought to produce a sense of humility within us.

It has been suggested that Wittgenstein's preoccupation with logic and the limits of thought is parailel to his moral preoccupation with sin. In both cases the dividing line between right and wrong must be recognised and not crossed. His preoccupation with only saying what can be said - that is, staying on the one side of the line while fighting off the tendency to cross the limits - is like his preoccupation with wanting to do the right thing while fighting off the tendency to sin. Remaining within the bounds of sense - of legitimate discourse - is like remaining within the limits of legitimate moral action. ${ }^{28} \mathrm{~A}$ testimony to this conviction is reflected by a report of Russell's in Ray Monk's ${ }^{29}$ biography of Wittgenstein. The story goes that Wittgenstein had often come to Russell's rooms in the evening to talk philosophy. He would spend hours tensely pacing up and down the room in complete silence till deep into the night. Russell never ventured to send him home for fear that if he did so Wittgenstein would 
commit suicide. On one such evening, while Wittgenstein was doing his pacing ritual, Russell ventured a question: 'Are you thinking about logic or your sins?' to which Wittgenstein fiercely replied: 'Both!'.

\footnotetext{
Vo schse because they are combined illicitly; no reference because the sentence in which they occur lacks logical form. Ryle's notion of 'category mistake' was inspired by these issues in the TLP.

Diamond. C., The Realistic Spirit. 1991.

Conant. W. 1989. 1992. 2000.

Goldfarb. W. Metaphsics and Nonsense: On Cora Dianond's The Realistic Spirtt, Journal of Philosophical Research, Vol. 22.1997.

"Conant 1992, p159: cf. Diamond. C.. The Realistic Spirtit, 1991, pl9.

Goldfarb, W.. Metaphisics and Nonsense: On Cora Diamond's The Realistic Spirit, Journal of Philosophical Research, Vol. 22. 1997. p.66; Conant, J., 1989b. p. 339.

Proops, The Vew Wittgenstein: a Critique in The European Journal of Philosophl; December 2001 , p.1.

"Conant. J., 2000, p.197.

"ihid.. 1993, p223. fn. 84

Conant. I., 2000, p. 216 , fn. 102.

1.mbig Hittgenstein: Lefters to Russell, Kernes and Moore, G.H. von Wright (ed.) p71, Aug. $19,1919$.

it Iene's from Ludwig Wittgenstein. Paul Engelmann, pp 143-44. The letter was written in 1919

Philosoplical Remarks. 4 4. R. Rhees (ed.), R. Hargreaves and R. White (trans.) 1975.

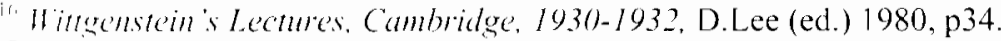

Rusiell. B., introduction to Tractatus Logico-philosophicas, translated by Pears, D.F. and McGuinness, B.F., 1974

Philosophical Grammar. R. Rhees (ed.). A Kenny (trans.) 1974, pp 126-7.

"Lextures on the Foundations of Mathematics: Cambridge. 1939, C. Diamond (ed.) 1976.

"Gluck. H.J. A Hittgenstein Dictionary, 1996. p246.

${ }^{21}$ Rematks on the Foundations of Mathematics, G.H. von Wright, R. Rhees, and G.E.M. Anscombe (trans.), (revised ed.), $1978(1956)(378)$.

$\therefore$ Ramsey. F. The Foundations of Mathematics, 1931

Veloooks 1914-16. G.H. von Wright and G.E.M. Anscombe (eds) 1961, p. 67.

- Paul Engelmann. Letter from L. Wittgenstein., pp 143-44. The letter was written in 1919

$\because$ Le'ture on Ethics, pp 11 -12, published in Philosophical Revie'n 74, No.1, 1965, pp3-16.

"ihid.

In conversation.

P.R. Shields discusses this issue at length in his book Logic and Sim in the Writings of Ludwig Wittgenstein, 1993.

"R. Monk. The Duty of Genius. 1990
} 


\section{Chapter 3: Linguistic Regularity}

By the time he wrote the PI Wittgenstein had abandoned the Picture Theory of meaning and had also given up the idea that all words are names. The new focus was now on general rather than singular terms. Furthermore, the relation between language and the world was no longer seen as located at the level of completely analysed constituents of language and their counterparts in the world - objects. Whereas the idea in the TLP was that in order to understand something you have to break it down into its smallest constituent parts, much in the way scientists attempt to understand a phenomenon by breaking it down into its constituent parts, in the PI the whole project of logical analysis is abandoned. The level at which words are applied to things is not at the end product of reductive analysis; rather, it is at the level of the words of everyday language, including general words. In PI 60 Wittgenstein presents an argument against analysis - against the idea that when we understand an expression we understand it by means of grasping the components that it can be analysed into.

When I say: "My broom is in the corner", - is this really a statement about the broomstick and the brush? Well, it could at any rate be replaced by a statement giving the position of the stick and the position of the brush. And this statement is surely a further analysed form of the first one. - But why do I cail it "further analysed"? - Well, if the broom is there, that surely means that the stick and the brush must be there, and in a particular relation to one another; and this was as it were hidden in the sense of the first sentence, and is expressed in the analysed sentence. Then does someone who says that the broom is in the corner reaily mean: the broomstick is there, and so is the brush, and the broomstick is fixed in the brush? - If we were to ask anyone if he meant this he would probably say that he had not thought specially of the broomstick or specially of the brush at all. And that would be the right answer, for he meant to speak neither of the stick nor of the brush in particular. Suppose that, instead of saying "Bring me the broom", you said "Bring me the broomstick and the brush which is fitted on to it."!- Isn't the answer: "Do you want the broom? Why do you put it so oddly?" - Is he going to understand the further analysed sentence better? - This sentence, one might say, achieves the same as the ordinary one, but in a more roundabout way. - 
Imagine a language-game in which someone is ordered to bring certain objects which are composed of several parts, to move them about, or something else of the kind. And two ways of playing it: in one (a) the composite objects (brooms, chairs, tables etc.) have names, as in (15); in the other (b) only the parts are given names and the wholes are described by means of them. - In what sense is an order in the second game an analysed form of an order in the first? Does the former lie concealed in the latter, and is it now brought out by analysis? -

True, the broom is taken to pieces when one separates broomstick and brush; but does it follow that the order to bring the broom also consists of corresponding parts? (PI 60)

This change in the formulation of the problem of the relation between language and the world is accompanied by a change in the solution. The problem with the earlier account is not just that it was mistaken about the level at which it located the connection between language and the world, but that it maintained that a one-off baptism (single ostensive definition) was enough to explain how we manage to use a word correctly in the future. Posing the question in terms of general words makes this deficiency more visible. A general word has an infinite extension; merely correlating a word with an object by no means explains how we manage to use that word to pick out a whole range of objects which are different but which also share some features with the original object, features in virtue of which they are united under the rubric of that word. What is needed, according to the $P I$, is a sustained contribution from us, the language-users. But the $P I$ also undermines the very effort of the TLP viz. to present an account of meaning. Although the TLP indicates that an account of meaning is impossible, what it advocates de jure is not in harmony with its de facto practice. In the $T L P$ the reasons against theorising has to do with the idea that some things 'cannot be said', but only shown.

Propositions can represent the whole of reality, but they cannot represent what they must have in common with reality in order to be able to represent it - logical form.

In order to be able to represent logical form, we should have to be able to station ourselves with propositions somewhere outside logic, that is to say outside the world.

Propositions cannot represent logical form: it is mirrored in them.

What finds its reflection in language, language cannot represent.

What expresses itself in language, we cannot express by means of language. 


\section{Propositions show the logical form of reality.}

They display it. (TLP 4.12-4.121)

The reason some things cannot be said but only shown has to do with Wittgenstein's account of propositions. A proposition depicts a possibility in the world. This being the case, it can be either true or false (true if the possibility obtains, false if it does not). However, a putative proposition that attempts to say something about the possibility of sense, for example, that the meaning of a name is the object it picks out, will not have depicted a possibility and so cannot be true or false. That the meaning of a name is the object it picks out is not a possibility; it is a pre-condition of the possibility of sense. It cannot be false, and thus by the same token cannot be true. Hence you cannot 'say' (depict) that which makes sense possible, since that which makes sense possible is not a possibility in the world. Propositions can only depict possibilities. But why can language only picture possibilities $i$.e. things which could be either true or false. Why can it not picture anything about the relation between language and the world? TLP 4.12 is instructive: 'In order to be able to represent logical form, we should have to be able to station ourselves with propositions somewhere outside logic, that is to say outside the world.' In other words, there is no vantage point outside of language (outside of our relation with language and the world); there is no independent fulcrum that can be used to get a grip on our relationship with language and the world. We cannot 'get outside language:

In the Pl the criticism of any attempt to construct a theory of language is in similar spirit but different rhetoric: Any attempt to explain the meaning of a phenomenon would require invoking another phenomenon to which we do not have independent access. We cannot identify the explanation of a phenomenon independently of the phenomenon itself. For example. if we attempted to explain the meaning of a general word in terms of a universal (which is its meaning) we would not be able to give an independent specification of the universal. The Picture Theory. being a theory of this kind, fails for the same reasons: if the meaning of a name is the object for which it stands, the only way to explain its meaning would be to refer to the object. The TLP suggests that the way to identify an object is to name it (TLP 3.203). However, doing so would not provide an independent specification of the meaning of the name and would thus fail to explain its meaning. The fatal flaw in realism forces him to look in the other direction - inwards. His new verdict is: 
It was true to say that our considerations could not be scientific ones. It was not of any possible interest to us to find out empirically 'that, contrary to our preconceived ideas, it is possible to think such-and-such' - whatever that may mean. (The conception of thought as a gaseous medium.) And we may not advance any kind of theory. There must not be anything hypothetical in our considerations. We must do away with all explanation, and description alone must take its place. And this description gets its light, that is to say its purpose, from the philosophical problems. These are, of course, not empirical problems; they are solved, rather, by looking into the workings of our language, and that in such a way as to make us recognise those workings: in spite of an urge to misunderstand them. The problems are solved, not by giving new information, but by arranging what we have always known. Philosophy is a battle against the bewitchment of our intelligence by means of language. (PI 109)

We have seen that in the TLP the way to establish whether a proposition is meaningful involves logical analysis of that proposition into its constituent elementary parts. These elementary propositions are then subjected to the acid test: they have to bear the hallmark of meaningfulness i.e. their names must designate objects and the propositions must bear the form of the general form of a proposition' that says that 'this is how things stand'. But before a proposition can be analysed in this way, its real logical structure that is hidden by its apparent surface structure must be laid bare In the PI Wittgenstein still thinks that there is a gap between surface grammar and real logical form - a gap that can mislead us - but he does not think that the real logical form is something that must be excavated. The distinction in the $P I$ is not between surface grammar and underlying grammatical form. but between surface and 'deep grammar'. 'Deep grammar' is revealed by a clear view - an Übersicht - of how we actually use language. When we are misled by the particular structure of a proposition our recourse is not excavation and analysis; rather, we should 'consult' the Ubersicht the map of the actual uses of language, and see whether a particular usage subscribes to the way the said expression is actually commonly used. The distinctive feature about his later work is that he is not digging under but looking on the surface of language and the acid test is not a ready worked-out formula but a test to see whether a proposition fits on actual use.

With this as a background, we can now get down to examining his account of the meaningfulness of language in the PI. The issue can be introduced by posing the question in lay terms first: we tend to think that when someone has understood something, he is in possession of some bit of knowledge 
or information - that he now has something in (his) mind. We think that he either has a picture, or a formula. or a definition, or an image in some very general sense, in mind. The trouble with this way of looking at the matter, is that whatever he has in mind can always be interpreted in a number of different ways, so that, simply on the basis of what he has in mind, we cannot say that he definitely means one thing and not another. In technical terms, what he means is underdetermined by the alleged image he has in mind. For example, let's say that when someone understands what a cube is he has some particular image in mind. (Cf. PI 139-141)However, it can always be contested that he could have that particular inage in mind and still mean some other object in the world. To rule out this possibility, one would have to add that not only does he have some particular image in mind, but he also has a code or formula which maps the image to some specific object in the world (the $P I$ calls such a formula a 'method of projection') The trouble with this defence is immediately clear: we could raise the same kind of concern about the code or formula that we raised about the original image. What's to say that that code could not be variously interpreted or applied, and so on?

The same problem arises when we think that somebody's understanding something consists in their having a definition in mind. Definitions (like those in dictionaries) contain words that can be variously applied, and so we would need to further define those words, ad infinitum. Meaning would thus remain indeterminate, so definitions cannot give a complete account of meaning. (Cf. PI 201)A blunt way of expressing Wittgenstein's solution to this problem is to say that according to Wittgenstein understanding (or meaning) something does not essentially have anything to do with having something in your mind (although, of course sometimes we may have some image in mind). Understanding the meaning of an expression is like understanding how to dance, or how to ride a bicycle. It is not that we are in possession of some factual knowledge (definition, image, interpretation, whatever) but that we know how to dance, know how to cycle. It is not about understanding that, but understanding how. In the case of knowing the meaning of a word, it means that we know how to use that word. It cannot be that we know a definition, have an image, or have 'interpreted the word (Wittgenstein thinks of a definition as a kind of interpretation), for if it were, the problem of indeterminacy of meaning sketched above would always arise. That was crudely putting the problem and solution into a nutshell. Below I examine the issues at greater length with more explicit reference to the $P I$ text.

In the PI Wittgenstein addresses the issue of meaning by exploring what fixes the meaning of general terms, and his investigation takes the form of exploring the conditions under which we are prepared to say that an expression has been used meaningfully. In PI 207-208 he argues that the 
indication that a word has been used meaningfully has to do with whether we can find regularity between what people say (the sounds they make) and their actions. There needs to be a regular employment of signs in order for us to say that certain behaviours count as speaking a language. (PI 207. 237)

In other places in the PI (for example PI 201) the issue of what fixes the meaning of an expression is discussed in terms of 'rules' and 'following a rule'. In the discussion that follows I will examine the conception of meaning in the $P I$ in the rhetoric of 'following a rule', although it must be noted that in every case of the meaningful employment of a sign there need not be a rule, but simply a regularity in the use of the sign (as indicated in PI 207-208).

Speaking a language is a normative activity. There are correct and incorrect ways of applying words. To use a word correctly is to have followed the rule governing the correct application of that word. Wittgenstein's examination of rule following can be broken down into two concerns. The one concern is what it is in virtue of that we can say that someone has followed a rule. The question here would be: what is the rule governing the correct application of a word? The second concern is how a rule guides a speaker. The question here would be: how does the speaker know how to apply a word correctly? So the first is an ontological issue (what are the rules); the second is an epistemic issue (how do the rules guide behaviour). Wittgenstein explores rule following in terms of two different but analogous cases viz. (a) the application of a general word and (b) the continuation of a mathematical series. These two issues differ in terms of the problems they present, and in terms of what would go toward answering the problem. They are united, nevertheless by the fact that they both concern the normativeness and the hence the meaningfulness of language. As far as the application of general words goes, this is how the problem is framed: a general word such as 'red' or 'horse' has a determinate extension: it applies to certain objects and not others. These objects are different. but share certain characteristics in virtue of which they are united under that general term. The question that arises is: what determines the extension of the general term? As for the problem of the continuation of a mathematical series, the problem is as follows: a mathematical operation like ' +2 ' demands that a particular series be followed, viz. '2,4,6,8....' Following the series in this way constitutes the correct application of the rule ' +2 '. The question that arises is: in virtue of what is following the series in this way correct? In terms of rule-following, the two problems present different questions: in the case of the application of general words, the question is: what is the rule for applying the general term in one way and not another; in the case of the second problem, we already have a specified rule i.e. ' +2 ' and the question is what determines that the rule be followed 
in one way and not another. It must be noted that although I have subsumed the problem of mathematical regularity under the discussion of the possibility the meaningfulness of language, it is a topic that also properly fits Wittgenstein's discussions on mathematics and regularity in mathematics. In fact Frascolla' believes that Wittgenstein had thought of the mathematical problem first: the problem of the application of general words to things being a corollary of the former. Pears ${ }^{2}$ however thinks otherwise. According to him there is evidence that the discussions on general words precede the discussions of mathematical regularity. For the purposes of this thesis I will treat the discussions on mathematical regularity as a contribution to the general problem of linguistic normativeness and treat this and the problem of the application of general words as separate but parallel discussions on linguistic normativeness.

PI sections 185-189 deal with the mathematical problem; sections 198- 200 deal with the issue of rule following in a general way, section 201-202 deals with the problem of the application of general words to things in terms of the impotency of definitions. This is an implied reference to the Vienna Circle's obsession with analyses and definitions. However the problem of the application of general words is examined in more general terms in an earlier section PI 139-141. The problem is that of the candidate for the meaning of a general term. In PI 139 the candidate considered is a mental image, in PI 201 the candidate is a definition. In both cases, the complaint is that neither can explain the interface between language and the world. PI 201 presents the solution: nothing can scrve as the required candidate since there is no such candidate. There is no mental talisman, nor any verbal formulation that can do the job of fixing the meaning of a general term. Nothing extralinguistic guides a person when he is following a rule; rule following is ground in action. Following a rule is a matter of having been trained to apply a word in a certain way, and we obey the rule in the way one obeys an order i.e. blindly and without hesitation, as if compelled to. But nothing external compels you - the compulsion comes from within, so to speak - from having been trained to react in certain ways and then responding to the training in a certain way. The way we respond to training is our natural tendency to react in certain ways; these natural tendencies are shared by the linguistic community. We can be said to understand the meaning of a word when we have mastered the technique for the use of that word.

In general terms, the debate about linguistic normativity is generated on the one hand by our intuitive understanding of how things must be given that our linguistic practices are stable, and on the other, by the implications of the philosophical explanations of that stability. To say that our linguistic practices are meaningful is to say that we apply words correctly or incorrectly. Intuitively, 
the standard in virtue of which our application of a word is correct must be independent of how we in fact do things, failing which there will not be a distinction between what we do and what we should do. A standard of correctness can naturally tell us that we have gone wrong. If the standard is not independent of us - if it does not support the distinction between what we do and what we should do - then we will not be able to use it to say when we have gone wrong.

Philosophers have had different conceptions of the candidate for the standard of meaningfulness. Broadly, they can be divided into two camps - those who endorse a realist conception, and those who endorse a form of constructivism. According to the realist conception, the standard of meaningfulness is independent of us - of our abilities, our cognitive limitations and our practices. It is independent of what we would do and what we could do, and tells us what we should do. Constructivists, on the other hand, think of normativeness as somehow not independent of, but tied up with. what we in fact do and could do. This is not to say that constructivists do not endorse the distinction between what we do and what we should do. Rather, they think that social practice in some way generates standards of correctness, and thus that whether we have followed a rule correctly can be judged relative to such social practices. So whereas they may not endorse talk of rules existing independently of our abilities and our practices, they do maintain that there are norms according to which we can say a rule has been followed. The Wittgenstein of the $P I$ is generally read as endorsing a form of constructivism which maintains that we determine the meaning of a word by looking at how we customarily apply it. Against the idea that understanding or meaning is a matter of having something in your head (an image) or understanding something (a definition) he says:

...there is a way of grasping a rule which is not an interpretation, but which is exhibited in what we call 'obeying the rule" and "going against it" in actual cases. ( $P$ I 201)

Language is ground in action or practice, and:

... a person goes by a sign-post only in so far as there exists a regular use of sign-posts, a custom. (PI 198)

We are initiated into the customs by training. Once trained, we follow the rules almost instinctively, as if we are obeying an order. 
Following a rule is analogous to obeying an order. We are trained to do so; we react to an order in a particular way. The training has been successful if the initiated does what the linguistic community does. But what if one person reacts in one way and another in another to the order and the training? Which one is right? Suppose you came as an explorer in an unknown country with a language quite strange to you. In what circumstances would you say that the people there gave orders, understood them, obeyed them, rebelled against them, and so on? The common behaviour of mankind is the system of reference by means of which we interpret an unknown language.' ( $P / 206)$

In the PI Wittgenstein attacks different candidates for the repository of meaning. The first important thing to realise about his attack is that it is directed not just against the Tractarian account of meaning, but against any account that attempts to make meaning static. Any realist-type account of meaning compromises the plasticity of meaning: by locating the repository of meaning in some language-independent reality, the meanings of words are, in a sense, carved in stone. They cannot undergo change and do not undergo change. However, in real life the meanings of words do not remain static but change over time. The Tractarian account fails to accommodate this. According to that account of meaning, the essence of language is embodied in a pre-existing structure or grid that acts as a kind of intermediary between language and the world. It is this pre-ordained structure that confers meaning on the words and sentences in languages. The structure consists in the totality of logical possibilities, and such that once we attach names to objects, a whole language would thus have been constructed. So although we have an option at the level of attaching names to objects, What we do after that is mandatory. The logical structure governs what counts as meaningful constructions of language. In this sense, the TLP endorses a particular kind of realism viz. Platonism about meaning and understanding. The structure of language and hence the repository of meaning is set over and against and hence independently of us - independent of our cognitive abilities and our practices. On a Platonist conception of meaning the meaning of our words resides in some kind of platonic entity - a platonic form - which is neither material nor mental, but which exists in a kind of platonic realm. This platonic form is the seat of the essence of a word; it is some kind of entity that unites a number of disparate objects under its umbrella. The TLP is Platonist only in that invokes a mind-independent reality that confers meaningfulness on language, or rather, determines the correct ways of using words. In the PI Wittgenstein spends more time marshalling an attack on what could be seen as the mental counterpart of the abstract grid of possibilities - the mental image. The two are of course indissolubly linked. The mental image is one possibility of what a language-user may 
have 'in his head' when he could be said to have understood a word. It is via the mental image that we could be said to be put in touch with the fixed structure outside our minds. In the PI, by contrast Wittgenstein says more about the mental counterpart of the external grid, and focuses less on the grid itself. However, both parts of the theory are of course necessary if we are going to give the kind of explanation Wittgenstein believed was necessary. The would be no point in locating the repository of meaning in something external to and independent of us unless we had some way of grasping it. By the same token, the mental image would be pointless if it did not put us in touch with the structure outside our mind. And, the mental image can only play the role it does because it is the mental counterpart of the repository of meaning. The complaint in the PI against both the structure outside our minds as well as the mental image is the same: it is invoked as the standard of correctness of our words - but, as such, it is commissioned to play an impossible role. The impossible role is one where. once a word is attached to a thing, the mental image or external grid determines the future behaviour of that word - the word is slot onto a pre-existing grid or locked onto rails extending into the future. The role is impossible because firstly, a limited set of examples cannot unequivocally fix an indefinitely prolonged sequence of correct applications, and secondly, anything in our minds - a formula or picture - can be applied in indefinitely many ways. An image can therefore not unambiguously fix meaning. So the idea of fixed rails is a fantasy and the idea of a mental image puts an impossible demand on the language-user's mind. What is required is our sustained contribution in the form of established practices that fixes particular series of applications. This shifts the seat of authority from the external logical structure to our very own linguistic practices. "B understands the principle of the series" surely does not mean simply: the formula "an $=\ldots$... occurs to B. For it is perfectly imaginable that the formula should occur to him and that he should nevertheless not understand. "He understands must have more in it than: formula occurs to him. And equally, more than any of those more or less characteristic accompaniments or manifestations of understanding. (PI 152)lt may now be said: "The way the formula is meant determines which steps are to be taken". What is the criterion for the way the formula is meant? It is. for example, the kind of way we always use it, the way we are taught to use it. (PI 190) Customary use determines the way the formula is to be applied. But teaching an initiate how to apply the formula is not a guarantee that he will be able to apply it correctly in the future. A contribution also has to be made by the initiate in the form of his natural response to the training. 
....Now - judged by the usual criteria - the pupil has mastered the series of natural numbers. Next we teach him to write down other series of cardinal numbers and get him to the point of writing down series of the form

$0, n, 2 n, 3 n$, etc.

at an order of the form " $+n$ "; so at the order " +1 " he writes down the series of natural numbers. - Let us suppose we have done exercises and given him tests up to 1000.

Now we get the pupil to continue a series (say +2 ) beyond 1000 - and he writes 1000, 1004, 1008, 1012.

We say to him: "Look what you've done!" - He doesn't understand.

We say: "You were meant to add two: look how you began the series!"

- He answers: "Yes, isn't it right I thought that was how I was meant to do it." - Or suppose he pointed to the series and said: "But I went on in the same way." - It would now be no use to say: "But can't you see....?" - and repeat the old examples and explanations. - In such a case we might say, perhaps: It comes natural to this person to understand our order with our explanations as we should understand the order: "Add 2 up to 1000, 4 up to 2000, 6 up to 3000 and so on."

Such a case would present similarities with one in which a person naturally reacted to the gesture of pointing with the hand by looking in the direction of the line from finger-tip to wrist, not from wrist to finger-tip.' (PI 185)

When someone learns to speak a language, several ingredients are present: there is an established (regular) way of using words or expressions, the language-user is initiated into the practice of speaking a language by training, the training takes hold because of the natural responses of the initiate. responses which are shared by other members of the linguistic community. The initiate has been successfully trained when he applies words in the way the community does, and follows the rule in the way one obeys an order, automatically or instinctively.

It must be noted that in Wittgenstein's discussions of the pupils who make outlandish mistakes when taught the meanings of general words by examples of their correct application, he is not meaning to say that these are probable mistakes that a teacher should be aware of in real life. The point rather is that they are possible mistakes, a possibility discussed because it is instructive in 
coming to understand what the whole issue of what holds together the things to which a general word applies and distinguishes them from other things. In Wittgenstein's own view the student's misapplication of rules does not indicate or constitute a real-life problem: in real life, if the lesson has been well-designed with appropriately chosen examples, there is only one way in which he understands them - the natural way - and where there are minor variations, they can be easily cxcluded by further examples. In Lectures on the Foundations of Mathematics he makes a similar point about the way in which children are taught the sequence of cardinal numbers:

This hangs together with the question, how to continue the series of cardinal numbers. Is there a criterion for the continuation - for a right and wrong way - except that we do in fact continue them in that way, apart from a few cranks that can be neglected? ${ }^{3}$

He goes on to explain the confidence with which we ignore the cranks:

This has often been said before. And it has often been put in the form of an assertion that the truths of logic are determined by a consensus of opinions. Is this what I am saying? No. There is no opinion at all: it is not a question of opinion. They are determined by a consensus of action: a consensus of doing the same thing, reacting in the same way. ${ }^{4}$

It must be noted that although in this paragraph he is making the point about the 'truths' of logic, from the context we can see that he is extrapolating this point from the discussion on the meanings of individual words. We don't take the cranks seriously not because we are of the opinion that they are wrong, but because of the consensus of action on our part about the right way to go on. There is no decision involved in what counts as the right thing. There just is this consensus of action that is a brute fact about us. We all, given the same training, happen to go on in the same way. Our language has the stability it does not because we decide, from a range of possible ways of going on, to respond in some particular way, nor because there is some extra-linguistic entity (a formula, image or platonic universal) that guides us, but because of the brute fact about us that there is a consensus of action. The idea of 'consensus' of action could be a bit misleading. It gives the impression that 'consensus' means an explicit agreement of some form - coming to hold the same view after some deliberation or decision of sorts. This is a misunderstanding of Wittgenstein's point: his emphasis 
that the consensus he is talking about is not a question of opinion is to drive home the point that these reactions are automatic or instinctive, so to speak. They are the reactions that we find natural. The point however, is not just that there is a consensus of action, but that there is a consensus of action. It is what we do that fixes the standard of correctness. As PI 201 emphasises

What this shews is that there is a way of grasping a rule which is not an interpretation, but which is exhibited in what we call "obeying the rule" and "going against it" in actual cases.' Acting meaningfully, or understanding a sign does not have anything to do with having 'something in mind', but rather with acting in a certain way - a way that can be described as 'obeying the rule'.

So whereas in the TLP language is based on our recognising or knowing the possibilities of combination of simple objects, in the $P I$ the conception is that what lies at the bottom of the ability to use language is 'our acting'. In On Certainty. Wittgenstein says:

Giving grounds, justifying the evidence, comes to an end; - but the end is not certain propositions striking us immediately as true, a kind of seeing on our part; but it is our acting that lies at the bottom of the language-game. ${ }^{5}$

Wittgenstein's complaint against platonism is not just limited to linguistic issues - he saw platonist tendencies at work both in philosophy and in ordinary thinking. We have seen what's wrong with platonism: it solicits, on the one hand, a recondite entity to play an impossible role, and on the other hand. something familiar, mental item (the mental counterpart of the external grid), to play an equally impossible role. The most crippling defect however, is the one discussed in chapter one: platonism attempts to explain our linguistic practices by appealing to putative independently existing items which, on examination, cannot be identified independently of the way we happen to use language. What then leads us to this theory? What underlies our platonist convictions, Wittgenstein believes, is an illusion generated by the experience of following a rule. At PI 219 he says:

"All the steps are already taken" means: I no longer have any choice. The rule, once stamped with a particular meaning, traces the lines along which it is to be followed through the whole of logical space. But if something of this sort really were the case, how would it help? 
No: my description only made sense if it were to be understood symbolically. - I should have said: This is how it strikes me.

When I obey a rule, I do not choose.

I obey the rule blindly.

The observation about following a rule blindly is an observation about the phenomenology of rule following. When we follow a rule, we follow it in a way that can be described as having followed it blindly, or following it as if we are compelled to follow it in that way, as if we had no choice. The feeling that we are on a pre-ordained path is a projection of the feeling of inevitability when we apply a word. This experience gives the impression that there is some external force that locks us on a certain path where 'all the steps are already taken'. From this experience we conjure up the idea that the rule conducts you like a gangway with rigid walls. This, however, is only a dramatisation of the experience of following rules and must be understood symbolically rather than literally. We thus have a philosophically distorted perspective of expressions such as

'the steps are determined by the formula'

the way the formula is meant determines which steps may be taken...'

This distorted philosophical picture asks us to imagine either some item that magically throws open to view the red carpet of correct applications or some item that contains, in some sense, all the possible applications of a word. These fixed rails are really a fantasy - an attempt to forge a factual picture out of some kind of poetry. The charm of this picture derives from the fact that it seems to adequately capture what must be the case given our experience. But charm is all it has - when its implications are played out, we see that what it imagines - a self-signifying item - is impossible, puts an impossible demand on the language-user's mind, and can in no way guide us: any finite series of examples can always be taken in an infinite number of ways. To reiterate, Wittgenstein's tactic is as follows: he presents us with what seems to be a problem (no course of action can be determined by a rule). But this problem derives from a distorted picture generated by a misguided attempt to make philosophical sense of the experience of following a rule. Given this, what is required is then not to answer the impostor question, but to expose the soil that gave rise to the (question (a dramatisation of an experience). Once the breeding ground is exposed for what it is (an illusion) we don't need to answer the putative question any more, for there is no question of that sort. The compulsion that we experience when we follow a rule does not come from outside, but from within from our own natures. The regularity in our language is maintained by the fact that, in response to training, we act in a certain way. This acting is natural and common to language users 
(PI 206). The misguided scenario is one where we are kept on the pre-ordained tracks in some mysterious way - as if we are locked onto it, or as if we are in some gangway that forces us down a particular path, but Wittgenstein disturbs the peace of the situation by highlighting that we are in fact not safe on these tracks - deviation is a very real possibility. But we do not deviate, so the question becomes - what keeps us on the tracks - if it is not the tracks themselves? Our shared natural responses honed by the trained we have received, keep us on track. But this being the case, talk of a 'track' becomes superfluous. It is then our shared natural responses that play a role in the next step we take and not some imagined pre-ordained pathway.

Jettisoning the idea that there is a fixed pre-ordained structure that determines all the correct applications gives the impression that we can make things up as we go along - that we can take the Humpty-Dumpty attitude: 'this is my word and I can do what I like with it'. In other words, if there is nothing independent that governs the meanings of our words, then it seems that we can do as we please - there is no overarching arbitrator that binds us to behave in certain ways. We seem to be in a position of someone who is told to 'do the right' thing' but then not given any guidance as to what counts as the right thing. However, this imagined situation is the result of having a particular idea of what 'guidance' should consist in. We expect the guidance to come from outside - from something independent of us - and when this idea is undermined, we think we are left in the lurch.

But we are not left in the lurch because any guidance post only guides in so far as there is some way of applying it. '. .. any interpretation still hangs in the air along with what it interprets, and cannot give it any support. Interpretations by themselves do not determine meaning.' (PI 198) No definition, no explanation, no series of examples can take us from language to the world. They can always be applied in more than one way. As a repository of meaning they are impotent. The lifegiving force is the application we make of them.

In all language there is a bridge between a sign and its application. No one can make this for us; we have to bridge the gap ourselves. No explanation ever saves the jump, because any further explanation will itself need a jump. ${ }^{6}$

In PI 198-202 Wittgenstein criticises any theory of meaning that only offers verbal analyses of particular words since definitions do not tie language down to the world. This is an implied criticism of the program of the Vienna Circle, as well as the propositions of the TLP that inspired it. 
3.26 A name cannot be dissected any further by means of a definition: it is a primitive sign.

3.261 Every sign that has a definition signifies via the signs that serve to define it; and the definitions point the way.

However, whereas the Vienna Circle was solely pre-occupied with definitions, the TLP recognised that definitions can ultimately not explain the interface between language and the world and that the meaning of a name or proposition is shown in its application: "What signs fail to express, their application shows.' TLP 3.262. Since what is shown cannot be said, the TLP concludes that the relationship between language and the world is ineffable. However, while it may be correct to say that the link between a sign and the world is shown in its application, it does not follow that this relationship is ineffable. In other words, simply because there is no theoretical construct that can adequately explain the relationship between language and the world, and because that link is something we make when we apply the word, it does not follow that we can give no general account of the application of words to things. What we can in fact do is describe what happens at the interface between language and the world. The description would factually explain what is involved in this application and how regularity is preserved in application. This is what Wittgenstein does in the $P I$.

Nothing can bridge the gap between language and the world - 'we have to bridge the gap ourselves'. Does this give us free rein? The mere fact that communication is possible shows that we do use words in a regular way. We now know that this regularity does not and cannot come from some other entity that lays down a fixed pathway for us to follow. We now know that we make the application. Something about us must then govern this application. And this 'something' is our shared natural responses. But, does this appeal to shared natural responses upkeep the distinction between what we do and what we should do? Does recourse to shared natural responses imply that we have to wait and see what we would do in some considered case before we can say what we should do? Wittgenstein's answer comes via two notions -- that of a technique and that of customs or institutions. The short answer is that our shared natural responses are governed by a technique that we are taught. Learning the meaning of a word involves learning the technique of applying it; understanding a word is to be master of that technique. Obeying a rule (using a word correctly) is a custom. So our behaviour is hedged in by the established custom. The custom develops in the confines of our natural responses and our natural environment and it is then our natural responses 
that are ultimately responsible for the boundaries of our behaviour. So the ingredients of his new approach are as follows. There is a technique of application. This technique is customary (it is an established use, and not an extra-human mandatory regulation), but it is shaped by our shared natural responses and the parameters of our natural environment.

In LFM, Lecture X, Wittgenstein says:

Suppose we in this room are inventing arithmetic. We have a technique of counting, but there is so far no multiplication. Suppose that I now make the following experiment. I give Lewy a multiplication. - We have invented multiplication up to 100; that is, we've written down things like $81 \times 63$ but have never yet written down things like $123 \times 489$. I say to him, "You know what you've done so far. Now do the same sort of things for these two numbers." - I assume he does what we usually do. This is an experiment - and one which we may later adopt as a calculation. What does that mean? Well, suppose that $90 \%$ do it all one way. I say "This is now going to be the right result" The experiment was to show what the most natural way is - which way most of them go. Now everybody is taught to do it - and now there is a right and a wrong. Before there was not.

It is like finding the best place to build a road across the moors. We may first send people across, and see which is the most natural way for them to go, and then build the road that way. Before the calculation was invented or the technique fixed, there was no right or wrong result. (LFM, X, p95).

The point here is that the way in which human beings find it natural to proceed becomes the standard of correctness. Wittgenstein's criterion for "the natural way to proceed" is the way in which "most of them go". It is a brute fact about human beings that, given a certain background, setting and training. most of them will, naturally proceed in a certain way. In PI 242 Wittgenstein calls this natural convergence of behaviour "agreement in judgement". This "agreement in judgement" is the foundation upon which the development of language is possible. For a language to be possible there has to be a regular or consistent employment of symbols - else there would be no sense in saying that a word means something (one thing rather than another). This regular or consistent employment is secured by the fact that we all have a natural inclination to, given the same background, follow the same path. 
If language is to be a means of communication there must be agreement not only in definitions but also (queer as this may sound) in judgements. This seems to abolish logic, but does not do so. - It is one thing to describe methods of measurement, and another to obtain and state results of measurement. But what we call "measuring" is partly determined by a certain constancy in results of measurement.

The particular way in which we proceed becomes established as a custom or practice and becomes the standard of correctness against which we judge whether future applications are correct or incorrect. Individuals that partake in this custom or have mastered the custom can be said to possess the technique for doing $\mathrm{X}$. Two individuals can be said to be partaking in the same technique simply because they belong to the same community, have the same inherited background, have been trained in the same way, and share the same natural human responses. This is what guarantees sameness.

A particular application is judged correct or incorrect not by a standard independent of the technique or practice. Realism demanded that the standard of correctness be independent of what we would do or be inclined to do. This demand, as we have seen earlier, led to a dead end. It turned out that the criterion (the universal) which was supposed to be independent of our practices could not be identified independently of our practices, and so did not offer a genuine explanation of our practices. In the case of the appeal to a technique an application is judged correct or incorrect if it accords with the practice (which is the manifestation of the technique). There is no further independently available criterion.

In LFM 201 Wittgenstein says:

You might ask: what are we convinced of when we are convinced of the truth of a logical proposition? How do we become convinced of, say, the law of contradiction? We first learn a certain technique of using words. Then the most natural continuation for us is to eliminate certain sentences which we don't use - like contradiction. This hangs together with certain other techniques. "Recognising the law of contradiction" would come to: acting in a certain way which we call "rational".

Here there is an explicit mention of the term "technique". Using words - using language - is a technique and this technique hangs together with - feeds into - is interwoven with - other 
techniques. Here too Wittgenstein emphasises that what human beings take to be law-like is what human beings find natural. Although Wittgenstein does not explicitly state it here, this as an implicit argument against the idea that our logical rules derive their validity from something independent of us. The notion of the platonic universal which, in the realist's account, played the role of justifying the extension of a word, or justifying our logical rules, has been replaced in Wittgenstein's later work with the interwoven concepts of 'technique', 'what we find natural', 'custom and human agreement in judgement'.

McGinn criticises Wittgenstein's notion of a custom accusing Wittgenstein of overcooking an idea which plays no significant role in the later account of language ${ }^{7}$. McGinn claims that if human bcings have a capacity to do something, there seems no reason that the point has to be made that the capacity has to be played out several times and by several people (i.e. McGinn takes issue with PI 199: "It is not possible that there should have been only one occasion on which only one person obeyed a rule...."). What McGinn fails to appreciate is that a technique can only become a standard of correctness when it is executed several times and when the members of that community agree on that application. It is this agreement that establishes the custom and it is this custom that we look to in order to establish whether an application counts as correct. One may complain that Wittgenstein's account of technique is somewhat vague, since it cannot be given a complete verbal formulation. However, a technique is, in a manner of speaking, a moving target: a specific technique can never be fully articulated in terms of a formula or inventory because the past and present applications always under-determine the future applications. Furthermore, it is in the nature of a technique that the possessor cannot or may not be able to say what it consists in, but can nevertheless have a know-how of it.

We now need to know whether appeal to technique is an appeal to investigation-independent criteria and thus upholds the distinction between what we do and what we should do. A technique is of course not an inventory containing all the correct applications - it cannot be since the possible applications of a word are infinite. A technique can also not be completely specified in words. Because future applications are different to past applications, the way a word was applied in the past does not set the blue-print for how it should be applied in the future. But past applications inform the technique, and influences the way the word will be applied in the future. However, does this mean that we have to have to wait and see how we apply a word in order to say what the correct application of that word should be? In one sense we do have to wait and see, but what we are waiting to see is not some arbitrary application on our part; rather we are waiting to see how the technique will play itself out - a technique which will, independently of what we in fact do, allow 
certain moves and not others. Pears ${ }^{8}$ uses the notion of 'fit' to articulate how the technique works. The general idea is that how a general word is applied to a thing on one occasion contributes to the meaning of the word and plays a role in determining the way it is used on the next occasion - so the past feeds into or influences the present and future. The bearer of a technique thus does not have free rein in future applications, but is constrained by the how the technique was developed in the past. Pears' had suggested (in conversation) that the notion of 'fit' works like a zip-fastener: the fastening or closing of any particular link depends on the closing of the previous links and this is turn contributes to setting the scene for closing the next link. He later revised this. In the case of a zip-fastener, all that happens is simply that the closing of each link creates a situation that makes it possible for the next link to be closed. In Pears $2004^{9}$ he suggests that the past influences the way in which the technique will be employed in the future, though never completely determines it. This is part of the reason a technique cannot be specified in words: it is a way of doing things which although we may be able to give particular examples or manifestations of it, because it is able to generate an infinite a series of applications different to the past but nevertheless not arbitrary, it defies complete specification. It is a moving target. It is precisely this 'moving target' feature of the technique that separates it from all other accounts that attempt to put meaning on a static basis. Because the repository of meaning is not once and for all specifiable, because it does not reside in, or is constituted by some static item, real innovation or mutation is possible. Only appeal to technique can explain this plasticity of language. The meanings of words change over time, and any account which locates meaning in some static repository will not be able to accommodate this. Being in possession of a technique puts the speaker in possession of something which allows for mutations, but does not give completely free rein in future applications. The technique governs future applications although it is not completely specifiable.

\footnotetext{
Frascolla. P.. Wittgenstein s Philosoph of Mathematics, 1994.

- Pars. D.F., Paradox and Platitude in Wittgenstein's Philosophy (unpublished).

"Witgenstein's Lectures on the Foundations of Mathematics: Cambridge 1939. C Diamond, 1976, p. 183.

ibid.. p. 184.

On Certaints, G.E.M. Anscombe and G.H. von Wright (eds), D Paul, and G.E.M. (trans.), 1969, 204.

" Wittgenstein's Lectures. Cambridge 1930-1932.

Wright C.. Critical Notice of Coin Mc Ginn's Witgenstin on Meaning, in Rule-following and meaning, Miller A. and Wright C. (eds.). 2002.

"Pears. D.F., Paradox and Platitude in Wittgenstein's Philosophly, (unpublished)

"ihid.
} 


\section{Chapter 4: Private Language}

In the PI, unlike in the TLP, Wittgenstein does not offer a theory of meaning; what he does offer are remarks - some descriptive, others logical and yet again others critical - which together can be taken as his later conception of language. His views on language come out most strongly in the rule-following considerations discussed above and the battery of arguments that immediately follow it viz. the celebrated private language argument. The private language argument can be seen as a way of making the point already made in the rule-following considerations, but from another angle: in the rulefollowing considerations the notion of an established practice for the possibility of language is introduced as the repository of meaning. The argument takes the form of undermining any verbal formulation of a rule since the words used in such a formulation stand open to various interpretations and can thus not unambiguously fix a course of action. It cannot explain the interface between language and the world. In the private language argument the role of established practices is brought out by examining a scenario where they would be absent. The scenario is that of a putative private linguist trving to set up and follow his own linguistic rules to record his immediate private sensations phenomena which he alone has access to - without buying into and using the resources of a public language. The putative private linguist tries to set up a language without recourse to the established linguistic practices of the linguistic community and also without recourse to the physical world which plays a role in producing the sensations he has. The argument attempts to show that such a language would not only be unshared in practice, but unsharable and hence unteachable in principle. In fact the argument attempts to show that such a 'language' is not a language at all; nothing that the putative private linguist does or could do could count as speaking a language. Such a 'language' would be unintelligible to everyone else including the putative private linguist. The idea then is that in the absence of the linguistic community and the physical world, a language cannot get off the ground, and that any account of language that tacitly assumes a position, or pre-suppositions the kind of which on closer examination would amount to a private language (a radically unsharable language), would then be wrong.

Before I go proceed I need to qualify my introduction of the private language argument. I am not suggesting that Wittgenstein intended to demonstrate the significance of social institutions by means of the private language argument, although some philosophers have suggested that this is part of his motive (see Stroud'); what I am suggesting is that in the private language argument Wittgenstein 
subtracts the resource of established linguistic practices and the physical world which plays a role in producing these responses and in so doing corroborates the significance of the linguistic community. What is unanimously agreed upon is that the immediate target of the private language argument is both Carnap's idea of a private phenomenological language, as well as Wittgenstein's own view during his verificationist phase, both of which endorsed the idea of a language that refers to private inner sensations. The wider target is the Cartesian assumptions that underlie many philosophers' thoughts about language. What is not entirely clear is the role Wittgenstein intends us to understand the linguistic community plays. The question thus is: does the importance of the linguistic community derive from the fact that it plays a particular kind of role - a role which some other item could also play - or is the point that the linguistic community as such is indispensable - nothing else could play its role:? This question stands at the intersection of a number of important inter-related considerations. One is that it has bearing on the private-language-solitary-language debate; another is that it will help us understand more clearly the logical status of established practices or customs in his discussion.

The broad target of the private language argument is the mainstream of modern philosophy from Descartes through classical British empiricism and Kantianism to contemporary cognitive representationalism - the common denominator being the tacit presupposition of the possibility of a private language. This presupposition is built on two natural assumptions. The first is that the meanings of words are determined by what they stand for - this is part of the Augustinian picture of language. The second assumption is that, in the case of psychological terms, what they stand for are phenomena that are only accessible to the individual. So for example, the word pain refers to an epistemically private experience and it follows not only that no one can know what I have when I am in pain but also that. because of this, no one else can know what I mean by 'pain'. So, if both the contents for all our words and the evidence for our beliefs are provided by ideas, impressions, intuitions, sense-data, then the whole of our language is private in this sense. It is this picture of language and language-learning that lies at the bottom of. and unites the conception of representationalists, idealists, rationalists, empiricists and Kantians. Russell's conviction that the meanings of our words must be sense-data led him to be the first to accept the conclusion of Locke's inverted spectrum: given that meanings are private experiences, what one person means by 'red' may be what another means by 'green'. He was so strongly convinced of this that he regarded it as a precondition of intersubjective understanding that two people cannot mean the same thing by their words. The TLP also bought into this idea, although the 'objects' which are the meanings of 'simple names' are not sense-data but objects of acquaintance - 
shades of colours, points in the visual field. During Wittgenstein's verificationist phase he endorsed, together with Carnap and Schlick, the idea of a primary phenomenological language which refers to immediate experiences. We see this in Philosophical Remarks where he says:

We could adopt the following way of representing matters: if I, L.W., have a toothache, then that is expressed by means of the proposition 'There is toothache'. But if that is so, what we now express by the proposition 'A has toothache', is put as follows: 'A is behaving as L.W. does when there is toothache'......It's evident that this way of speaking is equivalent to ours when it comes to questions of intelligibility and freedom from ambiguity. But it's equally clear that this language could have anyone at all as its centre.

Now among all the languages with different people as their centres, each of which I can understand, the one with me as its centre has a privileged status. This language is particularly adequate..... - The privileged status lies in its application....2

Between 1932 and 1935 he rejected the idea of a phenomenological language and then attacked idealism and solipsism. The notion of a private language first appears in the lectures of 1935-6. The final condensed version is in PI 243-315, sections 270-272 being particularly scathing of the consequences of endorsing the idea of a language which refers to private immediate experiences.

In PI 243-55 Wittgenstein introduces the idea of private language and shows that our psychological vocabulary is not private in this sense, in sections $256-71$ he argues that the very notion is incoherent. This is followed by sections 272-315 where he argues that the preceding considerations do not amount to saying that the mental is unreal. In $P I 258$, he invites us to imagine a case where someone (a putative private linguist) wants to keep a diary about the recurrence of a certain sensation. To this end the private linguist associates the sensation with the sign " $\mathrm{S}$ " and writes the sign in a calendar for every day on which he has the sensation. He makes this association by concentrating his attention on it and saying "S" to himself - a kind of 'inward' ostensive definition. Thus baptised, the private linguist can record a recurrence of the sensation. Wittgenstein denies that this amounts to a meaningful employment of "S". The putative private linguist claims in our public language that he is using a sign " $\mathrm{S}$ " as part of a language. that is, according to rules, albeit rules only he understands (PI 261. 270). But it transpires that he cannot explain how this is done without connecting " $\mathrm{S}$ " to communicable rules of a public 
language. So, if we are to grant the putative private linguist any success at his attempt, it would show that he was not doing - in fact - could not do, what he intended to. He is only successful when he deploys the resources of both the material world and the linguistic community. Following the text, the first restriction Wittgenstein says the private linguist faces is that his definition of the sign cannot be formulated in a public language, since a private language cannot be understood by anyone but the putative private linguist. Furthermore, the sign in the private language cannot be said to refer to a sensation or even to something, for 'sensation' and 'something' are words belonging to a public language. (PI 261). The only way, it seems, for the private linguist to endow his sign with meaning is to define it extensively, by 'concentrating his attention' on the inner experience and, 'as it were, pointing to it inwardly', thereby 'impressing on himself' the connexion between the sign and the experience. To this suggestion Wittgenstein retorts:

\section{But, "I impress it on myself" can only mean: this process brings it about that I remember the connexion right in the future. But in the present case I have no criterion of correctness. One would like to say: whatever is going to seem right to me is right. And that only means that here we can't talk about "right". (PI 258)}

And of course, if we cannot talk about "right" i.e. if we cannot talk about a word being applied correctly or incorrectly. then we cannot talk about a word having any meaning. The point is that we cannot talk about "right" unless we have a criterion of correctness. And this is precisely what the private linguist lacks. Verheggen ${ }^{+}$, in her article Wittgenstein and Solitary Languages, following Barry Stroud . cautions against reading Wittgenstein's reasons for claiming that the private linguist has no criterion of correctness as being verificationist inspired. She examines the way Pears ${ }^{6}$ presents the matter. Pears, according to her being representative of holding such a view. According to her, Pears claims that a private linguist has no criterion of correctness because the private linguist could never be in a position to tell whether the applications of his signs are correct or not. And it is for this reason that a private language is not possible. Pears writes: 'someone who cannot discover what he is in fact doing will not be able to maintain any proficiency at doing it, and will never be in a position to learn to do it, or even to try to do it." ${ }^{-7}$ And again: 'We cannot even try to acquire a skill without a usable criterion of successful performance. ${ }^{8}$ The problem with such an interpretation, according to Verheggen, is that it makes it seem as if the dilemma for the private linguist is that he has no way available to him (no way 
independent of how things seem to him) to verify the truth of his subsequent reports. But the real trouble. she argues, is not that the private linguist is in this aproductive position, but that there is nothing in which a correct application consists in. So it seems as if she thinks that Pears thinks that the private linguist faces an epistemic difficulty: bereft of recourse to the public domain the private linguist has no way of telling whether an experience is 'the same as' one that went before (one that he has identified and ostensively baptised).

Stroud. although he does not mention Pears in his article, complains that this way of taking the matter (the view Verheggen ascribes to Pears) amounts to a kind of verificationism: a state of affairs is intelligible only if it is ascertainable by means of a particular test or criterion on each occasion that it does obtain or that it does not. Now although Stroud does not explicitly attribute this view to Pears, he echoes Verheggen's charge of Pears and probably is the inspiration behind her charge - Verheggen being a student of Stroud's. The verificationist charge applied to their reading of Pears would be that, according to Pears, because the private linguist cannot verify his sensations (cannot supply a truthvalue for his descriptions), we can say that there is no criterion of correctness. In the words of Verheggen "Wittgenstein's conclusions, in PI 258, that the would-be private speaker has no criterion of correctness is in fact misleading." She adds as a footnote that it has misled numerous commentators, though not all - Stroud being one of those not so mislead. And she goes on: "For it is not just that she has no criterion of correctness to assess the application of her private sign, but that there is no criterion of correctness to which her application can be subject." ${ }^{10}$ So, it is not just that the putative private speaker has no way of telling whether he has applied his sign correctly or incorrectly, but that there is no such thing as applying his sign correctly or incorrectly. There is no such thing as applying his sign correctly or incorrectly just because no standard has been set up in the naming ceremony the private linguist attempted to undertake. No connection between sign and experience has been made, where a comnexion is understood as something that puts you in a position to use the sign correctly in the future. To corroborate her view on the source of the problem for the private linguist she then reproduces the PI arguments against the workability of ostensive definitions, ending by stressing the importance of established linguistic practices.

It appears that Verheggen and Stroud have both misunderstood Pears. Firstly, it does not appear that Pears is advocating any verificationist-inspired reason for the failure of the private linguist to set up his private language. Secondly, what Verheggen sees as part of the reason why the private linguist has no 
criterion vi:. that no criterion has been set up by the bogus naming-ceremony, is something Pears never disputes. According to Pears, the naming ceremony has achieved nothing - it is empty. No standard or model of correctness has been established. Furthermore, in the specific case of the private linguist, if he can never discover whether he is right or wrong, then this just means that he has not set up a criterion. It does not help to say that there may well be one, for in the private linguist's amputated world the only criterion can be one that he would have set up. If the domain of our examination were the material world with our public language. then one could draw a distinction between someone's not being able to know something, and there being a fact of the matter. However, in the private language scenario, if he could not know something, then it follows that there is nothing (no fact of the matter), since the private linguist's world is cut off from anything that could serve as 'the fact of the matter'. Pears' reading fits nicely with the text: he can't talk about 'right' because he has no criterion of correctness (PI 258). In other words, he cannot say whether his application of the sign is correct - whether his applying the sign to a future occurrence is a reoccurrence of the original occurrence - since he has not even determined what would count as an instance of "S". He has not set up a criterion. So, if he cannot tell whether his application is correct. it just means that he has not set up a criterion - and given that he takes his world as complete, then, if he has not set up a criterion, there is no criterion (in his world). And we cannot say that there is a criterion in the material world, since he has cut himself off from the material world. The indispensable role of an independent criterion of correctness which happens to be the external world is stressed in Philosophical Grammar :

... Time and again the attempt is made to use language to limit the world and set it in relief - but it can't be done. The self-evidence of the world expresses itself in the very fact that language can and does only refer to it.

For since language only derives the way in which it means from its meaning, from the world, no language is conceivable which does not represent the world. ${ }^{11}$

And again, in Philosophical Occasions he discusses the futility of privately setting up a criterion for the use of the word red (a discussion parallel to the one about privately setting up criteria for the use of the sign ' $S$ ' to name the sensation 'pain' which the putative private linguist allegedly experiences in $P I$ $2581:$

How does he know that he sees red/has the visual imp[ression]/ i.e. how does he 
connect the word 'red' with 'a particular colour'? In fact what does the expression 'a particular colour' here mean? What is the criterion for his connecting it/ the word/ always to the same colour/ experience/ ? Is it not often just that he calls it red?

In fact, if he is to play a lang[uage] game, the possibility of this will depend upon his own and other people's reactions. The game depends upon the agreement of these reactions; i.e. they must describe the same things as 'red'.

"But if he speaks to himself, surely this is different. For then he needn't consult other people's reactions and he just gives the name 'red' now to the same colour to which he gave it on a previous [288] occasion." But how does he know that it is the same colour? Does he also recognise the sameness of colour as what he used to call sameness of colour, and so on ad inf[initum]? It is quite true he/ connects/ uses, in agreement with or[d]ina[r]y use, the word "red"/ and the same colour/ and that he would not say that he saw now the colour he had seen before, that that colour is red but that what he sees now is not red etc.

It is quite true he connects the word and the exp[erience].

But 1 could use language just for making entries in my diary and without ever having learned it. I could have invented a name for the particular colour sensation, say, the name "red" and then used this name to note down whenever I had that colour sensation. That means, you (would) play a private language game with yourself. But let's see, how are we to describe this game? - Christening. The words " 'seeing red' means a part[icular] experience" are senseless unless we can follow them up by namely this $\rightarrow$ (pointing) or else they may say experience as opposed to phy[sical] obj[ect], but then this is grammar. ${ }^{12}$

The point is clear: there is no way a language can be set up unless the standards of correctness are independent of the potential language-user. These standards must come from the world - the world being the source of the meanings of our words. Clearly this is not a verificationist position, but an emphasis on independent criteria of correctness. There is no inner world cut off from the external world and our practices. Speaking a language is an accomplishment driven by an intention to accomplish something i.e. it is not like sneezing, which is an automatic response. And, like with all events that are accomplishments driven by an intention, two fundamental criteria must be secured (i) the person must 
know what it is that he has to achieve, and (ii) he must be able to measure, or verify, whether his attempts have been successful, i.e. whether he has hit the target so to speak. For example, if someone is running a race with the intention of completing the distance before the other participants, he has to know (a) what would count as having succeeded - in this case, reaching the finish line, and reaching it before anyone else does, and (b) how he is performing vis-à-vis the other participants, and how far he is from the finishing line. If he is running a race against others, and he has no clue how he is performing, and never will. or never could know, then there is no way that we could ever say (or he could ever say) that he has accomplished anything. In fact, under these conditions he cannot even set out to accomplish any thing. (Cf. 'Imagine someone saying: "But I know how tall I am!" and laying his hand on top of his head to prove it.' (PI 279)). He does not have any idea of what he is supposed to achieve, and $a$ forfiori. no idea of whether he is successful at his attempt. With respect to the private linguist, his task is to master a technique (apply a word in a regular fashion), but he lacks the resources for intentional accomplishment.

What I want to do now is examine why the private linguist has not managed to set up a criterion. This question introduces the issue raised earlier about the role Wittgenstein means us to understand the practices of the linguistic community play. The question to be addressed is: do the established linguistic practices fulfil an indispensable logical role, or is appeal to the practices themselves indispensable? Another way of addressing the question is to ask whether a solitary, as opposed to a private language is possible. Whereas a private language is one in which the would-be speaker attempts to record experiences which he alone has access to, and to rely solely on the occurrence of these experiences cut off lrom their physical causes or behavioural consequences, a solitary language would be one which a would-be speaker attempts to record events in the physical world, but has never had access to any human communication and hence is not a member of a linguistic community. The difference between the two situations would be that whereas the private linguist only has his immediate experiences to go by. the solitary linguist has access to standard physical objects that endure over time. What this amounts to is that whereas the private linguist's resources are only accessible to him, and a recurrence can only be checked by his recalling a memory of a former occurrence, the solitary linguist's resources are publicly available and durable: although there is no one around him to correct him should he make a mistake, he could in principle be corrected because physical objects are public objects. Furthermore, he does not have to rely on a memory to evaluate a potential recurrence - physical objects are durable and hence independently available. 
If we think that a solitary language is possible it means that we regard the role that the linguistic community plays as indispensable. It is a role that can be fulfilled by something else - presumably physical objects. If we think that a solitary language is not possible, then we think that appeal to the linguistic community itself is indispensable - bereft of which a putative speaker cannot be said to be speaking a language. Now the PI does not concede to or refute such a position; however, according to Pears ${ }^{1+}$ nothing in Wittgenstein's discussions rules out the possibility of a solitary language. In other words, nothing in Wittgenstein's work indicates that it is the appeal to the linguistic community rather than its role. which is the indispensable factor. Anyone contesting this reading would have to show either that the $P I$ does rule out such a reading, or that such a reading is inconsistent with the general tenor of the PI, or that a solitary language is not possible on logical grounds.

We go back to the question of why the private linguist has not managed to set up a criterion. The private linguist maintains that one can give a meaning to " $S$ " independently of any public language, by means of a private ostensive definition. He has a sensation and baptises it by concentrating his attention on it and saying "S" to himself. Subsequently he keeps a diary in which he records an " $S$ " every time he has the same sensation. Wittgenstein denies that this amounts to a meaningful employment of "S". No criterion of correctness has been established. 'I impress (the sensation) on myself "can only mean: this process brings it about that I remember the connection right in the future. But in the present case I have no criterion of correctness." (P/258) And therefore he can only go by what seems right. This remark has been interpreted as resting on scepticism about memory: I cannot be certain that I use "S" only when I have "S", because my memory is fallible. However, understanding the above passage this way invites the retort that the fallibility of memory is just as much a problem in the case of a public language. The argument is therefore either unsound or undermines the possibility of language in general. However, fallibility in public language need not be a problem if mistakes can be corrected - a resource which is not available in the private language scenario.

While checkability is an important ingredient in the possibility of language, what is at issue is not the truth of the utterance "There is S again" but its meaningfulness. The point is therefore not about the reliability of memory, but about whether there is anything to remember - whether a criterion has been set up in the first place. 
There is no question of my memory's playing me a trick - because (in such cases) there can be no criterion for its playing me a trick. ${ }^{15}$

since the original ceremony failed to establish a rule for the use of " $\mathrm{S}$ ". This position rests on Wittgenstein's further argument that there cannot be a private ostensive definition, since there are no mental analogues to the essential features of public ostensive definitions. Public ostensive definitions work only because the thing to be named has already been individuated, in a manner of speaking. In other words. the person for whom the ostensive definition is intended already has to understand the logical category of the thing that is being named, or, put more generally, the logical category of the definiendum needs to have been determined. Its overall role in the language-game must already be clear. By the time the person learns the name of a thing, he should already have had the concept, so to speak. By simply uttering a word in the presence of some object does not tell the person what features 10 attend to and hence what features must be looked out for when using the word subsequently. The person has to have the concept before an ostensive definition can be of any use; the ostensive definition cannot create a concept. In Philosophical Occasions Wittgenstein is emphatic that there can only be a name (one can only name something) if there already exists a technique for using it, and this technique must be something independent of the language-user as well as being public:

The relation between name and object. Lang[uage] game of builders. What is the relation between names and actions names and shapes? The relation of ostensibly defining. That's to say, in order to establish a name relation we have to establish a technique of use. And we are misled if we think that it is a peculiar process of christening an object that makes a word the word for the object. This is a kind of superstition. So it's no use saying that we have a private object before the mind and give it a name. There is a name only where there is a technique of using it and that technique can be private; but this only means that nobody but I know about it, in the sense in which I can have a private sewing machine. But in order to be a private sewing machine, it must be an object which deserves the name "sewing machine," not in virtue of its privacy but in virtue of its similarity to sewing machines, private or otherwise. $^{16}$

In the case of the putative private linguist, for the ostensive definition to do any work, the logical 
category of what is being named must already have been determined viz. that "S" is the name of a sensation. However, 'sensation' is a word in our public language that is defined by reference to behavioural criteria. Since the private linguist has severed this connection, he needs to explain the categry or 'post' of "S" afresh. However, simply uttering 'This is $S$ ' does not make "S" the name of a sensation. since it leaves undetermined what 'this' is. He cannot therefore create a category or a concept just by uttering a word in the presence of some occurrence. Nothing, by means of which the occurrence is to be individuated or determined, has hereby been established. Concentrating one's attention cannot establish criteria of identity for subsequent uses of "S". Such criteria can be provided only by specifying what kind of thing is at issue through a sortal term. But the private linguist has not established what he is concentrating on. He cannot say that it is a certain 'experience' or 'phenomenon'. since he lacks the resources for explaining those terms provided by our public language. He cannot even say that "S" refers to something he has, since 'has' and 'something' are also words from our public language with a determinate grammar. This kind of elenctic argument forces the putative private linguist to the point where he 'would like just to emit an inarticulate sound' (PI 257, 261-3). If a private ostensive definition cannot provide a standard of correctness, then its putative sample - the inner private object - drops out of the picture as an 'idle wheel'. Any explanation of the possibility of language cannot contain reference to private objects -- objects which speakers refer to but which cannot ever be known to others. Wittgenstein's 'beetle-in-a-box' example has bearing here: in a language-game in which everyone has a box and refers to its contents as a 'beetle', but in which no one has access to the contents of other people's boxes, the contents of the box and their nature are irrelevant to the meaning of 'beetle'. The same is true if we imagine the inner object (the sensation S) changing constantly without our noticing. The reason is not that the private object is unknowable, but that it is semantically irrelevant.

Imagine a person whose memory could not retain what the word 'pain' meant - so that he constantly called different things by that name - but nevertheless used the word in a way fitting in with the usual symptoms and presuppositions of pain" - in short he uses it as we all do. Here I should like to say: a wheel that can be turned though nothing else moves with it, is not part of the mechanism. (PI 271)

...... (We as it were turned a knob which looked as if it could be used to 
turn on some part of the machine; but it was a mere ornament, not connected with the mechanism at all.) (PI 270) (Cf. PI 293)

This however gives the impression that we are left with a kind of behaviourism which denies that there is anything behind our outward behaviour. To this possible charge Wittgenstein says:

And yet you again and again reach the conclusion that the sensation itself is a nothing." -Not at all. It is not a something, but not a nothing either. The conclusion was only that a nothing would serve just as well as a something about which nothing could be said. (PI 304)

And then to the charge that he is saying that everything except human behaviour is a fiction he says that the only fiction he is pointing out is a grammatical fiction. The sensation is a semantically irrelevant 'grammatical fiction' if we construe the grammar of 'pain' on the model of object and name. There are no criteria of identity for private mental entities since any attempt to articulate its identification (or misidentification) can only be done in a public language -- where the meanings of words are learnt differently. This does not imply that there are no such objects (sensations), but that sensations cannot be understood as private entities. The meanings of words like 'pain' are thus fixed by criteria other than the experience of the sensations. And it is for this reason that the putative private linguist cannot set up a criterion of correctness.

We have yet to answer the question: is it the linguistic community as such that plays an indispensable role or can this role be replaced by something else i.e. is it the role that the linguistic community plays which is indispensable or is it the linguistic community itself which is indispensable? The traditional way in the literature of approaching the problem is to attempt to imagine a would-be solitary linguist and then to ask what advantages he has over the private linguist. When you introduce the issue like this you quickly see that the solitary linguist has public objects available to him - public objects being objects which are not just accessible to him but to others as well. The advantage of public objects is that. whereas the private object has to be identified or individuated from a stream of experiences by the private linguist. the solitary linguist has access to objects that are already individuated, so to speak. Having access to such ready-individuated objects, the solitary linguist has another advantage: whereas 
the private objects were only accessible to the private linguist and nobody except he himself could give a verdict on whether he has had a reoccurrence of an experience; in the case of the solitary linguist the objects he intends to record are available to others. So, should he go wrong, someone else could, in principle. point out that that he has gone wrong. But there is no 'someone else' in the world of the private linguist. So. how could mistakes be pointed out to him?

Pears. in The False Prison. (vol. II) argues that the solitary linguist can calibrate, or judge his recordings on standard objects. Standard objects can be used to determine whether you have used a word correctly. The plausibility of this turns on the explanation of how a connexion has been set-up between the standard object and the word. The question now is: would the putative solitary linguist run into the same kind of trouble the putative private linguist runs into: in both cases, is the naming ceremony empty? The position of the solitary linguist might at first glance have appeared more promising than that of the private linguist, since, in the case of the private linguist he does not have the impossible task of having to, without buying into the public language, individuate the 'thing' he intends to name. In the case of the solitary linguist the identity of the objects around him 'shouts out at him'. They are already individuated. But one wonders how he made the name-object connexion in the first place. To address this question, I want to re-examine what Wittgenstein says about the linguistic community's practices. The established practices act as a criterion - a model - of correct usage. To say that they act as a criterion of correct usage is to say that they fix or determine the meaning of a word. And the meaning of the word is not some particular object, but the role of that word - the use that is made of the word. So that, if a word lacks a particular use, if it does not fit into some language-game it lacks meaning. People do certain, and not other things, with that word, that is why it has that meaning. There is a practice of using a word in a certain way. ${ }^{17}$ Thus a word only has meaning if there exists a practice for its use. The practice fixes its meaning. This much is agreed upon by both advocates of the possibility of a solitary language and those who deny its possibility.

Now let's imagine ourselves in the primordial position of the solitary linguist. He has to set up the practice by himself. To set up a practice by himself means to establish a tradition of using a word in the same way on subsequent occasions. So, first he has to connect a word to a thing. The problem for the private linguist was that he had to individuate his sensation and that can only be done in the public language. In the case of the solitary linguist, his 'things' are already individuated; however he still has to determine what aspect of the thing he is concentrating on i.e. whether it is the shape or the colour. 
What is important to notice at this point is that whereas someone born into a linguistic community finds himself in a world of established practices which serve to order his world - to direct what he must want. so to speak, the solitary linguist's behaviour will be guided only by his basic desires: his desire to eat and drink and avoid bodily harm etc. So let's assume he eats a fruit and it tastes bad. He might utter some word in its presence to refer to say, the colour or the shape of the fruit. An observer may not immediately know what exactly he has referred to; we may need to observe future occurrences and put the pieces together, in a manner of speaking. But I can see no reason to think that the solitary linguist has not focussed on a particular aspect and connected his word to that feature of the fruit. But perhaps there is something left out before reaching this conclusion. The issue here is whether the solitary linguist can set up a rule, and to set up a rule is to set up a defined course of action for accomplishing something. After all. what would drive such a recurrence of behaviour would presumably be a recurrence of the desire to perform it. This seems to be important, since, if the solitary linguist reacted in a similar way in the presence of a particular stimulus on numerous occasions, it does not seem to be enough to call such behaviour 'following a rule'. For example, let's say that every time he walks in a swampy area his foot becomes stuck in a muddy patch and he pulls hard to get it out. He might do this on every occasion. but he is not following a rule. What he needs is some goal that must be achieved, some course of action that must be repeated in the same way on subsequent occasions in order to achieve success. It might not immediately be appreciated why the solitary linguist needs a goal, since when we compare him to the public linguist, we see that often times the public linguist does what he does because that is the rule, and the rule is what everybody does; there may not be, or he may not have a goal. However, the point about the importance of a 'goal' for the solitary linguist is that he does not find himself embedded in a world of 'concerns' already established independently of him, and into which he has to be initiated. In the case of the solitary linguist he must have an agenda, so to speak, and his natural 'concerns' provide such an agenda - an agenda that leads him to want to associate a sign with an object. The significance of this discussion is to suggest how the solitary linguist might, in a world cut off from ready-made concerns and practices, come to focus on some particular aspect of an object. When driven by the same goal or desire, he exercises his 'method' or 'technique' for achieving it.

A naming ceremony can yield a criterion of correctness only when it establishes how to use a sign in the future (what would count as the correct employment of the sign). In the case of the private linguist, his ceremony establishes no such thing. With no resources from the physical world, he cannot say what he is concentrating on. Wittgenstein's remark that an ostensive definition is only productive when the 
language learner already knows the grammar of the word indicates that one must already 'know' what is to be picked out before you can apply a word to it and not the other way round, since there would be 'nothing defined or particular' that you have named. In the case of the public speaker, an ostensive definition is productive only if he already knows the grammar of the word, although he may not know the actual word. In other words, he knows how such a word is to be applied. This point about ostensive definitions indicates that ostensive definitions cannot be the beginning of language-learning (of accuiring a language). But in the case of the solitary linguist all he has at his disposal to get things going is ostensive definitions. So the question is about whether his naming ceremony (ostensively defining some item) establishes how to use a sign in the future. And it seems it can: the solitary linguist focuses on some particular aspect - the aspect he focuses on being driven or directed by whatever his need may be - and in so doing establishes how the word must be used in the future. I think it is important to stress the role played by what I have called the 'agenda' that drives the solitary linguist to focus on one aspect rather than another, of an object. Take the case of the private linguist again. He utters "S" in the presence of a sensation. The trouble with this ceremony is that it does not tell you how the sign " $\mathrm{S}$ " is to be used in the future, precisely because it has not really been 'used' in the ceremony. Nothing about the sensation was focussed on such that we can say that 'that' is how " $\mathrm{S}$ " is to be used. Why not? The reason given before was that the private linguist does not have a repertoire to do so. The idea was that any aspect he may want to focus on is an aspect that comes from and belongs to the public linguistic community - and derives from the resources available to this community. But why could the private linguist not focus on an aspect of the sensation that does not need the resources from the public language? We would have great difficulty imagining such a situation simply because it would involve our having to give an example or conceive of a situation which is in principle unintelligible to us (since it must be an example which must not be articulated in public language) something which of course we can't do. This shows up something fundamental about the status of a private language: we cannot genuinely intelligibly set up such a situation. So, if we cannot even intelligibly set up a scenario that would count as the speaking of a private language, any account of language that tacitly assumes a private language is not a genuine rival as a theory of language. Any theory of language tacitly assuming a private language is thus wrong not because it is incomplete or false. but because it assumes premises that do not amount to an intelligible rival theory.

But there is something else that is significant about the private language scenario: the private linguist presumably has to start from scratch. And from this tabular rasa position, he has to focus on some 
aspect of his sensation. If he still has to set up a language, then presumably he does not already have a stock of 'aspects' that he could draw from. He has no resources since he has no other concerns - neither concerns thrust upon him by any community, nor concerns prompted by the natural world or physiological concerns. He has, to put it bluntly, nothing in his world to get anything going. In the case of a public language learner in the linguistic community, the grammar of signs is already established he just has to 'catch on'. He has to learn the established technique for using signs correctly. Colour words, number words, shape words are already there - the various aspects of how we can speak about an object has already been determined; it is simply a matter of his being initiated into this language. In the case of the solitary linguist. the grammar of signs is not set up, but, the way nature makes its presence felt (some things taste unpleasant, some things hurt) and his biological interests (to avoid unpleasant things, for example) steer his focusing on this or that aspect of an object. The private linguist however, cut off from the natural world, is like a 'minister without a portfolio'. He has no resources whatsoever. and hence nothing to go by.

I have noted above that while Wittgenstein does not explicitly rule out the possibility of a solitary language, whether the idea of a solitary language would at all have been accepted by Wittgenstein has puzzled commentators. Pears ${ }^{18}$ suggests that much of the obscurity comes from the fact that Wittgenstein uses the sensation of pain as his working example. Now this example is not problematic in itself; it is the way he deploys it that prejudices his arguments: he concentrates almost exclusively on the effects of pain, and ignores their causes and the role they play in learning the meaning of a word like 'pain`. For example, in $P I 257$ he asks:

\section{"What would it be like if human beings showed no outward signs of pain (did not groan, grimace, etc.)?"}

The point he is intending to lead up to here is that if pain were separated from its natural expression (outward signs of pain) it would not be teachable. Hence he answers the question with

\section{"Then it would be impossible to teach a child the use of the word 'tooth-ache'."}

Pears ${ }^{1 "}$ suggests that since both the question and the answer are segregated from the rest of the passage by inverted commas this may indicate that it is Wittgenstein's interlocutor and not Wittgenstein himself 
who has given the answer; however the comments that follow do not make mention of the possibility of learning the meaning of the word 'pain' through the stimuli that cause the sensation:

- Well, let's assume that the child is a genius and itself invents a name for the sensation.

- So does he understand the name without being able to explain its meaning to anyone?

From this we see that Wittgenstein does not at all consider the connection of the word pain with its various possible stimuli; in the absence of the expression of pain (hence the absence of a community) a child will not be able to talk about his pain. It is odd that Wittgenstein fails to mention pain stimuli. which undoubtedly plays a role in teaching the use of the word pain. This would have to be put down to neglect rather than rejection of the role of stimuli in learning the use of sensation words. Although, as Pears suggests, pain has always played a central role in the sceptical treatment of perception, and that may explain why he concentrated on it, it did produce an imbalance in his treatment of sensation words. Thus the exegetical problems which his discussions raise come from (a) choosing pain as his main example (and neglecting cases with a uniform stimulus and no uniform effect), and (b) focussing exclusively on the external manifestations of pain and neglecting its causes. This has led to a bias favouring the role of established linguistic practices and communication between people and neglecting the role that standard objects play: our vocabulary must track types that are regularly connected in the world around us. The point is that the regularity in our language is sustained not only by the linguistic practices of the community, but also by the regularity in types of standard objects in the world. And of course it is our relation with standard objects that Pears deploys in his discussion of the possibility of setting up a language by calibrating on standard objects. ${ }^{20}$

It is worthwhile to note that this is an area of philosophy that stands at the junction between science and philosophy. The abstract philosophical discussions of the possibility of a solitary linguist can be supplemented. or for that matter even replaced, by empirical evidence: discoveries of children that survive since birth in complete isolation from a linguistic community indicate that they were able to perform tasks successfully on many occasions. The kinds of tasks needed to survive would not be those that can be described as mere stimulus-response behaviour, but behaviour that required the person to m'cth to do the same thing again. ${ }^{21}$ To follow a rule, to speak a language, is to do something intentional 
and to do something intentional is to know what counts as succeeding in what you're doing. It could be shown, empirically, that such children who have survived in isolation have in fact needed to follow rules, have needed to know what counts as succeeding in what they're doing. Given this, the task would no longer be one that attempts to philosophically demonstrate the coherence or possibility of a solitary language. but one which has as its starting point the existence of a solitary language and which tries to understand and describe how the solitary linguist manages to survive.

\footnotetext{
Stroud, B., Wittgenstein and Logical Necessity, in G. Pitcher (ed.), Wittgenstein: The Philosophical Investigations. 1968. Philosophical Remarks. R. Rhees (ed.). R Hargreaves and R. White (Trans.), 1975.58.

IIttronstein 's Notes for Lectures on "Private Experience" and "Sense data". 1936. R. Rhees (ed.), Philosophical Review" 77 (1968). pp 275-320: "The Language of Sense data and Private Experience - Notes taken by R. Rhees of Wittgenstein's Lectures. 1936". Philosophical lonestigations 7 (1988). pp 1-45 and pp 101-40.

tVerheggen, C. Wittgenstein and Solitary Langlages, in Philosophical Investigations 18:1, January 1995 , pp 329-47.

stroud. B.. Wittgenstein and Logical Necessin, in G. Pitcher (ed.), Wittgenstein: The Philosophical Imestigations, 1968.

"Pears. D.F. The False Prison: A stud of the Development of Wittgenstein's Philosophr, Vol. ii, 1988.

ihid.. p. 333.

"ibid.. p. 345.

"Verheggen. C. Wittgenstein and Solitary Languages, in Philosophical Imvestigations 18:1, January 1995, pp 329-47.

"ihid.. pp $321-47$.

Philosophical Grammar. R. Rhees (ed.). A Kenny (trans.) 1974.

Philosophical Occasions: 1912-1951, J. Klagge and A. Nordmann (eds), 1993.

el. Pears" discussion of the marksman in The False Prison, vol. II, 1988.

Pears. D.F. The False Prison. 1988. Vol. Il.

"The' Language of Sense' Data and Private Experience - Notes taken by. R. Rhees of Wittgenstein's Lectures, 1936 ", 8. Philosophical hivestigations 7, 1984, pp 1-45, pp 101-40; see PI 260.

"Philosophical Occasions: 1912-51, J Klagge and A. Nordman (eds), 1993, 448.

$1^{-}$That practise in turn is embedded in a network of other inter-related and intertwined practices, values, standards etc.

". Pears. D.F. Parados and Platitude in Witgenstein's Philosophy; (unpublished).

itidi..

"Pears, D.F. The False Prison. Vol. II, 1988.

2 CI. Wittgenstein's insistence that the private linguist is not doing anything intentional and hence not doing any thing. See
} Pears. 'Private Language Argument'. British Academy Lecture, 1941, in Wittgensteinian Occasions, pp 447 ff. 


\section{Chapter 5: Necessity}

Wittgenstein's discussions on necessity in his later work center around two areas - (i) the explanation of the necessity of the inference from contingent premises to a contingent conclusion in a valid argument (proof using logic) and (ii) the explanation of the necessary status of a theorem derived from a set of axioms in a logical proof (proof in logic). The explanation of the necessity in these two cases has generated a classical dilemma: does the necessity derive from correspondence with independently necessary features in the world, or does it have something to do with the internal structure of language? Does nature force these propositions upon us, or do we stipulate them? Note that in this case, as it was in the case of the application of general words to things, the problem is cast in terms of only two alternatives - either it is the case that necessary propositions capture independently necessary features in the world and are thus constrained by these necessary facts, or they do not describe anything at all and they are not constrained in any way and so our formulation of them is entirely capricious. So the dilemma is that either necessary propositions are objective or they are subjective. However, the dilemma obscures a third possibility, namely, that the rejection of realism does not automatically imply capricious conventionalism. This was the point made in the earlier discussion on the application of general words to things. Realism about universals had failed to explain the extension of a general word because the universal could not be identified independently of the set of things it was said to apply to. But the failure of realism did not imply that the extension of a general word could not be specified in a way that would yield an explanation without this shortcoming. In the case of the application of general words to things, the explanation offered was a scientific one. The scientific explanation was not meant as yet another contender on the same footing with realism. In fact, the scientific explanation is a "nonexplanation'. It is really a descriptive account of what actually takes place when we apply general words to things. It must be seen as the only possible account that can be offered given the failure of a philosophical theory. The account makes use of the notion of an incompletely specifiable technique. The technique could not be completely specified by any verbal formulation because although the technique influences the way a speaker will apply a general word, it never completely determines it. It is. in a manner of speaking. constantly under construction. However, because the technique is, in this sense. a moving target, it may seem to fare no better than the realist's appeal to universals - it too cannot be appealed to independently of what we in fact do. Nevertheless, although the previous applications do not completely determine the next application, it does influence how the word would be applied in the future. So although we do have to wait and see how we would apply a word, because the 
future applications are fed in by the past applications, the technique does not constitute appeal to a candidate that is not independently specifiable. The appeal to a technique as a candidate (rather than the realist's universal) also prevents being swung onto the other horn of the dilemma viz. capricious conventionalism. Although we do have to wait and see how a speaker would apply a word in every new case. the future application is influenced by the past applications, so the speaker does not have laisse-faire in future applications.

In the case of the student who followed the rule ' +2 ' in the way we do up to a certain point and then deviated from our way after a certain number has been reached, the question that was raised was: in virtue of what can we say that prior to the number after which the student deviated, he was following the rule the way we did? Or, in virtue of what can we say that two people are following the same rule where, up to the present. they have behaved in the same way. In the case of the notion of a technique, the same question can be asked: in virtue of what can we say that two people are following the same technique. or, in virte o what can techniques be individuated? The answer to this of course has to do with understanding how a technique I developed. We have seen that a community may eventually develop an an agreement on th proper wy to o something. Some prodedure is executed several times and the members of the community eventually agree on the application

Note again that the crucial feature of this appeal to technique is that it opens up the field to an explanation of a very different kind to that offered by realism. It offers a kind of empirical explanation, one that derives from a description of how we in fact do things. Realism addresses the question: what mus: be the case given that meaning is possible and then offers an a priori or transcendental explanation. Wittgenstein addresses the question: how are things in fact, given that our words have meaning. It treats the application of general words to things as part of human activity, and like other human activities, the explanation must be sought within the realm of human activity. It therefore offers an empirical rather than a metaphysical theory. The empirical alternative is not intended as just another contender to the realist theory, but is offered as the only available substitute. The search for a philosophical answer to the question failed, not because realism was an inadequate contender, but because it was not a contender at all. It was a bogus explanation since it appealed to items that are not specifiable independently of our vocabulary. The failure of realism opened the path to the only other possible kind of explanation. The scientific explanation is clearly not situated in either of the camps of the dilemma, but rather undercuts the dilemma. It neither makes appeal to items that are not independently identifiable, nor does it offer a capricious conventionalism. 
In the case of the explanation of the necessity of logical propositions we are faced with a similar situation. Again the debate is cast in terms of the dilemma between language and the world. The question is whether necessary propositions capture independently necessary features in the world, or whether they are simply arbitrary stipulations. And in this case too, we will come to see, Wittgenstein abstains from taking part in the debate. He offers an explanation which, on the one hand, does not make appeal to extra-linguistic factors and so does not face the charge of appealing to factors which we are not able to identify independently of our practices, but which, on the other hand, does not amount to capricious stipulation. His discussion of the incompatibility of two complementary colours demonstrates Wittgenstein position in the debate. He deliberates about what guarantees that two complementary colours (red and green) do not overlap - whether it is a feature of the world independent of our colour vocabulary, or whether it is something produced by our language. The source of the necessity of the incompatibility of red and green presents a special problem. Unlike in the case of a necessary proposition such as: 'something cannot be both a fish and a bird at the same time' the source of the necessity comes from mutually exclusive definitions. A bird may be described as a creature with wings and a fish may be described as scaly and wingless. But in the case of red and green a definition like this is not available. The only way to know what 'red' is, is to see red. Of course we could offer a definition in terms of light waves of the colour spectrum, but this is not what we have in mind when we use colour words.

In his earliest discussions on necessity after he returned to philosophy in 1929 he says:

To a necessity in the world there corresponds an arbitrary rule in language. '

A bit later he says more explicitly:

The only correlate in language to an intrinsic necessity is an arbitrary rule. It is the only thing that one can draw off from this intrinsic necessity into a proposition. ${ }^{2}$

In Zettel he qualifies both these verdicts at great length:

354. I want to say that there is a geometrical gap, not a physical one, between green and red. 
355. But doesn't anything physical correspond to it?

He goes on to deny that physical facts provide the complete explanation of the incompatibility.

356. But what is the right simile here? That of a road that is physically impassable, or the non-existence of a road? l.e. is it one of physical or mathematical impossibility?

357 We have a colour system as we have a number system. Do the systems reside in our nature or in the nature of things? How are we to put it? Not in the nature of numbers or colours.

358 Then is there something arbitrary about this system?

Yes and no. It is akin to what is arbitrary and what is not arbitrary.

Clearly Wittgenstein is denying that our colour system resides in the nature of colours and hence that what makes a proposition necessary is any kind of correspondence with anything independently necessary in the world. The question that would naturally arise here is whether the world plays any role at all and if so. what? Wittgenstein asks and answers this question:

364 .......but has nature nothing to say here?

Indeed she has - but she makes herself audible in a different way.

"You'll surely run up against the existence and non-existence somewhere!" But that means against facts and not concepts. ${ }^{3}$

One difficulty with getting our mind round the denial that the world is the dominant partner in the explanation of the formulation of our concepts is that it seems so natural to think that our colour rocabulary must have been set up the way it is because that is the way colours occur naturally. It seems there must be a correspondence between our colour vocabulary and the colours in nature. The short answer was given earlier: we cannot talk of the way colours 'occur naturally' simply because we do not have access to the colours except through our colour vocabulary. A fuller explanation is that if we were to ask a realist to identify two complementary colours without using our colour vocabulary at all he would not get very far. Deprived of such a vocabulary, he may resort to pointing to two coloured objects. But this of course will not work, since ostension does not provide us with the extension of the 
wo colour-words. He is thus faced with a dilemma. If he refrains from using the colour vocabulary he would not have said anything at all; if he employs the vocabulary, the incompatibility may just be a consequence of his use of the colour-vocabulary. The trouble is that it is only after necessary propositions have been formulated that we can ask about the source of their necessity. The point then is not that realism is false, but that the realist option cannot be independently formulated as an option. This might point to the real source of the difficulty in this problem: we cannot adjudicate between the two options simply because we do not have two clearly distinguishable alternatives. We cannot distinguish the realist alternative without using our colour-vocabulary. Our vocabulary is already involved even if only in the formulation of the problem. So then we do not have two options before us: language or the world. The problem seems intractable because we are trying to force an answer to fit onto one of the two alternatives, and clearly it cannot because we do not have two alternatives. This is not to say that because the problem has been formulated in language the source of our colour rocabulary is entirely in language, but only that the possibility becomes discussable at all only once it has been formulated.

However, as Wittgenstein's discussion on the incompatibility of two complementary colours indicates, he did think that the truth lay closer to the one alternative. Necessity is not an exotic import, but has its origins in native soil - human life and human conventions. But these conventions are not capricious. In a sense they are arbitrary, since nothing independently of the conventions make them right, or justify their adoption, but. their adoption is nevertheless hedged-in. Wittgenstein thus pays respect to the realist intuition that whatever determines what counts as necessary cannot be a matter of our whim - it has to be independent of how we happen to do things, but he escapes the fatal flaw in realism by locating the restraint not in some putatively independent hinterland, but within the domain of our natural history.

Wittgenstein"s critical remarks on realism must not be seen as an attack on a view he held in the TLP. In the TLP as well he repudiates realism, however, he still endorses what could be called a 'residual realism? a realism that appeals to the logical form of the world rather than factual truths as a validation of logic. In TLP 5.5521 he asks:

If there would be a logic even if there were no world, how then could there be a logic given that there is a world? 
On the one hand Wittgenstein is asserting that logic is independent of the world, on the other hand that there is a relation between logic and the world. We can reconcile these two claims by seeing that in the first part he is reacting against realism that requires for the existence of logic the existence of certain truths, for example, that there are universals or that the world has completely general features to which logical propositions correspond. Wittgenstein is totally against this: logic cannot owe allegiance to any facts: if it did, then if the facts were otherwise, it would mean that logic would run up against the facts, and this would mean that logic could be falsified. This would undermine the very character of logic. Logic cannot be true or false; logic is the pre-condition of propositions that have a truth-value.

The thing that is so difficult to understand can be expressed like this: as long as we remain in the province of the true-false games, a change in the grammar can only lead us from one such game to another, and never from something true to something false. On the other hand, if we go outside the province of these games, we don't any longer call it 'language' and 'grammar', and once again we don't come into conflict with reality.

Having said this, Wittgenstein still thinks that there is a relationship between logic and the world. The second part of the question (How could there then be a logic given that there is a world?) is answered in TLP6.124:

The propositions of logic describe the scaffolding of the world, or rather they represent it. They have no 'subject matter'. That presuppose that names have meaning and elementary propositions have sense; and that is their connexion with the world. It is clear that something about the world by the fact that certain combinations of symbols - whose essence involves the possession of a determinate character - are tautologies. This contains the decisive point. We have said that some things are arbitrary in the symbols that we use and that some things are not. In logic it is only the latter that express: but that means that logic is not a field in which we express what we wish with the help of signs, but rather one in which the nature of the absolutely necessary signs speak for itself. 
If we know the logical syntax of any sign-language, then we already have been given all the propositions of logic.

Logic does not require the existence of facts, but it does require that names have objects as their meaning and that elementary propositions have sense. This relationship between logic and the world is not one of correspondence, but one where logic shows that there are objects (which are the meanings of names) and that there are logical possibilities (elementary propositions have sense). These are not part of the content of the world, but represent the skeleton or logical scaffolding of the world. As Wittgenstein says in TLP 5.552:

The 'experience' that we need in order to understand logic is not that something or other is the state of things, but that something is: that, however, is not an experience.

Logic is prior to every experience - that something is so.

It is prior to the question 'How?', not prior to the question 'What?'

This is the 'vestigial' realism that Pears' talks about. The realism is vestigial because it represents the last traces of a realist account once the postulation of (a correspondence between) extra linguistic truths and logic are given up. It has the outer form of realism, but none of the content. This vestigial realism derives from his other commitments viz. his Logical Atomism and his theory of Tautology. Logical Atomism requires that the sense of a proposition depend on the sense of its analysed constituent parts. The end-product of this analysis is indefinable names. Indefinable names designate simple objects. Propositions have sense because simple objects, which are the meanings of indefinable names, exist. Logical propositions in the TLP consist entirely of tautologies and contradictions or propositions reducible to tautologies or contradictions. A tautology consists of at least two propositions joined by a logical connective. So a tautology requires that its constituent propositions have sense (and a propositions has sense if its names have meaning). Thus for logic to exist we need elementary propositions with sense. Then it is just a question of combining them in a special way (tautologies are combined in such a way that it includes all possibilities; contradictions that it excludes all possibilities).

Wittgenstein later abandons even this vestigial realism. In Philosophical Remarks 7 he says: 
If I could describe the point of grammatical conventions by saying they are made necessary by certain properties of the colours (say) then that would make the conventions superfluous, since in that case I would be able to say precisely that which the conventions exclude my saying. Conversely, if the conventions were necessary, i.e. if certain combinations of words had to be excluded as nonsensical, then for that very reason I cannot cite a property of colours that makes the conventions necessary, since it would then be conceivable that the colours should not have this property, and I could only express that by violating the conventions.

The following remark in Philosophical Grammar also undermines the idea that logic requires any contact with reality.

The thing that is so difficult to understand can be expressed like this: as long as we remain in the province of the true-false games, a change in the grammar can only lead us from one such game to another, and never from something true to something false. On the other hand, if we go outside the province of these games, we don't any longer call it 'language' and 'grammar', and once again we don't come into conflict with reality. ${ }^{6}$

In Cambridge Lectures 1, which marks his return to philosophy in 1929, he presents the new lay of the land:

"....it cannot be justified" (sc. By a realist demonstration of its correspondence with an independent reality) "it is not arbitrary in so far as it is not arbitrary what rules of grammar I can make use of. Grammar described by itself is arbitrary; what makes it non-arbitrary is its use. ${ }^{?}$

Logically necessary propositions cannot be validated in the way contingent propositions are validated. Whereas contingent propositions are either true or false, logical propositions do not have a truth-value. 
They do not correspond to anything, but rather are the conditions or possibility of producing contingent statements about the world. Logical propositions are a categorially different kind of proposition to contingent ones. By this time Wittgenstein had completely abandoned all trace of the residual realism and was well on his way to the conventionalism propagated in the $P I$. In the $P I$ he advocates that logic is autonomous (it does not owe allegiance to any extra-linguistic truths). However, this autonomy must be understood in the context of what Wittgenstein was reacting against i.e. realism. Wittgenstein repudiated the idea that the existence of logic needs the existence of truths, and that there is a correspondence (and for that matter any kind of relationship) between these truths and logical propositions. In the PI Wittgenstein does make reference to facts in explaining logic, but he does not present a metaphysical account; rather, he solicits facts in the world to play a role in the development of logical propositions. This is a very different kind of explanation, and uses facts in a very different way to which the realist does. The discussions below of proof in logic and proof using logic illustrate how he does this.

While the mutual necessary exclusion of complementary colour words discussed earlier articulates well Wittgenstein's rejection of realism, it nevertheless represents a limiting case, since it explores the relationship between a necessary proposition and facts in the world. With more typical examples of necessary truths we would explore the alleged relationship between the necessary proposition and some non-contingent all-pervasive features of the world - perhaps the kind Russell had in mind. However, it is because the colour-incompatibility example is a limiting case that it is so revealing, since it shows up that a realist explanation of the source of necessary truths is mistaken by discussing the alleged relationship between a necessary proposition and a much more familiar and tangible phenomenon i.e. colours. The colour incompatibility example shows up that necessary propositions cannot be validated in the way empirical propositions are validated i.e. by appealing to something in the world. This example is perfect because it allows us to see that appealing to correspondence with features in the world is a dead-end. but that features in the world can be appealed to, although in a very different way. Recall the discussion on the application of general words to things. The point there was that though it was a matter of convention what the particular extension of a general word is, the convention does not develop unbridled. It is hedged in by a technique of applying a word - a technique the development of which is a function of our needs (the need for communication, and hence homogeneity in the language we use), our physiology, our natural environment and what we find natural to do. In the case of necessary propositions, the problem is about explaining the connection between two techniques. The 
realist claims that this connection is already made independently of us, and we receive it as a readymade gift, as it were. Wittgenstein's explanation is that we are not so lucky. A necessary proposition is one that we make ourselves, and then have the benefit of its use later. To use another analogy, necessity is not a status that a proposition is born with - it does not come into the world as necessary in the way a prince is born into royalty. The situation is more like that of a group of people without an appointed leader. A few amongst the group assume responsibility from time to time, but there may be one who is always amongst those who assume responsibility. Over time, this person comes to be regarded as the leader. He was not the leader from the outset, he was just part of the group like the rest. But he earned leadership because of his deeds. It is important to note though that it is not merely in virtue of his deeds that he earns this position, but it is also that, because of his deeds, the people accept him as leader. This is what Wittgenstein had in mind in his explanation of the origin of necessary propositions. A particular pattern of reasoning may have been used over a long time and may always have, when fed true propositions, generated true conclusions. It encountered no recalcitrant experience. Over time, we start to think of this pattern of reasoning as necessarily true, necessary not in the sense that we have finally discovered a pattern of reasoning which was true independently of us anyway but which took us time to discover. but necessary because, as it happens, we have not encountered counter-examples to it. It is crucial to see that it is not the case that the pattern of reasoning was necessary all along unbeknownst to us. and that we came to discover it as necessary because of its performance. In other words, when we finally ascribe necessity to it, we do not do so in the following spirit: "Well of course it did not disappoint us (was always verified) since it was actually a necessary pattern of reasoning all along, clad in the garb of a contingent pattern of reasoning. The trouble lay with us - we took so long to recognize it. It practically had to prove itself to us. As for its outstanding performance (always verified by experience), well, what else can we expect? It is behaving true to its nature!" Nothing could be further from what Wittgenstein meant. The way Wittgenstein saw the matter, the proposition we regard as necessary was not a prince clad in the garb of ordinary folk. He was part of ordinary folk to start off with. And then he earned his position, not because his behaviour was in character, but just because, as it happened, it was verified on every occasion of its use. By the time it was regarded as necessary, it had genuinely graduated to this new status. It is a case of rags to riches. In the terminology of the later work. a necessary pattern of reasoning is an empirical pattern of reasoning that hardened or 'petrified' into a necessary one. 
96. It might be imagined that some propositions, of the form of empirical propositions, were hardened and functioned as channels for such empirical propositions as were not harden but fluid; and that this relation altered with time, in that fluid propositions hardened, and hard ones became fluid.

97. The mythology may change back into a state of flux, the river-bed of thoughts may shift. But I distinguish between the movement of the waters on the river-bed and the shift of the bed itself; though there is not a sharp division of the one from the other.

98. But if someone were to say "So logic too is an empirical science" he would be wrong. Yet this is right: the same proposition may be treated at one time as something to test by experience, at another as a rule of testing. ${ }^{8}$

Discovering necessities on the realist account is like a join-the-dot puzzle - the pattern is already there, we only have to join the dots. In the absence of such a realist picture, we have to explain how we construct necessities out of the only material that we have in hand i.e. our ordinary language, and tell a story that shows how we use ordinary language (and not some exotic Platonic postulate) to expand language. We have to show how the very material we have can be used to generate more such material. It is a case of using local talent rather than importing foreign material to manufacture new goods. Such an explanation solicits empirical facts to explain how and why we have come to adopt certain patterns of reasoning as necessary.

Of course the inferences used in proofs using logic are not the only kinds of logical propositions. There are also what we call analytic truths. Wittgenstein gives an explanation of analytic truths in a similar vein. These kinds of necessary propositions were once empirical propositions that have petrified into necessary propositions. The process is one where certain empirical facts about a phenomenon get incorporated as part of the definition of that phenomenon. So for example 'A is B' could transform from an informative expression stating some contingent fact about $\mathrm{A}$, namely, that it is $\mathrm{B}$ to a conceptual proposition where $\mathrm{A}$ is $\mathrm{B}$ is definitive of $\mathrm{A}$. The fact that a spider has eight legs might initially have been a contingent fact about spiders. However, that a spider has eight legs, might, over time. become part of the definition or the concept of a spider. So 'a spider has eight legs' might then become an analytic truth. The empirical proposition would hereby have been petrified into a necessary 
truth." Wittgenstein uses the analogy of the relation between the present state of a clock and the future movement of its hands across its face to make the point (PI 195). In that example, there are two ways of articulating the relation - it could be either necessary or contingent. If it were necessary, the only way to then explain it is to say that the future movement of the hands across the face of the clock was included in the criteria of the description of the present state of the mechanism. The necessary relationship between the present state and the future movement is thus a conceptual one. This kind of 'conceptual' explanation of necessity is what Wittgenstein refers to as 'petrifaction'. In Remarks on the Foundations of Mathematics VI. where he discusses the rule "+1" he says:

It is as if we have hardened the empirical proposition into a rule. And now we have not a hypothesis that gets tested by experience, but a paradigm with which experience is compared and judged. And so a new kind of judgment. ${ }^{10}$

It is important to note the two stages involved in the development of a necessary truth. The one is when, as a contingent proposition, it enjoys uncontested confirmation, and the other is when it is thereafter adopted as a necessary truth - 'petrified' as a definition. It is crucial that we keep the reasons we regard a proposition as necessary logically distinct from our having ratified it as necessary. Failure to do so would mean that we are using the fact that it is (has been ratified as necessary) as part of the reasons for ratifying it as necessary. In other words, it would amount to saying that the reason the proposition has not encountered recalcitrant cases is because it is necessary. This would then make the whole account incoherent, since it would rely on the status that we accorded it as part of the reason we accord it that status.

It is interesting to note that this conventionalism is already part of his thinking as early as the $T L P$.

We can foresee only what we ourselves construct. (TLP 5.556).

This is, in keeping with the general tenor of the book, a rather stark way of putting the matter. In both cases however, the point is an anti-platonic one: necessary propositions are manufactured by us. As in the case of the application of general words to things, once platonism is exposed as a fake, the worry is about how to explain the presence of necessary truth in a way that does not make it seem as if it is all a matter of caprice. The point has been made earlier that it is not a matter of caprice; we are under 
restraint, but nothing like the platonic kind. The world does play a role in the explanation of the restraint, but the explanation is in no way modeled on the kind of explanation that is involved in explaining the truth of empirical propositions i.e. a correspondence between language and features of the world. The conventions we adopt are the ones we find we can use; for example, they may be useful because they are without infinite complexity and they give the simplest descriptions.

This conventionalist account of language generates a specific kind of explanation of the growth of language. At first blush it might seem as if the picture it offers is one of the two antithical explanations: linguistic innovation is either invented or discovered. But this may be too stark a manner in which to put it: if linguistic innovation is a matter of discovery, it seems that we must already have had a idea of how things should be; logical proof would simply be a matter of confirming what is already the case. The trouble with this is that appeal to correspondence with some extra-linguistic reality in order to explain the growth of language will fail in the way any platonic-inspired explanation does. What it appeals to cannot be identified independently of what it is used to explain. However, if we say that language-growth is a matter of invention, we give the impression that growth proceeds unhedged, which of course compromises the objectivity of necessity and the rules of language. Wittgenstein's conventionalism accommodates both potential extremes: it neither makes the mistake of appealing to a reality which is not independently identifiable, nor does it leave the road open to caprice.

Pears" is illuminating in showing a connection between Wittgenstein's Theory of Tautology in the TLP and his conventionalism in his later work on the one hand, and a dominant theme in his account of language - one that is present in both the TLP and his later work - namely, the idea that language grows from the ground-level upwards rather than from the top downwards. Russell is an example of the top-down approach. In the case of Russell the idea is that the growth and development of language proceeds from a set of self-evident axioms that are then used to formulate theorems and generate futther axioms, the self-evident axioms being more primitive than the generated ones. Another example of the top-down explanation is Chomsky. His idea is that we come with a set of ready-made logical structures, which we use to recursively generate other logical propositions and patterns of inference. Wittgenstein's bottom-up approach is more like the theory of evolution. We start with very basic primitive propositions, perhaps, in some cases not even propositions, but primitive expressions of feelings like those of other social animals. Consider: 
It is a help to remember that it is a primitive reaction to tend, to treat, the part that hurts when someone else is in pain; and not merely when oneself is - and so to pay attention to other people's pain-behaviour, as one does not pay attention to one's own pain behaviour.

But what is the word "primitive" meant to say here? Presumably that this sort of behaviour is pre-linguistic: that a language-game is based on it, that it is the prototype of a way of thinking and not the result of thought.

Suppose someone explains how a child learns the use of the word "pain" in the following way: When the child behaves in such-and-such a way on particular occasions, I think he's feeling what I feel in such cases; and if it is so then the child associates the word with his feeling and uses the word when the feeling reappears. What does this explanation explain? Ask yourself: What sort of ignorance does it remove? - Being sure that someone is in pain, doubting whether he is, and so on, are so many natural, instinctive, kinds of behaviour towards other human beings, and our language is merely and auxiliary to, and further extension of, this relation. Our language-game is an extension of primitive behaviour. (For our language-game is behaviour.) (Instinct). ${ }^{12}$

And

......how does a human being learn the meaning of the names of sensations? - of the word "pain" for example. Here is one possibility: words are connected with the primitive, the natural, expressions of the sensation and used in their place. A child has hurt himself and he cries; and then adults talk to him and teach him exclamations and, later, sentences. They teach the child new behaviour.' (PI 244)

Our repertoire expands as a function of our needs, the rewards and obstacles that our environment provides, our natural responses and so on. The pattern of the development of language resembles a spider-web rather than a flow-chart with a hierarchical order. The idea is that language sprawls pretty much in the way a middle-eastern city sprawls as it expands. This piecemeal explanation of the 
development of language is the thinking behind his explanation of language in terms of languagegames in the PI. However, this bottom-up view is already present in the $T L P$, specifically in his account of logical propositions. The story there was that logical propositions can be explained in terms of it being a degenerate complex constituted by simple contingent propositions that are combined in a way that cancels out all sense. This explanation of necessary truths of the propositional calculus in terms of simple propositions combining to form more complex ones seems to be in the same vein as the later idea of the development of language in terms of simple propositions forming the building blocks of more complex ones. That Wittgenstein's treatment of necessary propositions in the TLP is a form of the more fully articulated bottom-up approach to the development of language that we see in his later work seems to be confirmed by his treatment of the views which his TLP account of necessity was meant to replace. The view he was replacing was the idea that language proceeded from a set of selfevident axioms and theorems that formed a calculus; once some of the theorems had been proved, they would provide new rules of inference. The trouble with this view was that it leaves unexplained the adoption of the original axioms and rules of inference. The shortcoming with the explanation of the development of language in terms of axiomatization is explained in the TLP:

Proof in logic is merely a mechanical expedient to facilitate the recognition of tautologies in complicated cases. (TLP 6.1262)

All the propositions of logic are of equal status: it is not the case that some of them are essentially primitive propositions, while others are essentially derived propositions.

Every tautology itself shows that it is a tautology. (TLP 6.127)

There is thus no explanation as to why certain propositions should be treated as primitive axioms from which other propositions are deduced. That 'every tautology itself shows that it is a tautology' indicates not only that logically necessary propositions are independent of each other but also that they are independently recognizable as such.

It is the peculiar mark of logical propositions that one can recognize that they are true from their symbol alone, and this fact contains in itself the whole philosophy of logic. (TLP 6.113) 
I will now examine his later treatment of proof in logic. His account of the role of proof in logic is a conventionalist one and is linked, as has been indicated earlier, to the idea that language grows from ground-level upwards. At first glance the connection seems obvious. We have determined so far that the development of language is not a matter of discovery. That route is a dead-end. We have seen that it is probably more accurate to say that it is a matter of invention, although not capricious invention. This being the case, whatever it is that proof in logic establishes, it would not be that it establishes that a pattern of inference is in fact correct. If we said that it establishes that a pattern of inference is correct we would be assuming that the connections already exist independently of and prior to us and that its correctness has to do with its correspondence with these independently necessary features. But if it does not exist independently of, and prior to us, then logical proof must play a different role. The role of proof in logic in Wittgenstein's conventionalist account is that it confers on a pattern of reasoning a new found status i.e. it becomes a rule of inference, and in this way proof introduces a new rule of inference and expands our repertoire of logical rules. Our repertoire of rules thus grows in a bottom-up fashion. A proposition is proved, and so becomes available to be put on the shelf as a logical rule, or in Wittgenstein's words, becomes available to be put into the archive.

In Remarks on the Foundations of Mathematics I where Wittgenstein talks about the development of mathematical rules he says (with reference to calculation):

164. I learned empirically that this came out this time, that it usually does come out; but does the proposition of mathematics say that? I learnt empirically that this is the road I traveled. But is that the mathematical statement? - What does it say, though? What relation has it to these empirical propositions? The mathematical proposition has the dignity of a rule.

So much is true about saying that mathematics is logic: its movement is within the rules of our language. And this gives it its peculiar solidity, its unassailable position, set apart.

(Mathematics deposited among the standard measures.)

165. What, then - does it just twist and turn about within these rules? - It forms ever new rules it is always building new roads for traffic; by extending the network of the old ones. 
166. But then doesn't it need a sanction for this? Can it extend the network arbitrarily? Well, I could say: a mathematician is always inventing new forms of descriptions. Some, stimulated by practical needs, others, from aesthetic needs, - and yet others in a variety of ways. And here imagine a landscape gardener designing paths for the layout of a garden; it may well be that he draws them on a drawing-board merely as ornamental strips without the slightest thought of someone's sometime walking on them.

167. The mathematician is an inventor, not a discoverer. ${ }^{13}$

Opposed to this is the top-down view, where we start off with basic axioms and rules of inference which are used to prove other axioms and rules of inference, the deduced axioms and rules of inference being ones that exist prior to our proving them and the proof serving as a discovery of what was always the case unbeknownst to us. We have already identified the problems with this: it relies on the idea that there is a language-independent reality which, as it turns out, is not independently identifiable, and it postulates axioms to explain the arrival of other axioms on the scene while failing to explain the origins of the initial axioms and rules of inference. The bottom-up approach seems to avoid these troubles. But it has troubles of its own.

Let's first examine Wittgenstein's account of the role of proof in logic in more detail. Language grow th is obviously not a matter of increasing any factual information. Language growth involves the expansion of our concepts and proof plays the role of expanding the conceptual repertoire of language. In the $T L P$ proof in logic was used to identify tautologies that were not easily recognizable as such. In the $P I$ proof in logic is used to create rather than to identify. The general idea is that when we prove a proposition. we are not just conferring on it a new status, i.e. as a rule of language, but after we have proved it we see the proposition in a new light. The proven proposition contains more information than before it was proved. It has, in a manner of speaking, expanded conceptually. The proof changes the character of the original proposition. In this way proof in logic creates new concepts. It creates a new norm of representation. 
When I said that a proof introduces a new concept, I meant something like: the proof puts a new paradigm among the paradigms of language; like when someone mixes a special reddish-blue, somehow settles the special mixture of the colours and gives it a name.

But even if we are inclined to call a proof such a new paradigm - what is the exact similarity of the proof to such a concept-model?

One would like to say: the proof changes the grammar of our language, changes our concepts. It makes new connexions, and it creates the concept of these connexions. It does not establish that they are there; they do not exist until he makes them. ${ }^{14}$

It seems then that we alter the grammar of the conclusion of a proof in the very process of driving towards the conclusion and in this way we are, in a manner of speaking, inventing new destinations.

In the course of the proof our way of seeing is changed - and it does not detract from this that it is connected with experience.

Our way of seeing is remodeled. ${ }^{15}$

One would like to say: the proof changes the grammar of our language, changes our concepts. It makes new connections, and it creates the concept of these connections. (It does not establish that they are there; they do not exist until it makes them. $)^{16}$

For example, someone who maintains that one can trisect an angle by means of a ruler and compass lacks a proper understanding of the relevant concepts ${ }^{17}$. It is only after grasping the proof of the impossibility of such a construction that a person will understand that the phrase 'the trisection of an angle by means of straight edge and compass' is nonsensical. In this case it is not a matter of a new concept that has been created but rather that a person has, by means of the proof, become conceptually enlightened. His 'way of seeing is remodeled'. It appears that once you understand the logical package, or what is logically packed into a concept, then you see it with new light. Goldstein ${ }^{18}$ suggests that what Wittgenstein may have had in mind can be illuminated by a comparison with Kuhn' ${ }^{19}$ idea of 'revolutionary science' - a conceptual revolution in which the old paradigm is abandoned and a new set of conceptual tools and research methods are adopted. For example, in relativity physics the concepts 
of mass and length are quite different from those in classical physics. In relativity physics, length is not an absolute measure, but depends on the relative velocity of the object being measured and the measuring device. This being the case, Newton would not be able to understand a conjecture in relativity theory before he understood the concepts, and he can only acquire such an understanding by learning the theory. In a similar way, when doing a proof in logic or mathematics, we create new concepts and the proposition proved cannot be understood independently of an understanding of those concepts and that proof. The comparison with Kuhn, as Goldstein warns, should nevertheless not be pushed too far, since Kuhn thought that conceptual revolutions are rare, and that, most of the time, we are doing 'normal science'. For W, however, the normal state of logic and mathematics is revolutionary.

Earlier on we saw another way in which language expands conceptually: an empirical proposition hardens or petrifies into a conceptual one when a bit of empirical information is included in the definition of a phenomenon. The process involved the scientific community agreeing that an empirical proposition that has not faced recalcitrant instances be regarded as a conceptual one: the empirical information becomes part and parcel of the concept of a phenomenon. In the case of proof, innovation in language is achieved not by adopting a new definition, but by unpacking the logical connections that add up to the proposition being proved. Once a proposition is seen in the light of these logical propositions, there is a sense in which the proposition has changed in character. It is like learning new information about a person, information that in a way changes the identity of the person for us. For example, say we come to know A as the husband of so-and-so. Later we come to know B as the local practitioner. But we don't know that $\mathrm{A}$ is $\mathrm{B}$. Later we come to know that $\mathrm{A}$ is $\mathrm{B}$. In this case it is not just that we come to know more information about $\mathrm{A}$, the husband of so-an-so, but that we have established that the person whom we knew under the description of the local practitioner is in fact the husband of so-and-so. We then see $\mathrm{A}$ in a new light after we know the additional information. The analogy is of course of limited value in this case - it serves to illustrate how new information can alter or expand the identity of something - how something can come to be seen in a new light.

Wittgenstein's account of the source of necessity of analytic propositions and logical inferences used in proof using logic (petrifaction) as well as his account of the proof in logic paints a picture of how he saw growth in language. In the case of the adoption of a definition, his view is that what may once have been regarded as a contingent proposition can later be regarded as a necessary one. In the case of proof 
using logic he maintains that the necessary status of the inference from premises to conclusion is an achieved status: we have not always regarded the inference as unassailable. But in the case of proof in logic there is a double whammy: the proven proposition not only has a new status and in this way adds to our store of concepts, but the proven proposition also undergoes a change in character. Once a proposition has been proved we know something different or more about it than before it was proved. It undergoes a change in epistemic character as well as in content. In the case of petrifaction of propositions, the birth of a new concept comes about when a connection between specific contingent properties is forged and treated as necessary. In the case of proof, the birth of a new concept comes about when connections are forged between logical structures. In both cases a contingent proposition is withdrawn from the stock of hypotheses and 'placed under the aegis of stipulation'. 20

The explanation of the growth of language in terms of proof using logic and proof in logic is, however, somewhat paradoxical. The trouble is that we say that we are constructing a proof for proposition $\mathrm{x}$, and when we have in fact established the proof, we have a proof of not proposition $x$, but proposition $\mathrm{x}+\mathrm{n}$ - a new proposition. Thus we set off to provide a proof for $\mathrm{x}$, but we end up having produced a proof for $\mathrm{x}+\mathrm{n}$. The question that arises is: Have we then provided a proof for $x$ ? In Remarks on the Foundations of Mathematics VI.16 Wittgenstein's discussion of a mathematical example shows up this paradox clearly. These comments also apply to proof in logic. He says:

Thus the truth of the proposition, " $4+1=5$ ", is, so to speak, over-determined. Overdetermined by this, that the result of the operation is defined to be the criterion that this operation has been carried out.

The proposition rests on one too many feet to be an empirical proposition. It will be used as a determination of the concept "applying the operation +1 to 4 . For we now have a new way of judging whether someone has followed a rule."

Hence $4+1=5$ is now itself a rule by which we judge proceedings. The rule-grounding proceeding is the proof of the rule. ${ }^{21}$

The point here is that proving a proposition alters its sense.

Now how about this - ought I to say that the same sense can only have one proof? Or that when a proof is found the sense alters? 
Of course some people would oppose this and say: "Then the proof of a proposition cannot ever be found, for, if it has been found, it is no longer the proof of this proposition." But to say this is so far to say nothing at all. ${ }^{22}$

It is clear from this that proof in logic is completely different to the proof of a contingent proposition. In the case of the latter, you prove that something is the case, and the underlying assumption is that there is a fact of the matter. So when you prove that something is the case, you have simply found evidence that things are in fact thus and so - a state of affairs that would have obtained whether or not you ascertained it. With proof in logic, what you have concluded was not the case without the proof. The proof creates, in a manner of speaking, the conclusion. The conclusion did not have an existence before the proof.

Whether or not this account of necessity is adequate depends on whether it meets several criteria. The Platonist account was an attempt to explain the compulsion of logical inference by appealing to external factors that compel us to reason in a certain way. Because these factors were external to, and independent of how we happen to act, it secured the objectivity of logic. Logical inference is not capricious. Any account that withdraws access to such external resources faces the challenge of explaining what secures the objectivity of logic. A conventionalist account faces this challenge square in the face because it appeals to resources that seem, by their very nature, to undermine the requisite objectivity. Wittgenstein's conventionalism has been criticized as falling short of these two criteria. On the one hand the complaint is that his account does not adequately accommodate the compulsion that we feel when drawing a logical inference. Secondly, his explanation is seen as compromising the objectivity of the validity of an inference. The first of these criticisms takes issue with his account of drawing the conclusion of a valid argument from accepted premises.

"But am I not compelled, then, to go the way I do in a chain of inferences?" Compelled? After all, I can presumably do as I choose! - But if you want to remain in accord with the rules, you must go this way"

Not at all, I call this accord. - "Then you have changed the meaning of the word 'accord' or the meaning of the rule". - No. Who says what "change" and "meaning the same" mean here? 
However many rules you give me, I give a rule which justifies my employment of your rules. ${ }^{23}$

What seems to arrest commentators is Wittgenstein's remark that one is not compelled to reason in a particular way, and that one can go on as one chooses. The worry is understandable. Moving from a set of premises to a conclusion in a valid argument seems like something that should not be up to us. It seems that there should be reasons that take control of us - which give us no choice. We should not be able to 'do as we choose'. But the worry may start to be alleviated if we backtrack a bit. In the earlier discussion on linguistic regularity in P/ 201 the point was made that no course of action could be determined by a rule because every course of action could be made out to accord with the rule. What this was supposed to show is that there is a way of following a rule that is not an interpretation, but can only be described in terms of behaviour such as going with or against the rule. The historical context of this discussion is the Vienna circle's preoccupation with definitions as the full explanation of the meaning of a word. Wittgenstein's remarks are meant to show that any verbal explanation of a word would always leave its meaning hanging in the air - the words in the definition of an explanation could ahways be taken in different ways, ad infinitum. The gap between language and the world would only be bridged in the application of a word. So the focus is taken away from something outside our behaviour and placed squarely on us and our linguistic practices. Whatever 'must' there is in the application of a word comes from our practices. Hence Wittgenstein distaste for the term 'compelied' must be read as a criticism of the idea that anything external to and independent of us compels our linguistic practices. Man is the measure of all things. The discussion on the notion of technique in the application of general words to things is meant to clarify the sense in which man is the measure of all things. But it may not be suitable as part of a defense of his account of logical necessity. In the case of the application of general words to things, the problem was that we needed an explanation of what guides or determines the way a series is supposed to be continued, where past applications would not completely determine how the series should be continued. The notion of technique is meant to explain how we use language to get a grip on the world. In the case of necessity, the problem is not one of the relation between language and the world, but the relation between two techniques, where the relation between language and the world in the two cases has already been established. With reference to the text quoted above, where Wittgenstein makes the astonishing remark that in logical inference one can always justify an alternative way of proceeding, he says: 
It is true that anything can be justified. ${ }^{24}$

A bit later remarks:

But the phenomenon of language is based on agreement in action. ${ }^{25}$

And then he says:

We say that, in order to communicate, people must agree with one another about the meanings of words. But the criterion of this agreement is not just agreement with reference to definition - e.g. ostensive definitions - but also agreement in judgments. It is essential for communication that we agree in a large number of judgments. ${ }^{26}$

And:

If language is to be a means of communication, there must be agreement not only in definitions, but also (queer as this may sound) in judgments. This seems to abolish logic, but does not do so. - It is one thing to describe methods of measurement, and another to obtain and state results of measurement. But what we call measuring is partly determined by a certain constancy in results of measurements. (PI 242)

These two paragraphs clearly indicate a peculiar feature of Wittgenstein's position. It appears that his conventionalism is characterized by two aspects. "It is true that anything can be justified" marks a voluntarism aspect: "The phenomenon of language is based on agreement in action" marks his conventionalism. Failure to recognize that his conventionalism is characterized by these two phases will produce a caricatured version of his account. For instance, Dummett, in his Wittgenstein's Philosophy of Mathematics" ${ }^{27}$ represents Wittgenstein as what he calls a 'full-blooded conventionalist'. According to full-blooded conventionalism all necessary propositions are the direct expressions of linguistic conventions. The necessity of a particular statement derives from our having expressly decided to treat that statement as unassailable. Contrasted with this is moderate conventionalism according to which all necessary truths derive either immediately or remotely from linguistic stipulations or conventions. Dummett finds this full-blooded conventionalism that he ascribes to 
Wittgenstein unacceptable. He argues that if, given the axioms and rules of inference in a proof in logic. we could still have an option in the conclusion we draw, our adoption of necessary propositions would be entirely capricious. Dummett's point is that the axioms and rules of inference should determine, entirely independently of us, what conclusion must be drawn. It is at this point that it helps to see that Wittgenstein's conventionalism has two phases. The voluntarism aspect seems to be directed at a specific audience i.e. realists. In this phase, where Wittgenstein suggests that we have an option in the conclusion we draw (both in proof using logic and proof in logic), the idea is to shock the reader into recognizing that realism is not an option. When he says that we have an option in the conclusion we draw, he means to reject the idea that there is an independent set of necessities which takes us by the throat, as it were, and forces us along a particular path. In adjudicating between the different interpretations of Wittgenstein's account, it is always important to bear in mind why Wittgenstein rejected realism. The shortcoming of realism was that it was not a genuine explanation. It promises an explanation, but then does not deliver any goods at all. What it appeals to as an explanation is not independently identifiable. However, just because the features appealed to in this case is not independently identifiable, it does not mean that we cannot identify any features that can explain necessity. What we need is an account that preserves the objectivity of logic and so does not make logic a matter of caprice, but which does not appeal to factors that are not independently identifiable. It cannot be a theory which posits a correspondence with something independently necessary, so another kind of story altogether must be told. Dummett does not emphasize the reason Wittgenstein is discontent with realism and so takes Wittgenstein as allergic to the idea that any features can determine, completely or incompletely, what we hold as necessary. He thus looks right past phase two of Wittgenstein's conventionalism, where Wittgenstein discusses the ingredients of an account which acknowledges necessity and attempts to explain it in terms of contingent independently identifiable factors.

The point was made earlier that Wittgenstein's conventionalism is characterized by the fact that people agree in their applications of words to things. However, the criterion of this agreement - the way we ascertain that people are applying words in the same way as others do, is that the community share a whole lot of other agreements in judgments. For two people may overtly be doing 'the same thing', but the criterion for whether their application counts as the same must be sought further out - whether they share other judgments. In the terminology of the $P I$, they must share a form of life. 
240. Disputes do not break out (among mathematicians, say) over the question whether a rule has been obeyed or not. People don't come to blows over it, for example. That is part of the framework on which the working of our language is based (for example, in giving descriptions).

241. "So you are saying that human agreement decides what is true and what is false?" - It is what human beings say that is true or false; and they agree in the language that they use. That is not agreement is opinions but in form of life.

(PI 240-1)

There is no caprice in what we actually do, since what we actually do is a function of various other factors which govern our behaviour - facts about our natural dispositions (that we look in the direction of an arrow and not the other way, for example), our need for communication which brings about a homogeneity in the way we use words, the constraints of our environment (that objects do not appear and disappear randomly, for instance), our desire for descriptions that are simple, coherent, and can be used without infinite complexity. The requirement for objectivity is so as to preserve the distinction between what we happen to do or choose to do, and what we have to do. Wittgenstein's conventionalism is an attempt at providing an account that accommodates this. It is an account that does not appeal to transcendental factors that are not investigation-independent; it appeals to facts in the world. but does not model a theory of correspondence of the form appealed to in some theories of truth. Rather, it appeals to facts, and so leaves the field open to a scientific explanation. These remarks seem only to bear on the application of words to things. Our concern here is the problem of connecting two applications. What determines that two concepts are related in a way such that given the one another particular concept should follow? For example, given (if $p$ then $q$ ) and (if $q$ then $r$ ), one should conclude that $\mathrm{p}$ implies r. Or modus tollens: given that $\mathrm{p}$ implies $\mathrm{q}$ and that $\mathrm{q}$ is not the case, we should conclude that $p$ is not the case. Wittgenstein's discussion of mathematics raises an analogous situation to the one of logical inference and can be helpful in understanding the sought-after ingredient. He asks:

Could there be mathematics without agreement on the part of calculators?

Could there be only one human being who calculated?

Could there be only one who followed a rule?

Are these questions, say, like this one:

"Can one man alone engage in commerce?" 
Performing mathematical inferences requires that people agree in the judgments as to what counts as a correct inference. The rest of the questions that follow in the above passage indicate the direction of the point Wittgenstein is trying to make - namely, that mathematical inferences require agreement on the part of calculators. Both in the case of logical inference and the application of general words to things, in so far as they are used as tools for communication, there has to be agreement between languageusers as to the extension of a general word and, in the case of logical inference, as to which inferences becomes part of the stock of our conceptual apparatus.

If Wittgenstein's conventionalism is plausible, then it opens the way to the plausibility of alternative systems of thought. It has been complained that Wittgenstein's examples of such alternative systems are thin and unconvincing, and that this casts some doubt on the reasonableness of his views. We saw that Michael Dummett ${ }^{28}$ accused Wittgenstein of what he called 'full-blooded' conventionalism. Dummett's complaint is that Wittgenstein says of the conclusion of an argument that one is free to accept or reject the conclusion, the implication being that there is nothing in the formulation of the axioms and rules of inference and nothing in our minds at the time when we accepted these axioms and rules which beforehand shows whether we would accept the proof or not, and that this shows that there is nothing which forces us to accept the conclusion. It is only our acceptance of the conclusion that confers necessity on the theorem thus proved. Conferring necessity involves our 'putting the proposition in the archives' and counting nothing as recalcitrant to it. So doing, we make a new decision, and are not merely making explicit the implication of what was implicitly acknowledged or acquiesced to in the body of the argument. In this full-blooded conventionalism, Dummett maintains, we make up our minds about the conclusion quite independently of anything in the body of the argument - the axioms and rules of inference. Nothing forces us - we are making a decision capriciously. In the discussions above it has been argued that our coming to accept a principle of inference or a logical proposition is not capricious. There are many contingent facts that lead to a pattern of inference or a proposition's being accepted as inexorable. That Wittgenstein maintains that we are free to accept or reject the conclusion of a proof is a reaction against the realist idea that there is some external force that 'force-guides' us from premises to conclusion. But, just because Wittgenstein's reacts against this it does not imply that we draw conclusions capriciously. All this has been discussed above. Dummett goes on to complain that we cannot conceive of a situation where someone accepts the axioms and rules of inference, and yet rejects the proof, although they have 
understood the rules of inference and the axioms. He says because Wittgenstein's examples are thin and unconvincing it underscores his complaint that something is wrong with Wittgenstein's account. We cannot, according to Dummett, come up with cases that count as an alternative logic to ours own. Barry Stroud ${ }^{29}$ thinks that Dummett's worries about an alternative logic can be alleviated by recognizing the following: Wittgenstein maintains that it is essential to inferring, calculating, counting and so on, that not just any result would be allowed as correct. If people inferred any way they liked (or continued the series any which way), then "we shan't call it 'continuing the series' and also presumably not inference'., 30 So, although there is no external influence forcing us in a particular way ('Presumably I can go whichever way I like'), there is an internal influence - general agreement amongst people as to the correct results of calculations or inferences as well as a general agreement in the results of one's own calculations at different times are imperative for there to be such a thing as calculating or inferring at all. ${ }^{31}$ A calculation is thus different to an experiment, where with experiments one can, at different times and places, obtain different results. In the case of logical inference, Wittgenstein says:

The steps which are not brought in question are logical inferences. But the reason why they are not brought in question is not that they "certainly correspond to the truth" - or something of the sort - no, it is just this that is called "thinking," "speaking," "inferring," "arguing". 32

The passage above may suggest that Wittgenstein is making the standard claim that the source of all necessity lies in definitions or the meaning of words - i.e. standard conventionalism. This, Stroud argues, is not Wittgenstein's position. Stroud explores what, according to $\mathrm{W}$, the source of necessity is by examining why it is impossible to come up with and truly understand a putative alternative logical system. Wittgenstein's examples of the deviant student ${ }^{33}$ or the woodcutters who sell wood in a way different to us $^{3+}$ initially seem intelligible, but this is only so because they are examples that are severely isolated or restricted. We think we are able to understand them and we think they present genuine albeit unsophisticated and uncomplicated alternatives only because the further-reaching consequences of calculating, counting and so on in these deviant ways have not been explicitly brought out. The attempt to put oneself in the shoes of one of these deviant people and get a clearer understanding of what it would be like to be one of them would inevitably involve the progressive abandoning of our own familiar world and our patterns of thinking. The implication of this is that the 
more we successfully manage to situate ourselves in the world of these deviant people, the less ground we have left for finding them intelligible. In other words, we cannot both be one of them and find them intelligible, since our finding them intelligible rests ultimately on our being one of us. We cannot be one of them and still find them intelligible on our own terms, or by our own lights. However, this does not mean that we do not understand them because they are contradictory or meaningless, or because their putative behaviour is logically impossible. So despite suggestions that Wittgenstein is endorsing a standard conventionalism which entails that certain activities count as calculating or measuring as a matter of definition (it is just this that is called "thinking," speaking," "inferring," "arguing") involves considerations broader than just the alternative (or deviant) activities he describes. The necessity does not derive from the fact that we just call so and so such and such (stipulations or definitions), but from the fact that we all happen to go on in a certain way (obtain the same results). It s not that we agree on definitions but that there is a consensus of action - we all happen to, given the same training, go on in the same way. And the way we happen to go on is part of a larger picture of other activities that we happen to engage in. Any one kind of activity has its home in the web of other activities and beliefs - it is woven into these other practices and beliefs that are peculiar to us. Thus the consideration of an alternative practice involves the consideration of practices and beliefs which form the setting in which the activity under consideration is a part. One cannot understand isolated extreme eccentricities. Stroud argues that what all this can be taken to show is that since we can acknowledge the contingency of our practices, we can acknowledge that there can be different ways of calculating, measuring. inferring and so on, although we may not be able to understand what these alternative ways of thinking may have been or what they amount or come to. Our particular activities are embedded in a wider form of life, and, as Pears ${ }^{3 / 6}$ says, it would be asking too much to expect Wittgenstein to construct systems of thought which are as complete and useful as our inherited system which has evolved over time. Note though that Stroud's point is stronger than the one Pears makes. Both would acknowledge that any particular practice is embedded in a larger web which has a history, but all Pears is saying is that we cannot expect Wittgenstein to situate his examples of alternative practices in a web as complete and articulated as ours - such a web is massive and has evolved over time. Stroud's point, however, is that the more we are able to buy into this alternative system - the more we are able to become natives in this system - the less we are able to, by our own standards, regard alternative systems as intelligible. We would then be more of 'them' and less of 'us'. Understanding is about belonging to a system. But perhaps Stroud is being too extreme here. It certainly seems the case that practices make sense in the context of other practices and beliefs, but it does not mean that we have to become one of them, or give 
up being one of us, in order to understand practices alternative to our own. Ancient Greek represents a mindset radically different to our own, but we are able, with some effort, to study and understand them. It does not require that we give up modern civilization. That Wittgenstein's examples are thin, then, may not be, as Stroud suggests, because we cannot intelligibly set up alternative systems to our own, but may be simply that, as Pears suggests, a hugely elaborate task, one that could be embarked upon, but perhaps in another project. Thomas Kuhn's discussions of different scientific paradigms seem to indicate that we can entertain different systems of scientific thought (albeit not, according to Kuhn, a matter of rationality that we move from the one to the other); however, these different systems of scientific thought do not seem to be accompanied by far-reaching alterations in general thinking. The altemative geometries (for example, the Riemannian geometry developed in response to the descriptions of the world derived from Einstein's theory of relativity) is another such example. Nevertheless, we have not yet come up with alternative logics (a system where the principle of the excluded middle, or the principle of non-contradiction does not hold, for example) and it is not clear that we could come up with such alternatives. Perhaps Wittgenstein should have the last word on this:

Then according to you everybody could continue the series as he likes; and so infer anyhow! In that case we shan't call it "continuing the series" and presumably not "inference". And thinking and inferring (like counting) is, of course, bounded for us, not by an arbitrary definition, but by the natural limits corresponding to the body of what can be called the role of thinking in our lives.

For we are at one over this, that the laws of inference do not compel him to say or to write such and such like rails compelling a locomotive. And if you say that, while he may indeed say it, still he can't think it, then I am only saying that that means, not; try as he may he can't think it, but: it is for us an essential part of thinking that - in talking, writing, etc. - he makes this sort of transition. And I say further that the line between what we include in 'thinking' is no more a hard and fast one than the line between what is still and what is no longer called "regularity". ${ }^{37}$ 
'Hitgenstein s Lectures, Cambridge 1930-1932, p 57.

- Philosophical Grammar. R.Rhees (ed.) and A. Kenny (trans.), 1974, 133.

Zethel.G.E.M. Anscombe and G.E. ron Wright (eds.) G.E.M. Anscombe (trans.), 1981 (1976), 354-64.

+ Philosopinical Grammar. R. Rhees (ed.) and A. Kenny (trans.), 1974, 68.

"Pears. D.F.. The False Prison: A Study of the Development of Wittgenstein's Philosophy; vol. I, 1987.

"Philosophical Grammar. R. Rhees (ed.) and A. Kenny (trans.), 1974, 68.

Cambridge Lectures $1, \mathrm{p} 49$.

"On Certaintr. G.E.M. Anscombe and G.H. von Wright (eds.) D. Paul and G.E.M. Anscombe (trans.), 1969, 96-98.

"Compare Quine's holism and his explanation of analytic truth. He maintains that a necessary truth is one for which there has been the least recalcitrant evidence, and therefore one that is least germane to empirical facts. The difference between an analytic and contingent truth is then a matter of degree - with the analytic truth situated on the inner periphery of (the propositions) of language.

"Rematks on the Foundations of Mathematics, G.H. von Wright and G.E.M. Anscombe (eds), G.E.M. Anscombe (trans.) (revised edition), 1978, (1956), V1 22.

Pears, D.F., Paradox and Platitude in Wittgenstein's Philosophy (unpublished)

Zettel. G.E.M. Anscombe and G.E. von Wright (eds.) G.E.M. Anscombe (trans.), 1981 (1976), 540-41, 545.

"Remarks on the Foundations of Mathematics. G.H. von Wright and G.E.M. Anscombe (eds), G.E.M. Anscombe (trans.) (revised edition). 1978, (1956). 1 164-67.

${ }^{+}$Remaths on the Foundations of Mathematics, G.H. von Wright and G.E.M. Anscombe (eds), G.E.M. Anscombe (trans.) (revised edition), 1978, (1956), II 31.

is ihid.. III 30 .

"itrid.. III 31

ibid., III, 30

" Goldstein. L.. Clear and Queer Thinking, 1999

"Kuhn, T.. Scientific Rerolutions. 1970.

"Remarks on the Foundations of Mathematics, G.H. von Wright and G.E.M. Anscombe (eds), G.E.M. Anscombe (trans.) (revised edition), 1978, (1956), 1, 120.

ihid. VI 16.

ibid.. VII 10

ibid.. 1113 .

ibid.. 1113.

ibid.. VI 39

2t) ibid.

¿- Dummett. M. Wittgenstein 's Philosophy of Mathematics, in Pitcher, G. (ed.) Wittgenstein. The Philosophical Investigations, 1968.

$\therefore$ Dummett, M.,Wittgenstein's Philosophy of Mathematics, in Pitcher, G. (ed.), Wittgenstein. The Philosophical lmiestigations, 1970. Macmillan, London.

I" Stroud, B., Witgenstein and Logical Necessity, in Pitcher, G. (ed.), Wittgenstein. The Philosophical Investigations, 1970. Macmilian. London.

"Remarks on the Foundations of Mathematics, G.H. von Wright and G.E.M. Anscombe (eds), G.E.M. Anscombe (trans.) (revised edition). 1978, (1956), 1116.

ibid., II 66, 73 .

$\therefore$ ibid. I 155 .

ibid.. I 113.PI 185

ithid., I 149.

ibid.. I 155 .

"Pears, D.F., Paradox and Platitude in Wittgenstein's Philosophy (unpublished).

lhid. 1116 


\section{Chapter 6: Philosophical Method in the $P I$}

In the TLP Wittgenstein had offered a theory of propositional meaning, a project which, no doubt captivating, went quite against the de jure account of the role and method of philosophical discourse advocated in that book. In the TLP he advocated that the aim of philosophy is the logical clarification of thoughts and that philosophy is not a body of doctrine but an activity that does not result in philosophical propositions but rather in the clarification of propositions. He goes on to say that the job of philosophy is to set limits to what can be thought and hence to settle controversies about the limits of natural science. (TLP 4.112-5). However, despite his admonishing remarks about philosophy that were directed against the tradition of philosophy followed by his contemporaries and predecessors, the TLP still forms part of the metaphysical tradition Wittgenstein wanted to distance himself from. Throughout his philosophical career, however, he remained wedded to the idea that the problems of philosophy are not bona fide problems, but result from misunderstanding of the logic of our language. They are really misuses of language in the guise of factual discourse. The way to approach these problems according to this view is not to take them at face-value but to expose them for what they are and so do away with them. This is achieved by equipping ourselves with the logic of language so we can clearly see that they do not constitute legitimate uses of language. The TLP maintained that this logic of language was something that lay beneath the surface structure of everyday language and had to be excavated by logical analysis. Wittgenstein's task was to lay bare the essential structure of language. He tackled the matter by producing an account of the essential function of language (the Picture Theory), and the essential structure of language (atomism and the truth-functional account of language). From this he presented us with the most general form of the proposition - a form that is common to, and underlies all diverse factual expression. Armed with this we are in position to perform a litmus test on any proposition - we can test whether it does or does not, on analysis, bear the structural hallmark of a legitimate proposition. We are now in a position to, Wittgenstein would have us believe, separate the wheat from the fodder. By the time he wrote the $P I$ he had of course abandoned nearly everything which belonged to the former picture of language - the idea that the world had an essential structure which language reflected, that propositions ultimately describe the world, that both language and the world are atomistically structured, that the end-product of analyses are simple names which designate simple objects. However significant these realizations were, they do not represent the watershed change in Wittgenstein's approach to doing philosophy. The characteristic feature he believed the PI displayed is that it did not attempt a theory of language (or theories of any kind, for that matter). The failure of 
the particular theory of language in the TLP was not replaced with another go at a theory in the $P I$. The conviction behind this, which incidentally is a conviction maintained in the TLP as well, is that a theory of language is not possible because we can only give an account of language from the inside - outside there is nothing, outside you cannot breathe. This is a captivating metaphor - presenting an idea similar to the idea of the all-pervasiveness of space. Everything happens in space - there is nothing outside space - there can be no talk of 'outside' space. In a letter written to the newspaper editor of the Times at the time Einstein's theory of the curvature of space had been publicised, the reader asked: 'curved in what?' This is a revealing question, showing how difficult it is to grasp the idea that there can be no talk of 'outside space'. In the later work Wittgenstein presents an argument that is really the meat of the metaphor: We have no independent access to the putative external items that the realist solicits as validation for the meaningfulness of our language. This is not due to an epistemic handicap on our part; the point is a logical one. Any theory which appeals to language-independent items is an empty one we cannot refer to such putative items except by using the very language that the theory is meant to explain. We have no independent standpoint from which to refer to these alleged language-independent items. The motivation behind such quasi-explanations is the desire to model philosophical explanations on scientific explanations. However, in typical scientific explanations the explanation can be identified independently of what is to be explained, unlike with philosophical explanations. If we cannot explain the meaningfulness of language in this way, what is left for us to do? Wittgenstein advises that we must do away with all explanation and description alone must take its place.

It was true to say that our considerations could not be scientific ones. It was not of any possible interest to us to find out empirically 'that contrary to our preconceived ideas, it is possible to think such-and such' - whatever that may mean. (The conception of thought as a gaseous medium.) And we may not advance any kind of theory. There must not be anything hypothetical in our considerations. We must do away with all explanation, and description alone must take its place. And this description gets its light, that is to say its purpose, from the philosophical problems. These are of course not empirical problems; they are solved rather, by looking into the workings of our language, and that in such a way as to make us recognise those workings: in despite of an urge to misunderstand them. The problems are solved, not by reporting new experience, but by arranging what we have always known. Philosophy is a battle against the bewitchment of our intelligence by means of our language. (PI 109) 
The obvious question to raise here is: what kind of philosophical contribution would descriptions make, or rather, what do descriptions have to do with his project of drawing the limits of language? In the earlier work he claimed that underneath the diversity of language there is a single unifying structure its essence. He later realised that this idea was simply a preconception about language. He repudiated this view in the $T L P$ calling it a preconceived requirement, rather than the result of actually examining language, a requirement that distorted the form his earlier project took.

We see that what we call "sentence" and "language" has not the formal unity that I imagined, but is the family of structures more or less related to one another. - But what becomes of logic now? Its rigour seems to be giving way here. - But in that case doesn't logic altogether disappear? - For how can it lose its rigour? Of course not by our bargaining any of its rigour out of it. - The preconceived idea of crystalline purity can only be removed by turning our whole examination around. (One might say: the axis of reference of our examination must be rotated, but about the fixed point of our real need.)

The philosophy of logic speaks of sentences and words in exactly the sense in which we speak of them in ordinary life when we say e.g. 'Here is a Chinese sentence", or "No, that only looks like writing: it is actually just an ornament" and so on.

We are talking about the spatial and temporal phenomenon of language, not about some non-spatial, non-temporal chimera [Note in margin: Only it is possible to be interested in a phenomenon in a variety of ways]. But we talk about it as we do about the pieces in chess when we are stating the rules of the game, not describing their physical properties.

The question "What is a word really? Is analogous to "What is a piece in chess? (P) 108)

In the first part of PI 108 Wittgenstein challenges the idea that he held in the TLP - that the (unassailable) character of logic is only preserved by its possessing a 'crystalline purity' - a timeless independent and definite structure that is located in some platonic hinterland. The $P I$ claims that this hinterland is an empty vista, and that it is a futile exercise to look in this direction. We must instead 
turn our attention to the other direction - inwards - and look at our actual practices. We must rotate our axis of reference around the fixed point of our real need. By looking at our actual practices we will see the grammar of our language. It was not just a mistake to assume that logic has a crystalline purity (a preconceived idea), it was also a mistake to assume that what we are examining is something nonspatial and non-temporal (a chimera). The real subject matter of our examination is language-in-use. The TLP maintained that the meaning of a word was the object it picked out, objects have an independent logical form, and once a name is correlated with an object, it picks up its logical form, and this then determines the way a name can be combined - the logical form of the object determines the meaning of the name. The new idea is that asking for the meaning of a word is asking for the use we make of that word. "The meaning of a word is its use in the language." (PI 43) and "The question "What is a word really" is analogous to "What is a piece in chess?"

Rather than regarding the diverse forms of language as superficial differences united at a lower level by a common structure, he now came to see them as manifestations of the bona fide diversity within language. The diverse forms of proposition did not hide or camouflage something else underneath. The diversity we see is what is in fact the case - language has diverse uses. In the Blue Book he pins the source of this preconception down to the TLP's 'misguided craving for generality' which generated a 'contemptuous attitude toward the particular.' But doing away with this craving for generality and respecting the particular case in its own right did not mean that Wittgenstein was now no longer concerned with the essence of language. In the $T L P$ he had thought of language as an independent mechanism the basic rules of which are already written into it, so to speak, and which only required that we feed the mechanism with particulars and the mechanism churns out the result. In the PI he came to see language as the product of human activity. This is reflected in the way he talks about his subject of investigation in the $P I$. In the $T L P$ he was absorbed with the issue of the structure and function of the proposition, in the $P I$ he asks questions or makes statements about whether particular activities count as language (or. in the terminology in the $P I$ ) as 'following a rule', for example, he talks of 'regular connection between what people say and their actions', he says understanding a language involves mastering a technique, and that grasping a rule is exhibited in obeying the rule or going against it in actual cases', obeying a rule is a practice, and he asks whether obeying a rule is something of which we can say that its possible for only one man to do and to do only once in his life. 
He introduces new technical terms to talk about language. He articulates the notions of 'language' and 'proposition' in terms of 'language-games'. He first uses the notion of a game and then later the notion of family-resemblance to illustrate that language does not have an essence in the Tractarian sense, but that it is unified in a much loser way: first, he compares linguistic activities to a game. The point here is that just as games do not have a single common feature running through all of them in virtue of which they count as instantiations of the concept 'game', so too with language. Different games are related to each other by a complex network of similarities (such as being goal-oriented etc.) that overlap and intersect each other, in much the same way in which members of a family resemble each other in a variety of different ways. With regard to language one cannot put forward an analytic definition specifying the necessary and sufficient conditions for an expression to count as an instantiation of language, but you can point out how different expressions are related to each other and how these groups of related expressions are in turn related to other groups of related expressions. In PI 65 Wittgenstein's interlocutor complains that although Wittgenstein has much to say about languagegames, he has failed to state precisely what a language-game is and has therefore failed to say what the essence of language is. Wittgenstein retorts by acknowledging this complaint, but rejects the request for the essence of language on the grounds that language has no essence understood in the way the interlocutor asks for. In other words his acceptance of the interlocutor's charge is really a rejection of the interlocutor's underlying 'craving for generality'.

It might be argued that the $P I$ 's notion of language-games plays pretty much the same logical role as the conceptualised notion of language in the TLP i.e. according to the TLP language is constituted by simple names arranged in logical form; the $P I$ also imposes a conceptual structure on language by conceiving of language as a system of overlapping language-games. One way of responding to this is that the PI's talk of language-games is not meant to be understood as an a priori necessary structure of language, but as a convenient working model of language which derives from observing language-inuse, so to speak. It's a way of talking about language that accords better with and affords a 'clear view of the aim and functioning of ...words' ${ }^{2}$. In his discussion about the way in which games can be characterised Wittgenstein says:

And the result of this examination is: we see a complicated network of similarities overlapping and criss-crossing: sometimes overall similarities, sometimes similarities of detail. I can think of no better expression to characterise these similarities than "family 
resemblances"; for the various resemblances between members of a family: build, features, colour of eyes, gait, temperament, etc., etc. overlap and criss-cross in the same way. - And I shall say: 'games' form a family..... (PI66-67).

And:

Our clear and simple-language-games are not preparatory studies for a future regimentation of language - as it were first approximations, ignoring friction and airresistance. The language-games are rather set up as objects of comparison which are meant to throw light on the facts of our language by way not only of similarities, but also of dissimilarities.

For we can avoid ineptness or emptiness in our assertions only by presenting the model as what it is, as an object of comparison - as, so to speak, a measuring-rod; not as preconceived idea to which reality must correspond.

(The dogmatism into which we fall so easily in doing philosophy.) (PI 129-130)

The slogan which has come to characterise the philosophy of the later work: 'meaning is use' can give the impression that Wittgenstein has produced a new account of meaning specifying that the meanings of words consists in its use and that there is therefore something sacrosanct about the notion of 'use'. However, the new locutions of 'language-games' 'use', 'family-resemblance' do not constitute a systematic 'use theory of meaning'. Wittgenstein employs the notion of 'use' in an intentionally broad way since the uses of expressions are as disparate and various as the language-games in which they occur. Therefore no single formula can capture their variety. And he does not only confine himself to the word 'use'. He also talks of functions of words and sentences (PI 11, 17, 274, 556, 559), the aims and purposes of words and sentences (PI 5,6,8.348) and of their roles and employments (PI 66). These different locutions are meant to capture the general notion of the part an expression plays in language. Mastery of a language then consists in being able to employ expressions in the many different language-games in which they belong.

The numerous dialectical discussions on the use of various expressions in language, and the interconnections between these expressions can make it hard to see (i) how these descriptions 
are tied up with his project of drawing the limits of language, and (ii) what these descriptions have to do with the classical problems of philosophy. These questions can be answered simultaneously. In the both the TLP and the PI Wittgenstein claims, and quite rightly so, it seems, that language has a surface structure and a grammatical structure. In the TLP this grammatical structure was camouflaged and had to be excavated, in the $P I$ he says that the grammatical structure can be obtained by commanding a clear view, a surview, of the uses of language and the interconnections between (segments of) language. As Hacker puts it: the TLP sought to achieve a correct logical point of view by 'geological means', Wittgenstein's later philosophy seeks a correct logical point of view by 'topographical means'.

Consider the geography of a country for which we have no map, or else a map in tiny bits. The difficulty about this is the difficulty with philosophy; there is no synoptic view. Here the country we talk about is language and the geography grammar. We can walk about a country quite well but when forced to make a map we go wrong. ${ }^{4}$

The heir to the TLP's notion of 'the correct logical point of view' of language is this idea of a 'surview' of language. The surview consists of all the applications, logical connections, illustrations, and conceptions of a segment of language. The main source of misunderstandings characteristic of philosophy is the difficulty in surveying our use of language:

A main source of the failure to understand is that we do not command a clear view of the uses of our words. - Our grammar is lacking in this sort of perspicuity. A perspicuous understanding produces just that understanding which consists in 'seeing connexions'. Hence the importance of finding and inventing intermediate cases.

The concept of a perspicuous representation is of fundamental significance for us. It earmarks the form of account we give, the way we look at things. (Is this a 'Weltanschauung'?)(P/ 122)

This perspicuous representation of language is a kind of synopsis, or can perhaps be describes as a bird"s-eye view of the interconnections of the rules for the use of expressions. Once these reticulations 
are perspicuous, we have a clear understanding of the limits of sense and are in a position to see when the rules for the use of expressions have been violated. To say that we do not have a surview of language is not to say that we do not how to use language. As competent speakers there is a straightforward sense in which we know the rules for the use of our language. We can often correct both our own and the mistakes of others, and can explain the rules which we follow in our use of expressions. What we lack, however, is the view of the logical interconnections between different segments of our language. For example, we may know how to use verbs of perception and verbs of sensation (and their corresponding nouns), yet we may be unaware of the different ways in which they are used. We can thus be mislead to accept talk of 'visual sensations' that are supposedly caused by objects that we see, or that sensations are just 'the firing of c-fibres' in our brain. We may know how to use number-words, yet we may take at face-value the claim of the philosopher of mathematics that number-words are the names of numbers and that numbers are objects, for example. Although we are able to talk perfectly well of tables and chairs (and treat them as objects), and we are quite able to use numerals and apply arithmetical techniques, we are quite unaware of the differences in the way we talk of chairs, on the one hand, and the way we talk of numbers. So, for example, we may be gulled into talking about numbers in the way we talk about chairs: chairs exist just as numbers exist, and so we can ask questions about (the existence of) numbers in the same way that we can ask questions about the existence of chairs. Another example: we can talk perfectly well about mental states such as patience or determination, and we can talk equally well about marbles and stones. Yet we may not be aware that the way we talk about them is quite different. We can lend marbles, sell them, diminish or increase our supplies etc. We can clearly not speak of mental states in the same way. However, because we lack a perspicuous representation of the interconnections and differences between these different kinds of uses. we can be taken in by the philosopher's talk of 'whether I can have access to your pains', for example, or where your pain was before you had it.

Wittgenstein talks about this susceptibility to linguistic confusions in terms of an 'urge', on our part, to misunderstand language, in The Blue Book as a 'craving' for generality. He also uses pathological terms such as philosophy being a 'disease of the intellect', something we are inflicted with, and language having 'bewitched' us.

A main cause of philosophical disease - an unbalanced diet...(PI 593) 
The philosopher's treatment of a question is like the treatment of an illness. (PI 255).

Philosophy is a battle against the bewitchment of our intelligence by means of our language. (PI 109)

Bewitchment is a very strong term. It suggests not merely that the philosopher is on the wrong track (as man who mistakenly walks North to go from Oxford to London), but that we are unreasonably or irrationally convinced that we are on the right path. Given this drastic diagnosis, equally drastic measures to undo this are called for. We cannot simply tap the misled person on the shoulder and inform him that he has made a mistake and then re-direct him. The cure for this disease of the intellect is. according to W, via a kind of psychotherapy. The philosopher-as-psychoanalyst has the task of bringing latent or suppressed nonsense (linguistic confusions mistaken for metaphysical problems) into the clear light of day.

My aim is: to teach you to pass from a piece of disguised nonsense to something that is patent nonsense. (PI 464)

In ordinary psychotherapy it is usually the patient himself who recognises that he has some sort of problem and needs help - failing which the whole therapy may not take place. Typically, however, the philosopher does not think that there is a problem with him, but that he is dealing with something that is, by its very nature, profound and seemingly intractable. In Wittgenstein's own case it is very likely that that he thought he needed help. Philosophical problems genuinely tormented him, and he sought a solution that would give him peace. It is hard not to take the following paragraph as an unselfconscious auto-biographical note.

The real discovery is the one that makes me capable of stopping doing philosophy when I want to. - The one that gives philosophy peace, so that it is no longer tormented by questions which bring itself in question..... There is not a philosophical method, though there are indeed methods, like different therapies. (PI 133)

This not to suggest that Wittgenstein advocated the psychoanalytic method because he may, at some level. have felt he needed it. What may be reasonable to assume though is that his own philosophical 
(and perhaps other) turmoils made the metaphor of psychoanalysis all the more attractive to him. While philosophers typically seek an answer to philosophical conundrums, Wittgenstein wanted to be healed. However, given what Wittgenstein thought what was wrong with philosophy, the psychoanalytic method, quite independently of Wittgenstein's own experience of philosophical problems, is illuminating. The philosopher-as-analyst has to, together with the patient, try to understand the exact contours of the conflict in the patient's mind. It is only once the afflicted recognises it as the correct expression of his particular problem that the first step towards the realization that the boundaries of sense has been transgressed.

It is the business of philosophy, not to resolve a contradiction by means of a mathematical or logico-mathematical discovery, but to make it possible for us to get a clear view of the state of mathematics that troubles us: the state of affairs before the contradiction is resolved. (And this does not mean that one is side-stepping a difficulty.) (PI 125)

The philosopher thus aims to give the patient an insight into his own understanding and misunderstanding. It is once the patient has recognised the contours of his problem (when latent nonsense has been made patent), that the surview becomes useful. The analyst can now point out the actual interconnections between segments of our language and show the patient how he has deviated.

The work of the philosopher consists in assembling reminders for a particular purpose. (PI 127).

A perspicuous representation produces just that understanding which consists in 'seeing connexions. (PI 122).

The interesting question is: why could we not simply flash the surview of a section of language under consideration to the philosophically misled person - why the psychoanalysis? The answer was suggested earlier: the way Wittgenstein sees it, the patient is 'bewitched' - mesmerized, and so will not be susceptible to suggestions or arguments about correct grammatical use. 
A picture held us captive. And we could not get outside it, for it lay in our language and language seemed to repeat it to us inexorably. $(P / 115)$

And:

A simile that has been absorbed into the forms of our language produces a false appearance, and this disquiets us. "But this isn't how it is!" - we say. "Yet this is how it has to be!" (PI 112)

... One thinks that one is tracing the outline of the thing's nature over and over again, and one is merely tracing round the frame through which we look at it. (PI I14)

But this is not the only reason. Wittgenstein says that there is value in making such mistakes.

The results of philosophy are the uncovering of one or another piece of plain nonsense and of bumps that the understanding has got by running its head up against the limits of language. These bumps make us see the value of the discovery. (PI 119)

The discovery here, I take it, is the correct grammar supplied by the surview of a segment of language. Wittgenstein seems to give the impression that there is a difference between merely possessing a surview of a segment of language and being presented with the surview (or discovering the limits) after having made a mistake. He seems to suggest that there is a special value in seeing the correct answer (the correct grammar) when seen in the light of the kinds of mistakes that are (and could have been) made in its absence. He also says that philosophy should not merely try to terminate a disease of thought, for there is value in the slow cure of the illness. ${ }^{0}$ Again, he seems to suggest that there is intrinsic value in coming to recognise that a mistake has been made. It is plausible to think that Wittgenstein believed that when the misled person recognises the contours of his mistake he can better appreciate the solution, or rather, the correct path. What though, if we had a commanding view of a segment of our language to start off with? We would then not be tempted to make the kinds of mistakes we otherwise make in its absence. But Wittgenstein gives the impression that access to the surview is some how more valuable after the mistakes have been made. One way of making sense of this is to see that philosophical temptations are part of our human condition. Even if we have a commanding view of 
many segments of our language, we would never be immune to linguistic confusions since, as Hacker ${ }^{7}$ suggests, although a perspicuous representation may be illuminating for a given generation and prevent philosophical conundrums, advances in both knowledge and culture bring new and hitherto unencountered paradigms that capture our imaginations. Darwinism, Marxism, Freudian psychology, mathematical logic, computer science and artificial intelligence all breed new mythologies that distort our understanding in new ways. Philosophy will thus have to go over the ground afresh. The task of philosophy, like that of the psychotherapist, is thus never over.

But the question remains, why is possession of a surview of a segment of language more significant after a mistake than before? Why can we only have understanding after a close encounter with misunderstanding? This is like saying that one cannot achieve virtue without first having overcome the temptation of vice. The point to see here is that Wittgenstein's argument is not that we cannot appreciate the fine distinctions and interconnections between language uses unless we have first been taken in by the charm of a misunderstanding, for surely we are able to appreciate these interconnections on their own. However, appreciating these distinctions do not amount to an appreciation of the limits of language. You only know what counts as an illegitimate use of language when you know the boundary between a correct and incorrect use of language. You have to know that using an expression in a certain way marks the cut-off point - marks the departure - from sense. In a way this is like the argument that goodness cannot be appreciated as goodness unless you know what (counts as) badness or evil. Appreciating the customary uses of language as sense (as belonging to the one side of the line dividing legitimate and illegitimate uses of a word) necessarily involves knowing what counts as crossing the boundaries. Giving descriptions of actual uses is one thing, but drawing the boundaries of sense must involve the oscillation between sense and nonsense. We have to allow ourselves to attempt to cross the limits, and it is only once we have felt that we are in no-mans land (language has gone on holiday) that we know the precise point at which the limits have been transgressed - that we know where the limit is. The limit thus must be discovered by first going past it, and then coming back to ordinary use. It is like attempting to sit on a fragile chair without knowing the exact point at which the chair will give. The only way we can discover this point is by having gone beyond it slightly and feeling the chair starting to give. What we feel at this point is the limit of the amount of pressure we can exert or apply. In the TLP Wittgenstein attempted to provide us with a formula or standard against which we can measure whether a proposition has sense. But this formula was built on a misconceived idea about language - that diverse kinds of propositions have a common denominator. In the later work the 
various particular ways of using language is respected in their own right. Drawing the limits of language can thus not be done in one fell swoop but must be done piecemeal -- the limits must be discovered for all the different uses of language. What this means is that a philosophy of language cannot be systematic. In his preface Wittgenstein describes his method in the PI as one that travels criss-cross over the landscape of language - drawing connections between various misuses of language (philosophical conundrums), and indicating the subtle interconnections between various uses of language. With the new method we cannot remain in our philosophers' armchair and construct a holdall theory of language. We have to go into the field, as it were, travel the high-ground of the various uses of language (most notably philosophical uses of language) and discover when we are no longer on the stable ground of sense. Although Wittgenstein did not advocate this method in so many words the abundant dialectical discussions between himself and an imaginary interlocutor demonstrates this. We see for example in the private language argument that Wittgenstein draws out, by means of a reductio argument, the fatal implication of mistaken uses of language: the private language argument shows that when we talk about our sensations in the way we do about objects we end up with an empty theory. It is an explanation that makes speaking about sensations and learning to use sensation words, impossible. The target of the private language argument is the mistaken assumption that our learning to use sensation-words is like our learning to use object-words: sensation-words refer to mental objects as object-words refer to physical objects. The arguments demonstrate that a putative language that refers to private inner sensations cannot be taught and cannot be learned; in fact it does not count as a language at all. The very idea is incoherent. The immediate playing field of this argument is the learning of sensation-words but its reverberations go far: it challenges for example the phenomenalist's idea that all our words refer to sense-data (mental representation of objects in the world); it challenges the Cartesian idea that the only indubitable knowledge one can have is knowledge about one's own existence (knowledge cut off from sensory causes or effects). The discovering-the-limits method is elegantly presented in this cluster of arguments. Wittgenstein constantly tests or plays out the implications of the philosophical (mis)uses of ordinary words and shows that such (mis)uses produce incoherent conclusions.

By claiming that philosophical problems are in fact linguistic confusions Wittgenstein is not trivialising the nature of the problems. At PI 111 he says that 
The problems arising through a misinterpretation of our forms of language have the character of depth. They are deep disquietudes; their roots are as deep in us as the forms of our language and their significance is as great as the importance of our language. - - Let us ask ourselves: why do we feel a grammatical joke to be deep? (And that is what the depth of philosophy is.)

This remark anticipates the criticism that Wittgenstein had, as he says in PI 118 - destroyed everything that is interesting, great and important: philosophy is not what we thought it was i.e. an investigation into the essential workings of reality. Philosophers, he tells us, are like flies in the fly-bottle, unable to find their way out (PI 309), they are occupied by confusions that arise when language is like an engine idling (PI 132.) There is however, no real loss. What has been destroyed were 'houses of cards' anyway. But linguistic disquietudes, we are assured, are not trivial mistakes. It is not a trivial mistake to speak about sensations in the way we do about objects. Even if it is pointed out to us that we are struggling with a linguistic confusion (and not a metaphysical one), the struggle is nevertheless a hard one. It is a conceptual struggle, and conceptual struggles are extremely challenging - the best testimony to this being the $P I$ itself.

\footnotetext{
The Blue and the Brown Books, 1958, pp 17-18.

PI. 5

Hacker, P.M.S., Insight and Illusion: Themes in the Philosophy of Wittgenstein, 1997, p.152.

t Lectures, Michaelmas 1933, reported by A.Ambrose, 'Wittgenstein on Universals' K.T. Fann (ed.), Ludwig Wittgenstein,

The Man and his Philosophy, p. 336.

Big Tipescript, 410.

"Zettel, G.E.M. Anscombe and G.H, von Wright (eds), G.E.M Anscombe (trans.), 1981 (1976), 382.

Hacker, P.. Insight and lllusion: Themes in the Philosophy of Wittgenstein, 1977.
} 


\section{References}

Primary sources:

\section{Wittgenstein:}

Big Typescript: Ts 213. 1938, Oxford, Blackwell, 2005.

The Blue and the Brown Books, Oxford, Blackwell, 1975 (1958).

Culture and Value, G.H. von Wright (with H Nyman) (ed.), P.Winch (trans.), Oxford, Blackwell, 1980.

Ludwig Wittgenstein: Letters to Russell, Keynes, and Moore, G.H. von Wright (ed.), Oxford, Blackwell, 1974.

Notebooks, 1914-1916, G.H. von Wright and G.E.M. Anscombe (eds), G.E.M. Anscombe (trans.), Oxford, Blackwell, 1961.

Notes dictated to Moore in Norway, reprinted in Notebooks 1914-16.

On Certainty, G.E.M. Anscombe and G.H. von Wright (eds), D.Paul and G.E.M. Anscombe (trans.) Oxford, Blackwell, 1969.

A Lecture on Ethics 11-12, published in Philosophical Review, 74, no. 1, 1965, pp 3-16. 
Philosophical Grammar, R.Rhees (ed.), A. Kenny (trans.), Oxford, Blackwell, 1974.

Philosophical Investigations, G.E.M. Anscombe (trans.), Oxford, Blackwell, 1953.

Philosophical Occasions: 1912-1951, J.Klagge and A. Nordmann (eds) Indianapolis, Hackett, 1993.

Philosophical Remarks, R.Rhees (ed.), R.Hargreaves and R.White (trans.), Oxford, Blackwell, 1975.

Protractatus - An early Version of Tractatus Logico-Philosophicus, B.F. McGuiness, T.Nyberg, and G.H. von Wright (eds), D.F. Pears and B.F. McGuiness (trans.), London, Routledge, 1971.

Remarks on the Foundations of Mathematics, G.H. von Wright, R.Rhees, and G.E.M. Anscombe (eds), G.E.M. Anscombe (trans.), (revised edition), Oxford, Blackwell, 1978 (1956).

Tractatus Logico-Philosophicus, D.F. Pears and B.McGuiness (trans.), with an introduction by Bertrand Russell, London, Routledge and Kegan Paul, 1974.

Wittgenstein's Lectures on the Foundations of Mathematics : Cambridge, 1939, C. Diamond (ed.), Hassocks, Sussex, Harvester, 1976. 
Wittgenstein's Lectures, Cambridge 1930-32, From the Notes of John King and Desmond Lee, D.Lee (ed.), Oxford, Blackwell, 1980.

Wittgenstein's Lectures, Cambridge 1930-32. From the Notes of Alice Ambrose and Margaret McDonald, A. Ambrose (ed.) Chicago, Chicago University Press, 1979.

Wittgenstein's Notes for Lectures on "Private Experience" and "Sense Data", R.Rhees (ed.), Philosophical review, 77, 1968, pp.275-320.

Zettel, G.E.M. Anscombe and G.H. von Wright (eds), G.E.M. Anscombe (trans.), Oxford, Blackwell, 1981 (1976).

\section{Russell:}

Principia Mathematica, $2^{\text {nd }}$ edition, Cambridge, Cambridge University Press, 1927 (1910).

The Principles of Mathematics, $2^{\text {nd }}$ edition, London, Allen and Unwin 1937 (1903).

The Problems of Philosophy, Oxford, Oxford University Press, 1980 (1912). 'The Theory of Knowledge' (1913), in The Collected Papers of Bertrand Russell, vol. 7, E. Eames and K. Blackwell, London, Allen and Unwin, 1984. 


\section{Secondary Sources:}

Anscombe, G.E.M., An Introduction to Wittgenstein's Tractatus, London, Hutchinson, 1959.

Conant J. F., Kierkegaard, Wittgenstein and Nonsense in Pursuits of Reason

T. Coen, P. Guyer and H. Putnam (eds), Lubbok, Texas Teach University Press, 1992, pp. 195-224.

Frege and Wittgenstein on Elucidation, in The New Wittgenstein, A. Crary and R. Read (eds), London, Routledge, 2000.

Carruthers, P., Tractarian Semantics, Oxford, Blackwell, 1989.

The Metaphysics of the Tractatus, Cambridge, Cambridge University Press, 1990.

Diamond, C. The Realistic Spirit: Wittgenstein, Philosophy and the Mind, Cambridge, Mass., MIT Press, 1991.

Dummett, M. Wiitgenstein's Philosophy of Mathematics, in Pitcher, G. (ed.) Wittgenstein: The Philosophical Investigations, London, Macmillan, 1968. Dilman, I., Language and Reality, Uitgeverig Peeters, 1998.

Engelmann, P, Letters from Ludwig Wittgenstein, 1918.

Fann, K.T., Wittgenstein's Conception of Philosophy, Oxford, Blackwell, 1969.

Fogelin, R.F., Wittgenstein, London, Routledge, 1987 (1976). 
Frascolla, P., Wittgenstein's Philosophy of Mathematics, London, Routledge,

1994.

Glock, H.J., A Wittgenstein Dictionary, Oxford, Blackwell, 1996.

Goldfarb, W., Metaphysics and Nonsense: On Cora Diamond's The Realistic Spirit, Journal of Philosophical Research, 1997, Vol. 22, pp. 57-73.

Goldstein, L., Clear and Queer Thinking, Duckworth, 1999.

Hacker, P.M.S. Insight and Illusion: Themes in the Philosophy of Wittgenstein, Oxford, OUP, 1989.

Wittgenstein's Place in Twentieth Century Philosophy, Oxford, Blackwell, 1996.

Wittgenstein: Rules, Grammar and Necessity, Vol. 2 of An Analytical Commentary on the Philosophical Investigations, Oxford, Blackwell, 1990.

Harris, R., Language, Saussure and Wittgenstein, LondonRoutledge, 1988.

Hintikka, M.B. and Hintikka, J. Investigating Wittgenstein, Oxford, Blackwell, 1986.

Ishiguro, H, 'Logical rules, Necessity and Convention' in 'Wittgensteinian Themes: Essays in Honour of David Pears, D. Charles and W. Child, Oxford, OUP, 2001. 
Kenny, A., Wittgenstein, Harmondsworth, Penguin, 1973.

Kripke, S.A., Wittgenstein on Rules and Private Language, Oxford, Blackwell, 1982.

Malcolm, N., Nothing is Hidden: Wittgenstein's Criticism of his Early Thought, Oxford, Blackwell, 1986.

Miller A. and Wright C. (eds.), Rule-following and meaning, Chesham, Acumen, 2002.

Monk, R., Ludwig Wittgenstein: The Duty of Genius, New York, Free Press, 1990.

Mounce, H.O., Wittgenstein's Tractatus: An Introduction, Oxford, Blackwell, 1981.

Pears, D.F., Wittgenstein, London, Fontana, 1971.

The False Prison: A study of the Development of Wittgenstein's Philosophy, vol. i, Oxford, OUP, 1987.

The False Prison: A Study of the Development of Wittgenstein's Philosophy, Vol ii, Oxford, Oxford University Press, 1988. Proops, I., The New Wittgenstein: a Critique in The European Journal of Philosophy, December 2001.

Shields, P.R., Logic and Sinn In the Writings of Ludwig Wittgenstein, Chicago, The University of Chicago Press, 1993. 
Stenius, E., Wittgenstein's Tractatus, Oxford, Blackwell, 1960.

Stroud, B., Wittgenstein and Logical Necessity, in Pitcher, G., (ed.)

Wittgenstein: The Philosophical Investigations, London, MacMillan, 1968.

Private Objects, Physical Objects and Ostension, in

Wittgensteinian Themes: Essays in Honour of David Pears, D. Charles and

C. Child (eds) Oxford, Clarendon Press, 2001.

Verheggen, C., Wittgenstein and Solitary Languages, in Philosophical

Investigations, 18:1, January 1995, pp 329-47. 